\title{
Reinforcing production cooperation and dialogue spaces: the role of SMEs
}


EU-LAC FUNDATION 2015

Hagedornstraße 22

20149 Hamburg, Germany

www.eulacfoundation.org

DOI: http://dx.medra.org/10.12858/0615ES4

ECLAC reference: LC/L.4020

Copyright $\odot$ United Nations, May 2015. All rights reserved.

Member States and their governmental institutions may reproduce this work without prior authorization, but are requested to mention the source and inform the United Nations of such reproduction. 
The preparation of this document was coordinated by Sebastián Rovira and Gabriel Porcile, Economic Affairs Officers with the Division of Production, Productivity and Management of the Economic Commission for Latin America and the Caribbean (ECLAC), and by Renaud Guillonnet, Manager of the EU-LAC Foundation VENTURE programme. Stephany Scotto, Research Assistant with ECLAC, also participated in the preparation work. The coordinators thank all those who provided inputs for this publication: Jurgen Weller, of the Economic Development Division; José Durán and Sebastián Herreros, of the International Trade and Integration Division; Simone Cecchini, of the Social Development Division; Leandro Cabello, Felipe Correa and Fernando Sossdorf of the Division of Production, Productivity and Management; and Verónica Robert and Federico Poli, consultants.

This study was financed by the EU-LAC Foundation, which, in turn, is financed by its Member States and by the European Union. The content of this publication is the sole responsibility of its authors and may not be considered to represent the views of the EU-LAC Foundation, its Member States or the European Union.

For edition and publication activities ECLAC had the support of the project "Innovation for a sustainable structural change," implemented by ECLAC in conjunction with the Deutsche Gesellschaft für Internationale Zusammenarbeit (GIZ) and funded by the Federal Ministry for Economic Cooperation and Development (BMZ).

This publication is subject to copyright. However, it may be reproduced freely by any means for educational purposes or for the purposes of lobbying, mediation or research, providing the source is duly cited. The owners of the copyright request they be informed of any such use, with a view to impact assessment. Any party wishing to reproduce this text for any other purpose, to use it in other publications or to translate or adapt it must obtain prior written permission, which may be requested by e-mail to info@eulacfoundation.org.

The opinions expressed in this document are the exclusive responsibility of the authors and may not reflect the opinions of the Organizations they represent.

This document is a translation of a Spanish original which did not undergo formal editing. 


\section{CONTENTS}

\section{Reinforcing production cooperation and dialogue spaces: the role of SMEs}

Foreword

I. SNAPSHOT OF MAIN ECONOMIC TRENDS IN CELAC AND THE EUROPEAN UNION 10

$\begin{array}{ll}\text { 1. Ten years of social progress } & 10\end{array}$

2. Growth and external equilibrium 13

3. Fiscal space and the impact of the Great Recession 18

4. Dynamics of trade and foreign direct investment 21

5. Productivity and investment with a fast-moving technology frontier 26

II. SMES IN OPEN ECONOMIES: OPPORTUNITIES FOR INTERNATIONALIZATION AND PRODUCTION INTEGRATION 33

1. SMEs in CELAC and the European Union: a stylized overview 33

2. Main challenges for making SMEs more competitive $\quad 43$

2.1 Human capital and SMEs in Latin America $\quad 43$

$\begin{array}{ll}2.2 \text { Financing for SMEs } & 49\end{array}$

2.3 Small and medium-sized enterprises and their capacity for innovation 56

2.4 Environment and institutional framework for the support of SMEs $\quad 65$

2.5 Clusters, production integration and access to global value chains $\quad 69$

III. TOWARDS CLOSER COOPERATION BETWEEN CELAC AND THE EUROPEAN UNION FOR THE PRODUCTIVE DEVELOPMENT OF SMES 


\section{FOREWORD}

This document is the outcome of a joint effort by the Economic Commission for Latin America and the Caribbean (ECLAC) and the EU-LAC Foundation to deepen understanding of the important role played by small and medium-sized enterprises (SMEs) in bringing about structural change and development, and of their role in innovation and in value chains. This publication was prepared in the framework of the second Summit of Heads of State and Government of the Community of Latin American and Caribbean States (CELAC) and the European Union, to be held in Brussels on 10-11 June, in the expectation that it may serve as an input for the discussions during the summit and help to identify areas in which governments and production sectors of the two regions can work together.

Although the Latin American and Caribbean countries have experienced rapid growth and development over the past decade, significant challenges remain in terms of increasing the region's poor levels of productivity. Unless these are tackled, it will not be possible to progress towards more knowledge-intensive segments of value chains or to diversify production and create good-quality, skilled and better paid jobs. These are some of the challenges facing both the countries of CELAC and the European Union, and which are becoming all the more worrisome in light of what is fast becoming the "normality"for the next few years: lower international growth and heavier external and fiscal constraints.

It will not be possible to lock in and build on the progress the Latin American and Caribbean region has made over the past few years - stronger growth and reduction in poverty and inequality - without achieving a shift in the production structure. The structure must have a place for SMEs and be able to include them in the learning, production and export process. It must reduce the technology and financing gaps which hold back their growth. This document discusses the main obstacles facing SMEs today: limitations in terms of human capital, financing, innovation capacities, institutional and business setting, production linkages and access to global value chains. Overcoming these barriers will require public policy efforts, which become ever more urgent the faster the technology frontier moves away and the more complex the challenge of international competitiveness becomes.

These are some of the factors analysed in this document, which takes a comparative approach vis-à-vis the experience of the European Union countries to identify areas in which the two regions could intensify cooperation efforts.

Alicia Bárcena

Executive Secretary

ECLAC
Jorge Valdez

Executive Director

EU-LAC Foundation 


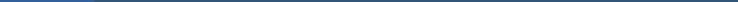




\section{INTRODUCTION}

Over the past few years, CELAC and European Union countries have gone through a common external shock: the Great Recession of 2008, which buffeted the economies of both regions. This shock drove each region in a different direction depending on its position in the world, its previous growth path and the policies adopted by countries in response to the crisis. Understanding these trajectories is key for examining the role of small and medium-sized enterprises in the production sector and their growth potential in a globalized economy where technological progress is taking place at an unprecedented pace.

The first part of the report reviews key macroeconomic and social trends in the two regions over the past decade and how they constrain or foster growth and development. These trends frame the study of SMEs set out in the second part of the report.The social dynamic (which determines the behaviour of the internal market), fiscal and monetary policies (and their impact on aggregate demand), pressure from the external sector (affecting indebtedness, external constraints on growth and variations in the real exchange rate) and the presence or absence of fiscal space needed to implement countercyclical policies and policies that promote structural change substantially shape the behavior and the role of SMEs.

Productivity and technology gaps weigh especially heavily on smaller companies, which play a central role in generating employment, both in CELAC countries and in Europe. This is the subject of the second part of the report, where the focus is on the differences in productivity and capacity among micro, small and medium-sized enterprises compared with large companies. A number of significant obstacles facing SMEs are identified; they are much greater for CELAC countries than for European ones. The negative impact on their competitiveness and capacity for external integration and on quality employment in the countries of Latin America and the Caribbean has important implications vis-à-vis the potential for taking more inclusive and sustainable development paths. Lastly, drawing on this analysis a number of areas for strengthening relations between CELAC and the European Union are laid out based on stronger trade and production links among enterprises of the two regions and enhanced economic policy coordination and cooperation between the regions themselves. 


\section{SNAPSHOT OF MAIN ECONOMIC TRENDS IN CEIAC AND THE EUROPEAN}

UNION

\section{TEN YEARS OF SOCIAL PROGRESS}

The great strides that Latin America and the Caribbean has made in reducing poverty and inequality must be maintained and improved

Latin America saw rapid growth in 2004-2013, with gains in employment, fiscal position and the external sector. These improvements were accompanied by substantial advances in social indicators. However they still lag far behind European countries. Consolidating and continuing the improvement of these indicators should be a priority for the countries of CELAC in the coming decade.

Poverty and indigence rates dropped significantly in Latin America and the Caribbean (LAC) between 1990 and 2014. Poverty has fallen by 20 percentage points (from $48 \%$ of the population to $28 \%$ ); indigence has gone down by 10 percentage points (from $22 \%$ of the population to $12 \%$ ) but has held at this level since 2011. Wealth concentration indices declined during the same period. The Gini coefficient dropped from 55 in 2006 to 52.3 in 2013, although this improvement still left the figures well above those for the countries of the European Union. The situation varies widely among countries within each region. In 2013 the Gini coefficient in Latin America ranged from 38.2 in Uruguay to 57.5 in Honduras. In the European Union (EU-15), Sweden posted the lowest score (24.9) while Italy (32.5), Spain (33.7), Portugal (34.2) and Greece (34.4) posted the highest.

Education indicators also improved in CELAC countries, although they are still far from the progress made by the countries of the European Union. From 1950 to date, the average educational level among the population aged 25 and over in Latin America and the Caribbean has increased from 2.9 years in 1950 to 8.0 years in 2012. In the countries of the European Union, this indicator has risen sharply as well, from 5.1 years to 10.7 years over the same period. As a result, the ratio between average years of education in the European Union and the average for Latin America and the Caribbean has fallen. Again, there are marked variations within regions. For example, the average years of education among the population aged 25 years and over in some countries of the English-speaking Caribbean (10.5 years in Belize and 10.8 years in Trinidad and Tobago) is better than in some European countries (8.2 years in Portugal, 9.6 years in Spain, 9.9 years in Italy and 10.2 years in Greece).

The "new middle class" in Latin America and the Caribbean can become an important factor for boosting consumption and production in the region, but vulnerability is also on the rise 
Improved educational levels in the countries of the region have, in recent years, come with the rise of the Latin American middle class, which has grown by a striking 82 million people between 2000 and 2014 . This is a jump from $21 \%$ of the population to $34 \%$ over the period under review. ${ }^{1}$ Meanwhile, the vulnerable population (with income between US\$ 4 and US\$10 a day) has edged up as well, from 35\% of the population of Latin America in 2000 to $38 \%$ in 2012 . The reason is the shift in persons living in poverty (earning less than US\$ 4 a day) to the vulnerable strata (see figures $1 \mathrm{a}$ and $1 \mathrm{~b}$ ).

Figure 1. Social groups in Latin America, 2000 and 2012 (Percentages)

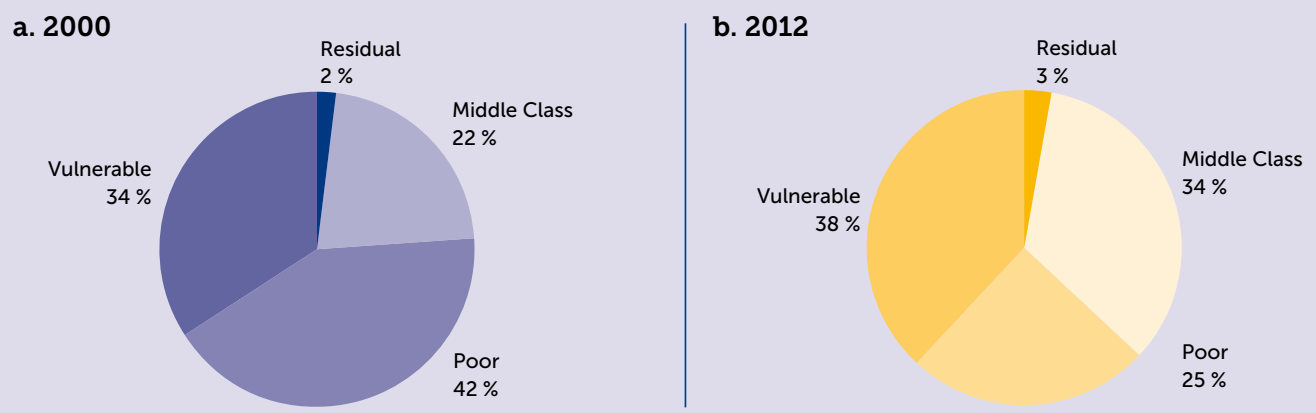

Source: Economic Commission for Latin America and the Caribbean (ECLAC), on the basis of United Nations Development Programme (UNDP), 2014.

The number of people belonging to the middle class has increased in all of the countries of Latin America and the Caribbean. But there are countries such as Uruguay, with $60 \%$ of its population belonging to the middle class, and others like Guatemala and Nicaragua, where the figure falls short of $10 \%$ (see figure $2 a$ and $2 b$ ).

This growth of the middle class poses major challenges in the form of new needs and expectations in education, infrastructure, safety and health care services, among others. But it also opens a number of opportunities for further growth and development, both because the new middle classes are a source of demand for new products and services and because they can play a key role as new producers and suppliers of services, as well as generating new businesses. And the emergence of a new, better-qualified workforce with more opportunities requires a production environment in keeping with their needs and wants, and where micro, small and medium-sized enterprises are called upon to play an ever greater role.

While this progress was made in a very favourable economic environment for the region, there are indications that this environment has deteriorated in recent years. The main economic trends of the decade are described below, as are some of the challenges ahead. An analysis of macroeconomic trends is followed by a review of the main developments in the fields of trade and foreign investment. Last comes a look at trends in investment and productivity. These trends define the context in which SMEs have operated and the one they must respond to in the coming years.

1 See UNDP, 2014. 
Figure 2. The rise of middle classes in Latin America and the Caribbean, 2000 and 2012 (Percentages)

a. 2000

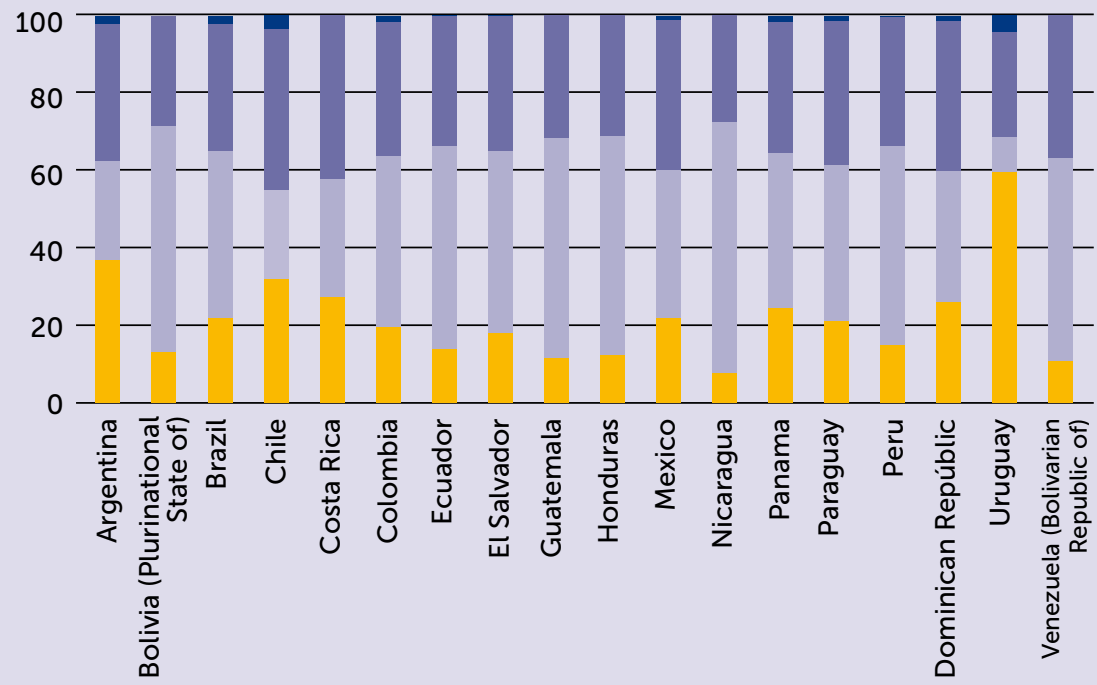

Middle Class Poor Vulnerable $\square$ Residual

b. 2012

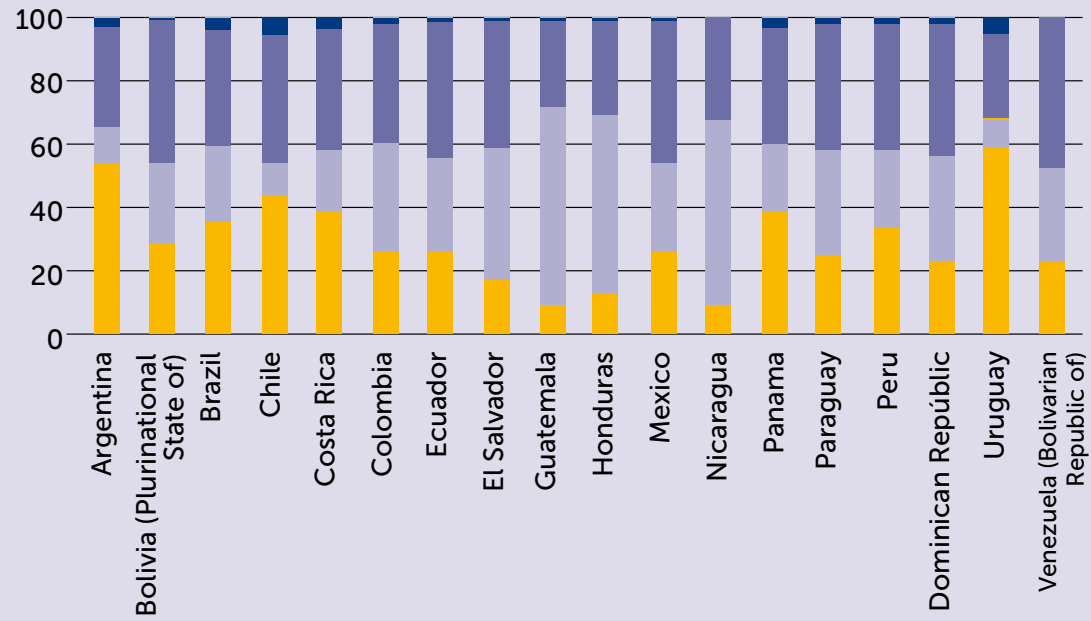

Source: Economic Commission for Latin America and the Caribbean (ECLAC), on the basis of UNDP, 2014. 


\section{GROWTH AND EXTERNAL EQUILIBRIUM}

CELAC is converging with the European Union in terms of GDP per capita, but both regions are losing ground to Asia

The period from 2004 to 2013 can be considered as the "Latin American decade", with the countries of CELAC converging with those of Europe. These years saw a narrowing of per capita income gaps between the two regions. Gross domestic product (GDP) per capita grew faster in Latin America and the Caribbean than in the European Union for all years of the decade (see figure 3).

Figure 3. Growth of GDP per capita, Latin America, European Union and China, 2004-2013 (Percentages)
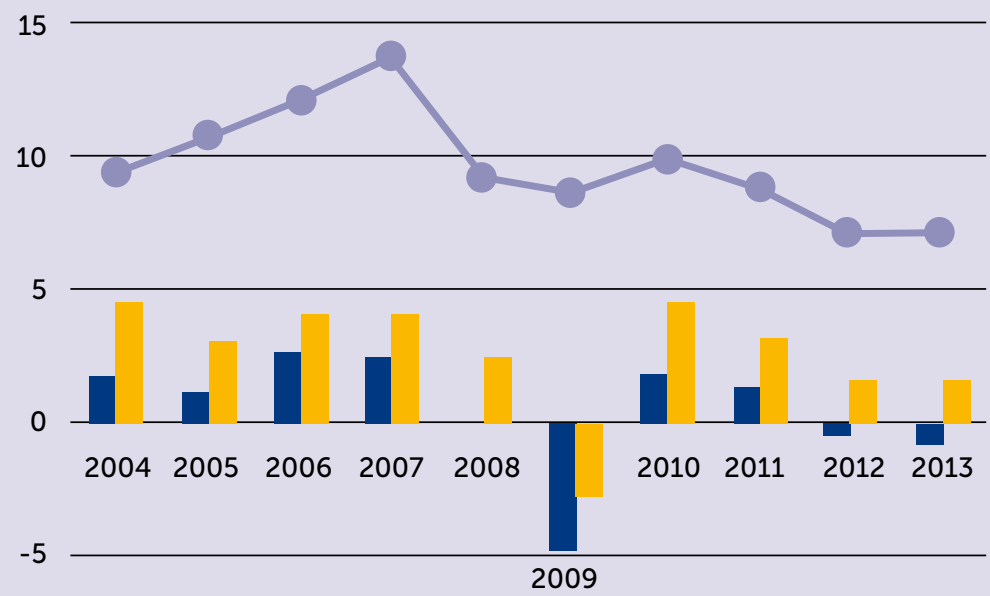

$-10$

Europe Latin America and the Caribbean $-\mathrm{C}$ - China

Source: Economic Commission for Latin America and the Caribbean (ECLAC), on the basis of World Bank, World Development Indicators.

But if China is included in the comparison, Latin America's performance does not look as good because the latter's economy improved much less than the former. In fact, the region lost ground in world GDP rankings, although proportionately less than Europe did (see figure 4). CELAC and the European Union together accounted for 32.7\% of world GDP in $2000(9.2 \%$ and $23.5 \%$, respectively). However, the ratio of the GDP of both regions to global output fell substantially in 2013, to approximately 26\% (17.2\% for the European Union and $8.7 \%$ for the countries of Latin American and the Caribbean). The Chinese economy made the greatest strides during the period (see figure 4). 
Figure 4. GDP, relative contribution of principal regions and countries, 2000 and 2013

a. 2000

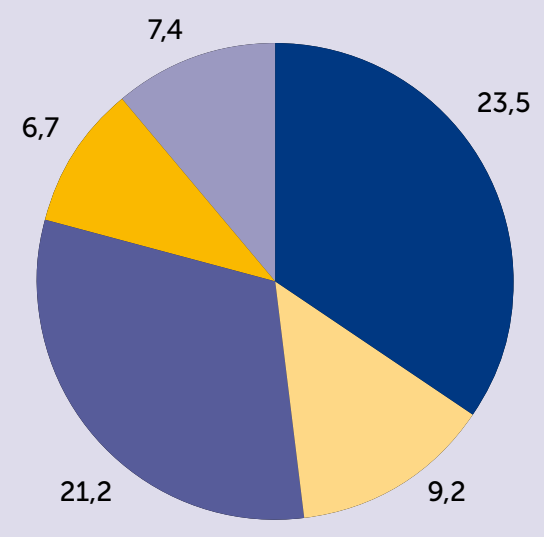

b. 2013

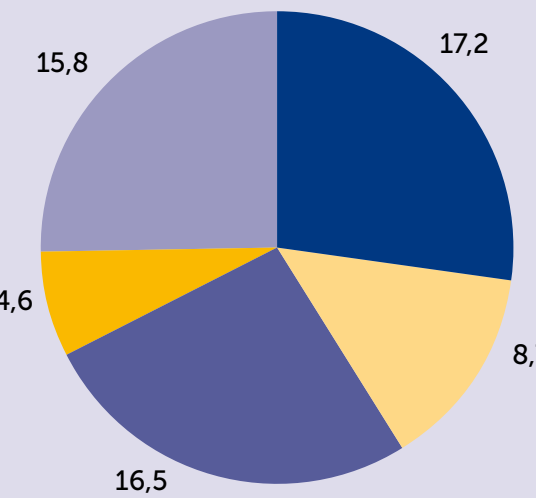

16,5
European Union

Latin America and the Caribbean
United States

Japan

Source: Economic Commission for Latin America and the Caribbean (ECLAC), on the basis of World Bank, World Development Indicators.

While it is not possible to point to any single variable as accounting for these differences in economic growth between countries and regions, the commodity boom was an important factor behind the more favourable figures posted by Latin America and the Caribbean. The commodity price boom was based on surging demand for natural resources and commodities driven by growth in China. Its impact was beneficial for most of the economies of the region, especially the mineral-exporting ones. The demand for natural resources soared during what some observers described as a new supercycle in the international prices of these resources.

Almost all of the countries of the region thus saw their terms of trade improve, particularly the mineral-exporting countries. For example, the World Bank estimates that the Bolivarian Republic of Venezuela showed the largest terms-of-trade improvement after Sudan among all countries for which data are available for this variable. Chile, Ecuador and Peru also posted substantial improvements in this regard. Conversely, many European countries experienced a negative terms-of-trade shock. Austria and France recorded drops of about 1.2\% over the same period (while Germany saw a deterioration of $0.6 \%$ ). The exception in Europe was the sharp improvement in the terms of trade benefiting Norway as a petroleum-producing country, which was also reflected in fiscal and current-account surpluses.

As a result of the commodity boom, the twin deficits (current-account and fiscal balance) gave way to current-account surpluses and improvements in the fiscal balance in most of the countries of Latin America. The external-debt-to-GDP ratio fell significantly in both the public sector and the private sector. Latin America and the Caribbean saw its average sovereign-debt-to-GDP ratio fall 
four points between 2007 and 2013, from 24\% of GDP to $20 \%$ of GDP. Meanwhile, reserves as a safety cushion against external shocks climbed from $17 \%$ of GDP to $19 \%{ }^{2}$

Current-account imbalance in Latin America and the Caribbean and slow growth in Europe: the two faces of the impact of the Great Recession

The favourable outlook on the external front changed with the Great Recession of 2008. Between 2004 and 2007 Latin America and the Caribbean posted current-account surpluses while the European Union was initially in equilibrium and then slid into deficit (see figure 5 comparing the two regions, and figure 6 referring to the three largest economies of Latin America and the Caribbean, namely Argentina, Brazil and Mexico). Current-account balance positions began to reverse in 2008. Latin America and the Caribbean quickly moved into deficit territory while Europe moved in the direction of current-account surpluses. This does not necessarily mean a positive trend for the European economies: the improvement in Europe's external position was in the context of a major recession (GDP per capita in Europe fell in 2012 and 2013), with surpluses being the flip side of European stagnation.

\section{Figure 5. Current-account balance in Latin America and the Caribbean and the European Uni- on, 2000-2013 (Percentages of GDP)}

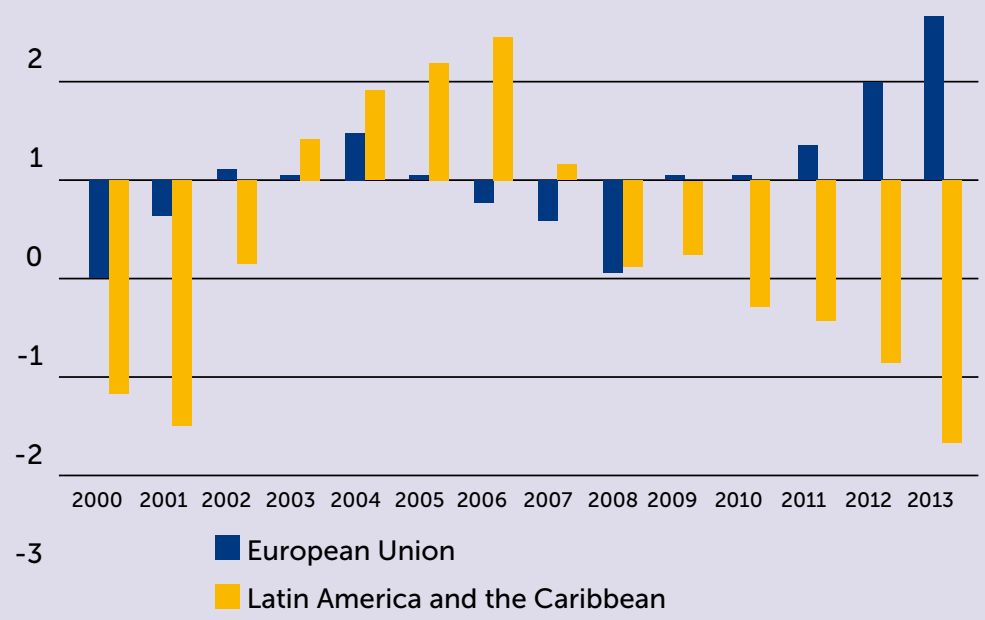

Source: Economic Commission for Latin America and the Caribbean (ECLAC), CEPALSTAT database.

2 See ECLAC/CAF/OECD, 2014. However, the good numbers in the aggregate should not mask the considerable heterogeneity across the region, as there are countries like Argentina, the Bolivarian Republic of Venezuela and Ecuador that have seen their reserves decline. The ratio of reserves to short-term external debt also varies widely from one country to another. In the Bolivarian Republic of Venezuela, the countries of Central America and Uruguay, the reserves-to-short-term-debt ratio is very close to one. At the other extreme are Peru and the Plurinational State of Bolivia, where it is greater than 10. 
Figure 6. Current-account balance in the principal economies of Latin America, 2004-2013 (Percentages of GDP)

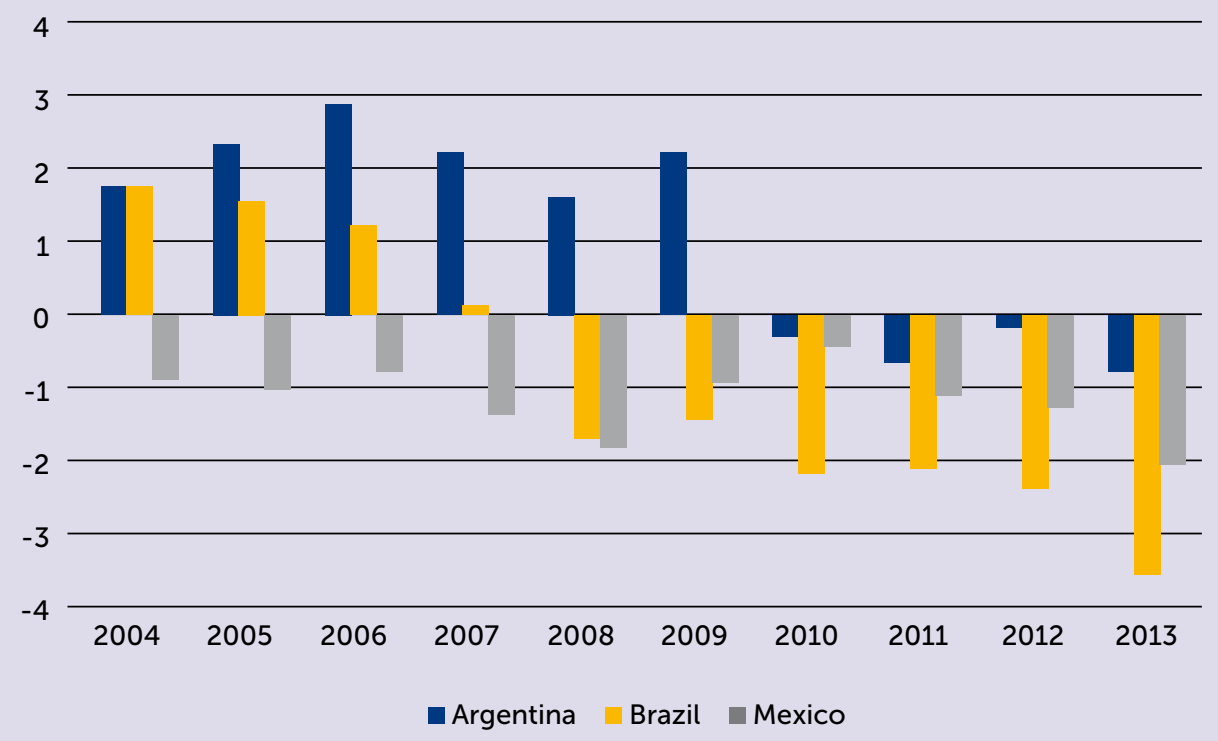

Source: Economic Commission for Latin America and the Caribbean (ECLAC), CEPALSTAT data-

base.

Latin America and the Caribbean saw deterioration on two fronts starting in 2008 (slower growth, greater imbalances) while the two variables moved in opposite directions in Europe. The recent decline in the value of the euro and the European version of quantitative easing may change this scenario; in Europe there is more space for growth without triggering negative current-account impacts than there is in Latin America. Figures $7 \mathrm{a}$ and $7 \mathrm{~b}$ track growth and current-account deficits in Latin America and the Caribbean and Europe. It is very clear that towards the end of the period between 2004 and 2013 the economies of Latin America are moving towards slower growth with higher deficits as a percentage of GDP. This makes growth vulnerable down the road, in that the external imbalance can act as a drag on expansion. Europe, however, continues to show negative growth rates and current-account surpluses during most of the period, with both indicators improving at the end.

Intraregional asymmetries are a major challenge, both for Europe and for Latin America and the Caribbean

There are substantial intraregional differences within Europe and Latin America and the Caribbean; the aggregates mask a variety of lag and catch-up patterns in each of the countries and regions. 
Figure 7: Growth and external equilibrium, 2004-2013

a. Latin America

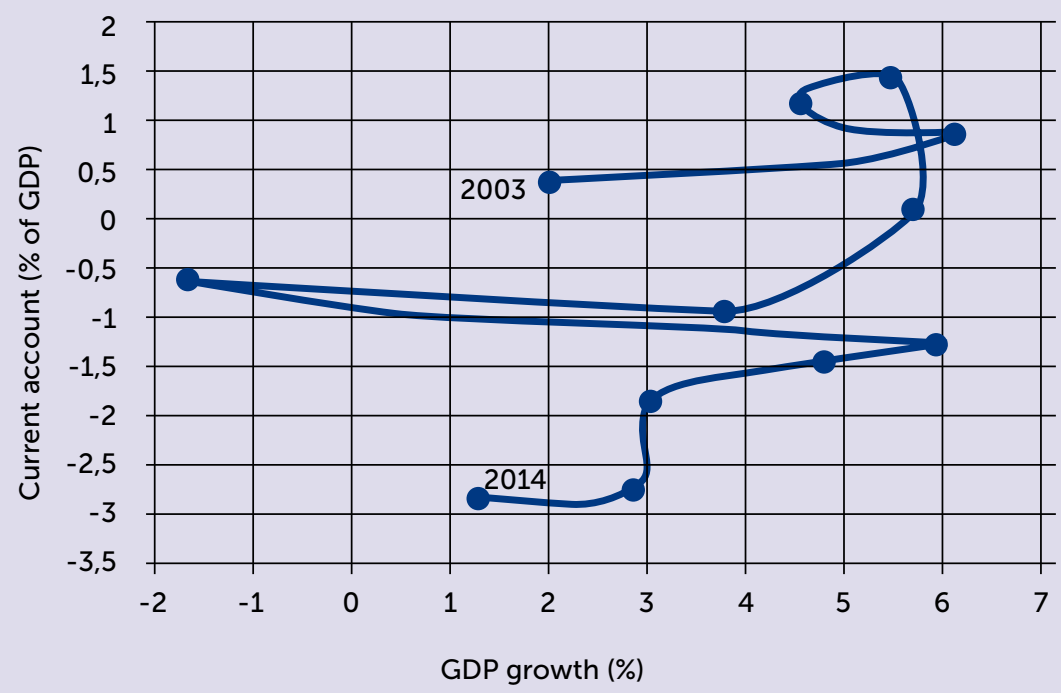

b. Europe

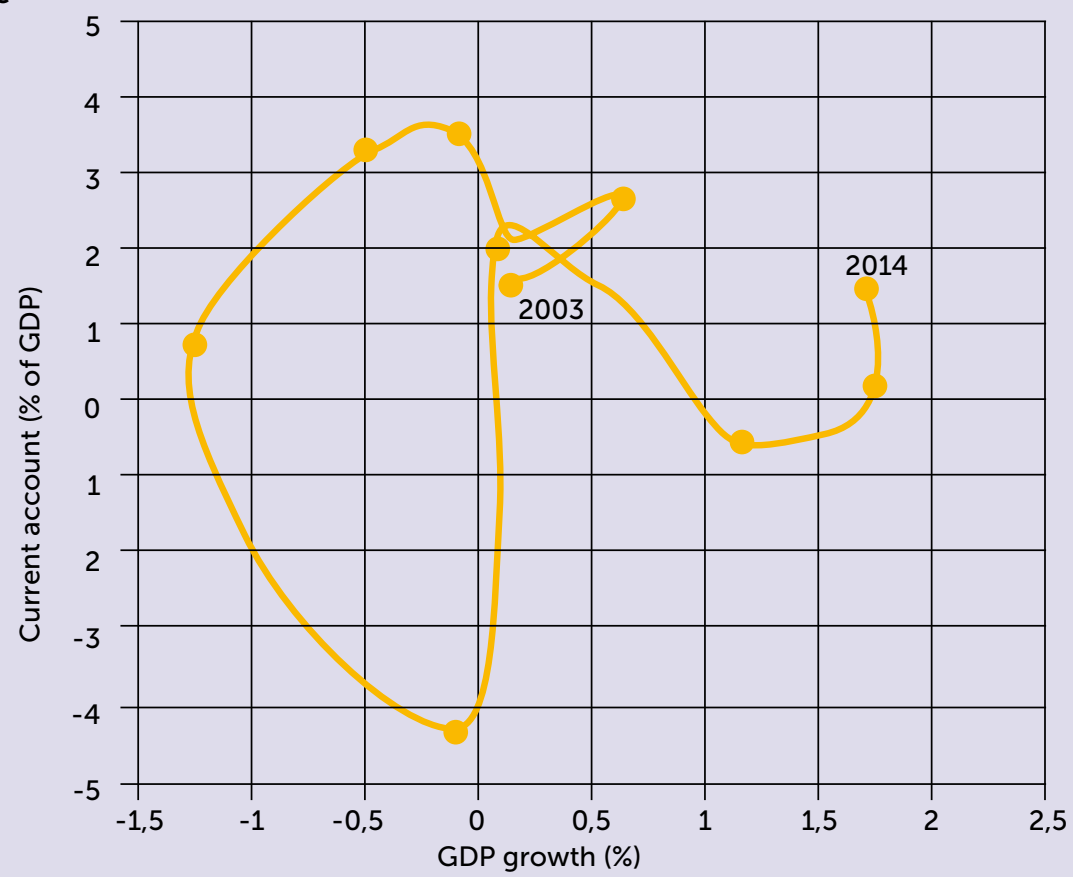

Source: Economic Commission for Latin America and the Caribbean (ECLAC), on the basis of data from the World Bank and CEPALSTAT database. 
In Europe surpluses coincided with marked imbalances within the eurozone. The Northern European countries posted positive balances, while the economies of Europe's periphery (both Southern and Eastern Europe) ran persistent current-account deficits. And patterns within Europe's periphery vary as well. Some Eastern European countries saw high current-account deficits associated with soaring investment rates and faster growth -a pattern that allowed the deficit to stabilize as a share of GDP. Other periphery countries, however, were unable to stabilize the deficit and sustain high rates of growth and investment. Among them are Greece, Portugal and Spain. The crisis in the economies of Southern Europe, meanwhile, has led to a gradual rebalancing among eurozone countries. For example, Germany's favourable trade balances are with countries outside the eurozone.

Intraregional heterogeneity is no less striking in Latin America and the Caribbean. There are significant variations in country rankings in terms of flat growth versus external balance, depending on the type of external integration and macro-price management. Mineral-exporting economies benefited the most from the commodity boom. Conversely, countries that rely heavily on manufacturing exports (or maquilas) and remittances from migrant workers for foreign exchange (as do the countries of Central America) have been hit hard by the recession in the central countries and intense competition from industrial goods from China. These countries have come up against the twin challenges emerging from their position as importers of natural resources and exporters of labour-intensive goods, and they are therefore subject to competition from the millions of Chinese workers who entered the global market.

\section{FISCAL SPACE AND THE IMPACT OF THE GREAT RECESSION}

With fiscal space shrinking in both regions since 2008, implementing policies is becoming more complex

The crisis of 2008 drove governments to respond in order to minimize its impacts. Latin America, China, the United States and Europe all adopted countercyclical measures with varying combinations of expansionary fiscal and monetary policies. These policies benefited from a high degree of consensus across countries and institutions ${ }^{3}$ and contributed to the recovery in international commodity prices starting in 2010 . Although the intensity and speed with which each country reacted were different, these measures kept the recession from deepening and sped up the recovery, at least in countries that faced fewer constraints on the external front and, in some cases, had accumulated some fiscal space during the boom. While the policy response was quite forceful in Latin America and the Caribbean and in the United States and China, and less so in Europe, in all of them there was a response.

3 See for example ECLAC, 2012. 
Latin America and the Caribbean recovered faster than Europe for a number of reasons, including the following:

- the relatively rapid recovery in prices and international demand for natural resources exported by Latin America and the Caribbean;

- the complex financial situation in the eurozone starting with the Spanish and Greek crises.

The macroeconomic situation has remained very fluid and changeable in both regions. On the one hand, the recovery in Latin America is being weakened by the combined effect of exhaustion of fiscal space, the slowing global economy and -in some cases- higher rates of inflation. On the other hand, looser monetary policy in Europe and the declining value of the euro are boosting effective demand. Here the roles seem to be shifting, with one of the actors (Latin America and the Caribbean) moving toward more austere policies and the other (the European Union) shifting towards more expansionist ones.

Figure 8 shows the return of fiscal deficits to the economies of Latin America and the Caribbean. Fiscal revenues benefited mightily from the commodity boom thanks to surging economic activity, royalty and tax revenue from mining exports, and, in some cases, new taxes and stricter control, which increased the tax burden. These factors contributed to the improved fiscal results for 20042007. But fiscal space shrank after the crisis; as shown in figure 8, structural primary deficits (surpluses) increased (decreased) in all of the countries of the region between 2007 and 2013, albeit with varying intensity depending on the country.

Figure 8. Structural primary balance, 2007 and 2013

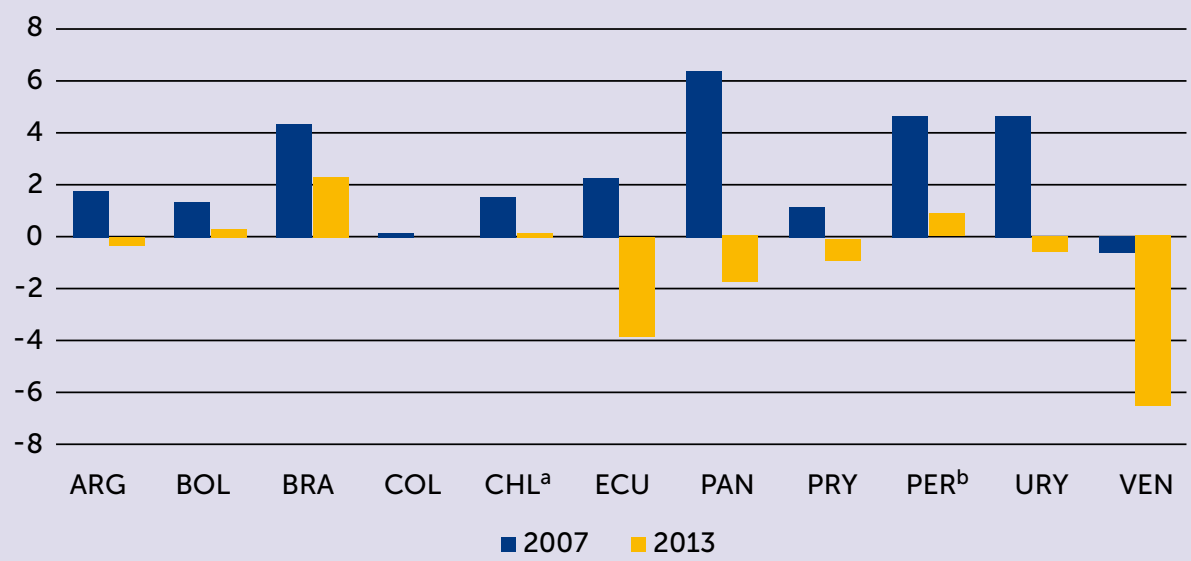

Notes: Latest figure for Ecuador is from 2012. ${ }^{a}$ Includes public enterprises and social welfare. ${ }^{b}$ The Ministry of Economy and Finance, in its latest macroeconomic framework, recorded a structural primary balance of $2.9 \%$ of GDP for 2007 and $0.7 \%$ of GDP for 2013 . These figures are different because of the methodology used.

Source: ECLAC/CAF/OECD, 2014. 
On average, the fiscal deficit in Latin America is not very different from the one in the Europe of 18, 17 or 16 (deficit equal to $2.7 \%$ of GDP). Meanwhile, the tax burden in Latin America is about $20 \%$ of GDP; in the Caribbean it is slightly higher. This figure is higher than for the subregions of Asia and Africa, but well below those of EU (15) , which has the highest tax burden. At a ratio of slightly less than $40 \%$ of GDP, it is higher than the 34\% average for Organization for Economic Cooperation and Development (OECD) countries. The tax burden differs significantly within Latin America. It tops $30 \%$ in Argentina and Brazil and is very low in countries like the Dominican Republic and Guatemala, where it is less than $15 \%$.

The countries of both regions (Latin America and the Caribbean and Europe) have seen their currencies fall in value, but there are striking differences in competitiveness across countries

Over the ten years between 2004 and 2013, many Latin American economies saw significant currency appreciation, fuelled by capital inflows, rising external prices and faster growth. More recently, the value of national currencies has declined sharply, reflecting the appreciation of the dollar and the emergence of growing current-account deficits. Figure 9 shows the real effective exchange rate in three Latin American economies: Brazil, Colombia and Mexico. There are three different patterns: Colombia and, especially, Brazil posted fairly sharp appreciation that began to correct in 2011 in Brazil and 2012 in Colombia. The value of the Mexican peso, however, remained low throughout the period, with a slight uptick in 2013, but even so it remains higher than in 2004.

In some of the countries of Latin America, spikes in inflation ate into competitiveness. The region posted an inflation rate of $6.2 \%$ (simple average), driven by double-digit rates in Argentina and the Bolivarian Republic of Venezuela. But the median rate for the region was much lower, at only $3.9 \%$, and in most countries there are no inflationary threats. In the case of the European Union, meanwhile, no country posted more than 2\% inflation; 2014 even brought concerns as to the potential for deflation in a context of weak domestic demand and falling oil prices. In late 2014, in 15 countries of the European Union consumer prices were lower than 12 months earlier.

Thus, a key challenge for the coming decade for the countries of Latin America and Caribbean is that they will have to find a path to growth in an unfavourable external environment, with less room for manoeuvre in fiscal matters. Two factors are cause for concern: most of the countries are running substantial deficits, so indebtedness is trending up, and the region has not managed to significantly diversify its export pattern, meaning that past problems of growth instability will tend to return. As for Europe, positive signs have emerged thanks to economic recovery stimulus measures. But the signs of recovery are still fragile and there are unresolved issues that have to do with debt and with competitive asymmetries between the economies of Northern and Southern Europe.

4 EU (15) includes the following countries: Austria, Belgium, Denmark, Finland, France, Germany, Greece, Ireland, Italy, Luxemburg, The Netherlands, Portugal, Spain, Sweden and the United Kingdom. 
Figure 9. Effective real exchange rate, selected countries of Latin America (2005=100), 2004-2013

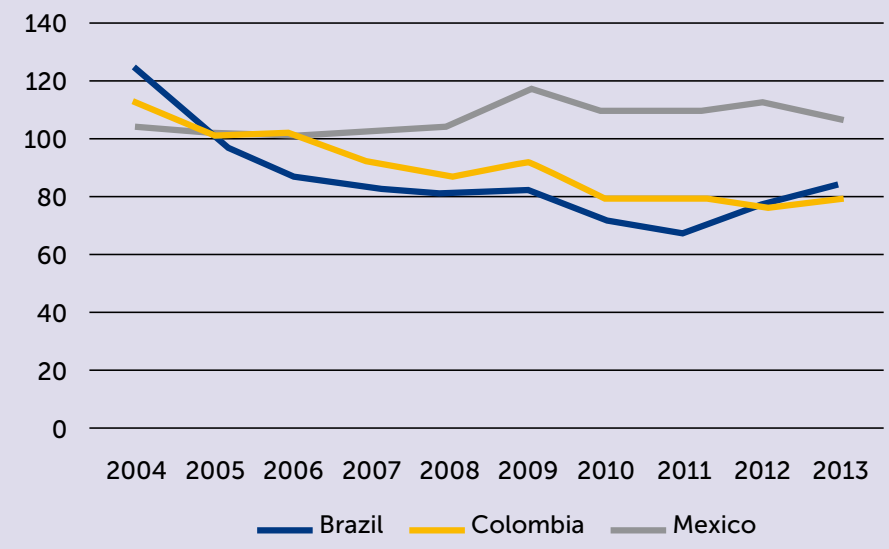

Source: Economic Commission for Latin America and the Caribbean (ECLAC), CEPALSTAT database.

\section{DYNAMICS OF TRADE AND FOREIGN DIRECT INVESTMENT}

Recent decades have seen exponential growth in the number of participants in global trade in goods and services, with a repositioning of the Asian economies -China in particular- and the United States, to the detriment of some mature economies such as Germany, Japan and Canada.

The growing importance of Asia, and especially China, in global trade and investment has redefined the relative importance of the different actors. Both Latin America and Europe have lost ground in both dimensions. The loss of space in the two regions is seen in image 1, which shows how the countries' relative share of world trade has changed. Countries with a strong trade presence in 1990 (such as Canada, Germany and Japan) slid back and accounted for a smaller percentage in 2013. Conversely, the United States and especially China enhanced their role considerably, both as exporters and as importers of goods.

Image 1. Principal importing and exporting countries, 1990 and 2013
a. Importers
1990

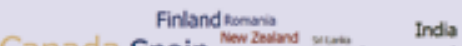 Spain Indonesia TurkeySwitzerland Denmark Germany-Japan
Malaysia
SingaporeThalland Korea, Rep. Australia
Portugal Mesicoose 2013 Tukey France

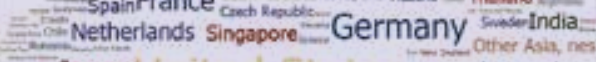
Podandapan United States United Kingdom Russian FederationKorea, Rep. Araxi Sniturand - China Belgium

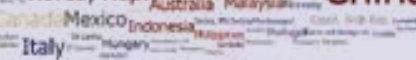

b. Exporters

1990

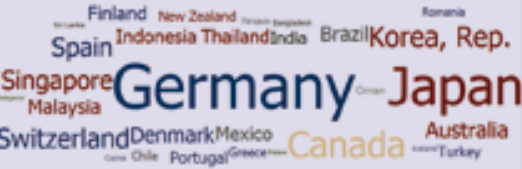

2013

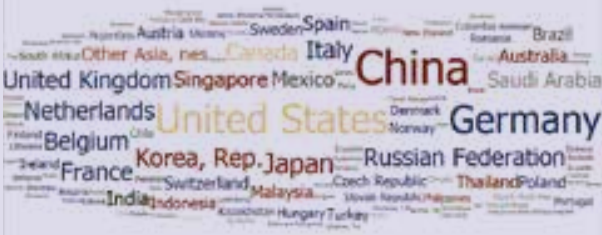


As for trade in goods, while Latin America and the Caribbean strengthened its pattern of specialization in primary goods, the European Union has enhanced its position in medium-tech goods

The trade structure of Latin America changed, too, as the influence of Chinese demand grew stronger. As shown in figure 10.a, Latin America and the Caribbean became more specialized in commodities. At the same time, the trade deficit rose, especially in medium- and high-tech goods. The opposite happened in Europe, where the primary goods deficit rose but the region went from a deficit to a surplus in high-tech goods and the medium-tech goods surplus surged. So it would seem that the boom decade reinforced country specialization. The set of capacities that is behind either specialization pattern is very different, and so are the learning trajectories deriving from their production base. Thus, capacity building could be expected to be more dynamic in Europe (see figure 10.b) than in Latin America. This has a marked impact on opportunities for and forms of insertion of SMEs in production and trade in each region.

Figure 10. Trade balance in accordance with product technology intensity, 2000 and 2013 (Percentages of total trade for each period)

a. Latin America

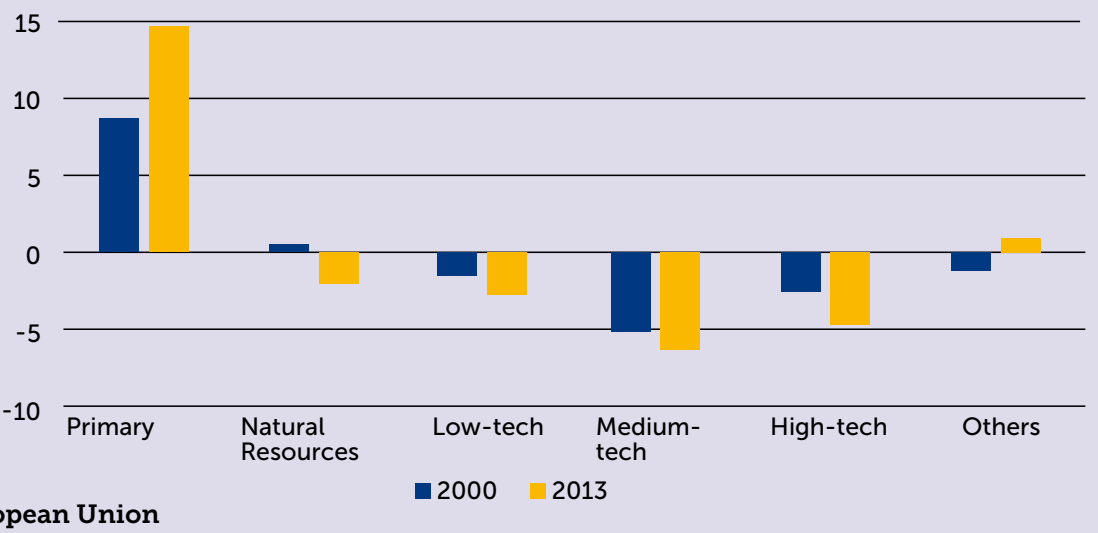

b. European Union

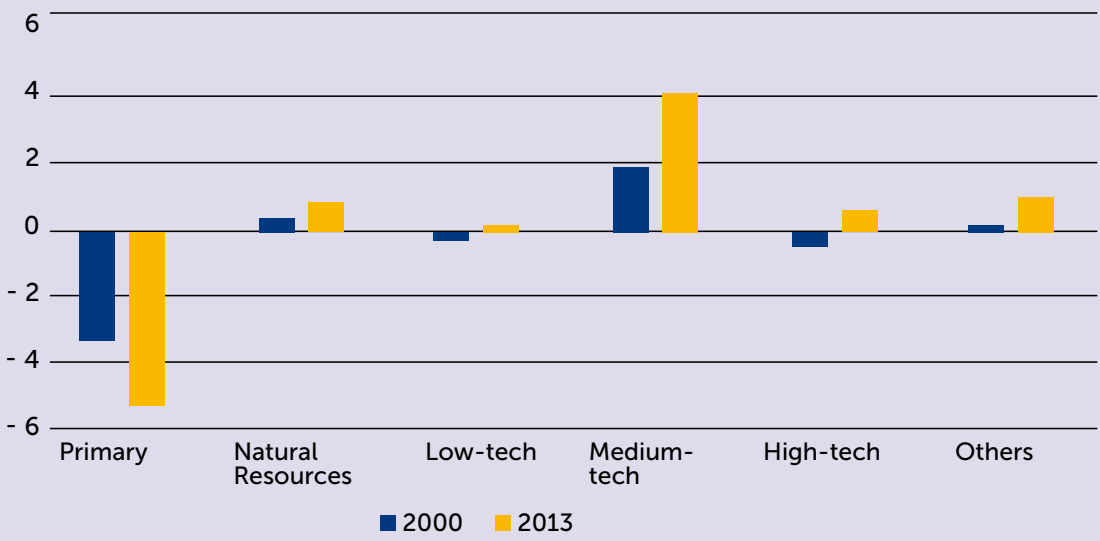

Note: Classification according to Lall's methodology (2000). For the European Union the basis was EU-15. Source: Economic Commission for Latin America and the Caribbean (ECLAC), on the basis of the Interactive Graphic System for International Trade Data (SIGCI Plus) 
Latin America and the Caribbean saw a favourable inward foreign direct investment trend that weakened at the end of the period

Foreign direct investment (FDI) is regarded as a key factor in the potential for growth and international integration, with significant impacts on a country's employment and production capacities. An analysis of the most recent data points to substantial inward FDI for Latin America and the Caribbean over the past 10 years, with the flow turning more volatile in the past few years. This reflects a global trend, with FDI dropping off dramatically after the financial crisis of 2008 . But that decline was sharper in the developed economies.

FDI in Latin America and the Caribbean in 2014 totalled US\$ 158.8 billion, which is $16 \%$ lower than the US\$ 189.9 billion, posted in 2013 and a reversal of a growth trend that began in 2010 (see figure 11). FDI inflows were affected by the slowdown in economic growth in the region, as well as sagging prices for many export commodities. The decline in FDI inflows was concentrated in the larger countries. Of the six largest economies in the region, Chile was the only one where FDI increased; it held steady in Colombia. The largest recipient was Brazil, where inflows have been stable for several years and totalled US\$ 62.5 billion in 2014. Mexico, the second largest economy in Latin America, was also the second largest recipient (US\$22.8 billion-less than the average for the previous decade, even in nominal terms). Chile posted US $\$ 20$ billion in 2014, which is higher than in 2013 but below its 2012 peak (US\$28.5 billion). Peru saw FDI flows fall for the second year in a row, to US\$ 7.6 billion in 2014. Most Central American countries received slightly more FDI.

\section{Figure 11. FDI in Latin America and the Caribbean, 1990-2014 (Millions of dollars)}

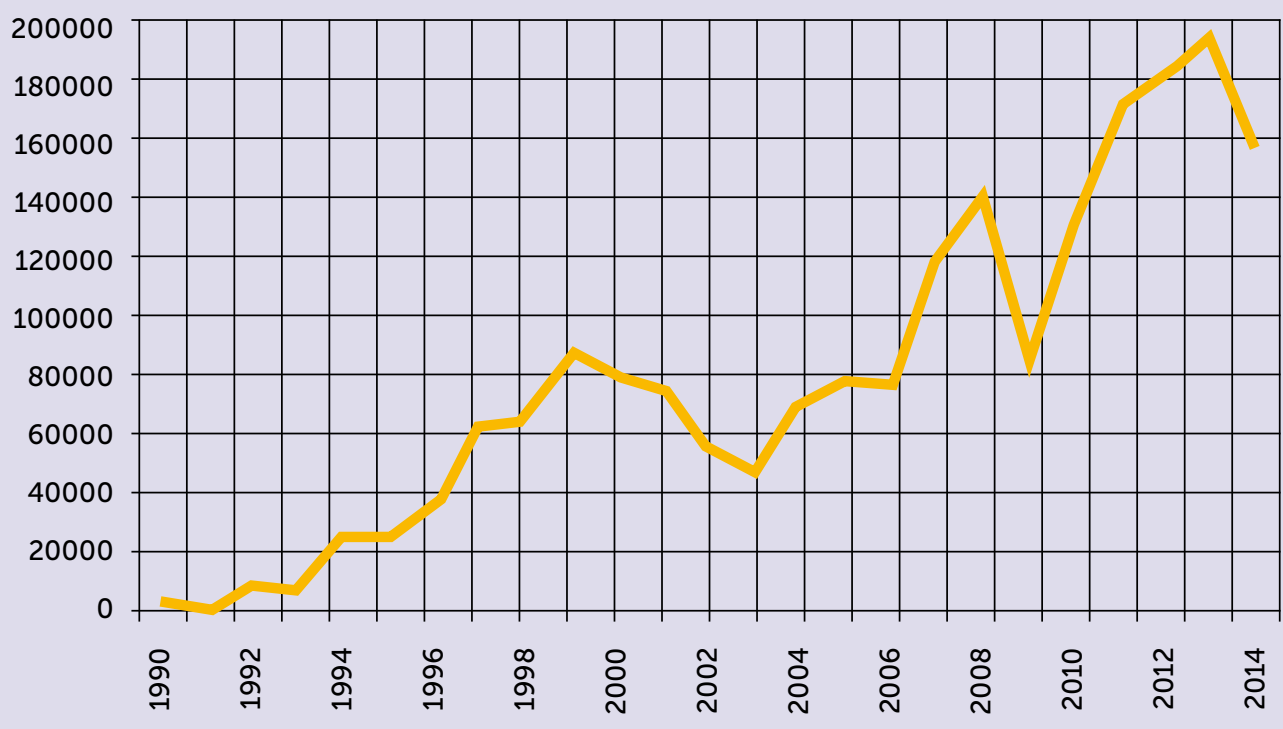

Latin America and the Caribbian 
Foreign direct investment patterns vary across the CELAC region: natural resources in the south, industry in large countries and maquila in Central America, with services accounting for a relevant portion in all of the countries

In South America, the bulk of investments go to natural resources (see figure 12). This is consistent with the incentive structure created by the commodity boom -and the resulting shift toward production of natural resource-intensive goods. Mining is particularly important in Chile, Peru and Colombia. Hydrocarbons receive much of the FDI flowing into the Bolivarian Republic of Venezuela, Ecuador and the Plurinational State of Bolivia, and, to a lesser extent, Colombia. In the larger economies of the Caribbean, natural resources also draw most of the FDI: in Trinidad and Tobago it is concentrated in oil and gas extraction; in the Dominican Republic the focus is on gold mining.

Figure 12. Latin America and the Caribbean, inward foreign direct investment, by destination sector, 2009-2013 (Percentages)

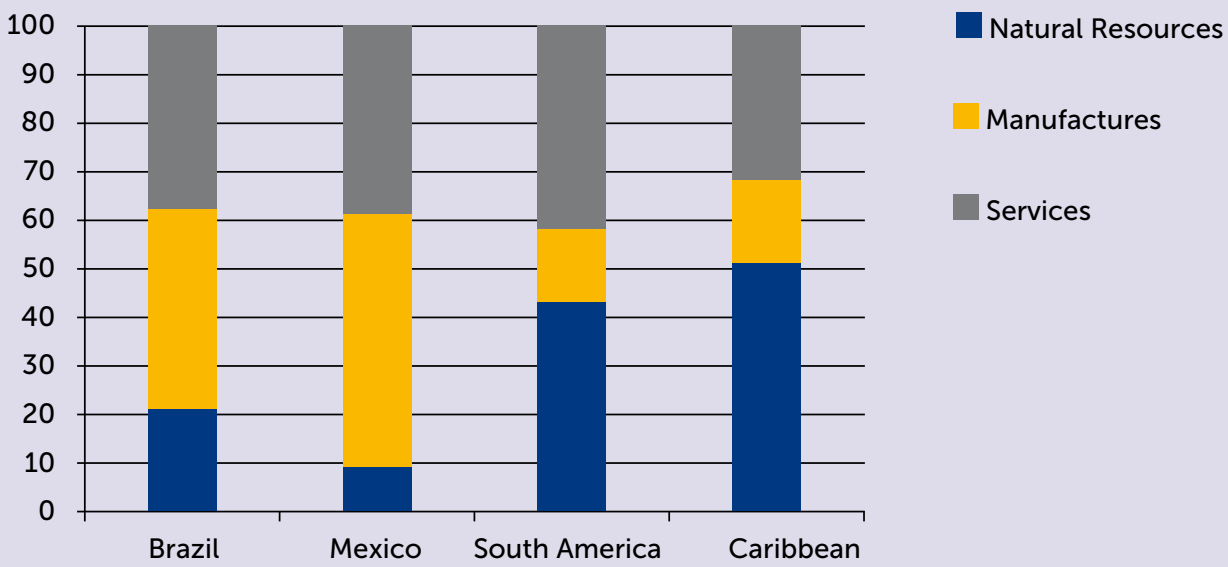

Note: South America includes Argentina, Chile, Colombia, Ecuador, the Plurinational State of Bolivia and Uruguay. The Caribbean includes the Dominican Republic and Trinidad and Tobago.

Source: Economic Commission for Latin America and the Caribbean (ECLAC), on the basis of official data.

In Mexico and some economies of Central America and the Caribbean, export manufacturing activities attract substantial FDI inflows. In Mexico, $52 \%$ of total inward FDI in recent years went to the manufacturing sector. Brazil has a more diversified economy where transnational enterprises invest heavily in the manufacturing sector. By contrast, local firms dominate agriculture, mining and hydrocarbons, so that the amounts of FDI flowing to these sectors are relatively smaII. Central America and the Dominican Republic have a substantial export manufacturing sector, especially for garments and medical devices. These sectors are major generators of employment but, because they are not very capital-intensive, the amount of FDI they receive is not very large. The services sector is, in almost all of the countries, the largest recipient of FDI, notably telecommunications, financial services, electricity and retailing. 
Europe is still a major source of FDI for Latin America and the Caribbean, but investment by trans-Latins in the region is increasing

Investments from the European Union are particularly important for the economies of South America. Fifty-six percent of total FDI flowing to Brazil in 2014 came from this source (see figure 13). Almost half of the investments received in Mexico that year were from Europe as well.

\section{Figure 13: Latin America, by source of foreign direct investment, 2014 (Percentages)}

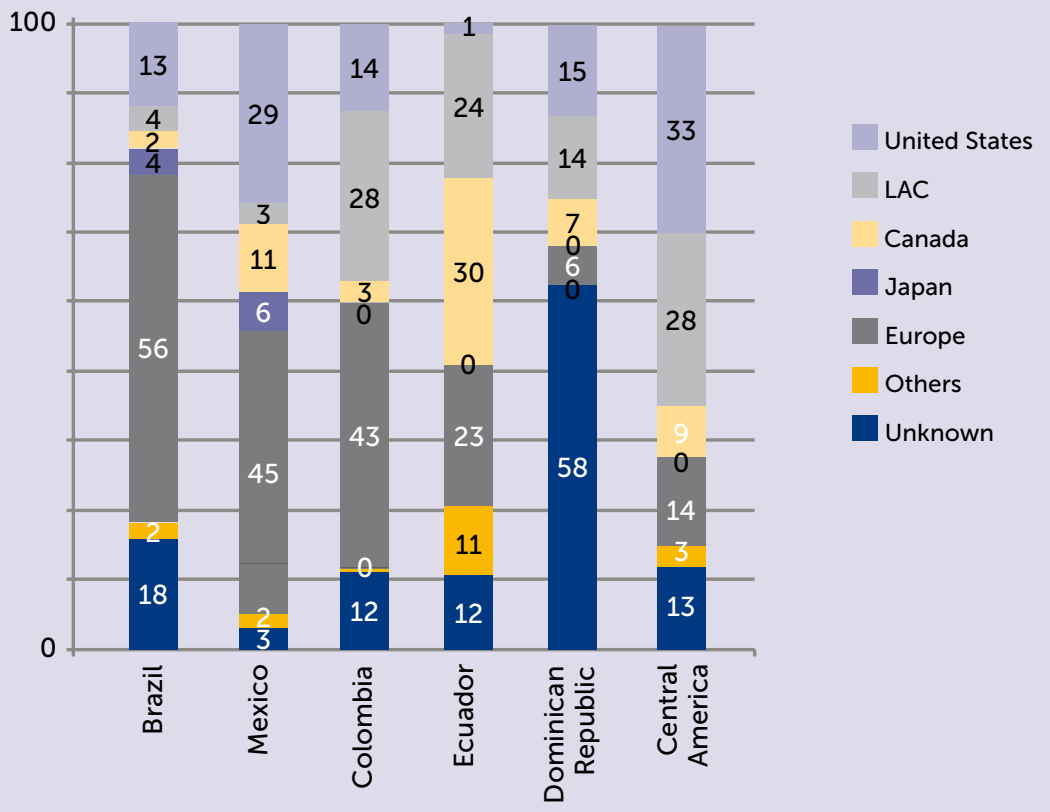

Source: Economic Commission for Latin America and the Caribbean (ECLAC), on the basis of official data.

In 2014, only 5 of the 20 largest cross-border corporate acquisitions in Latin America were carried out by European companies. The largest of these was the US\$ 4.1 billion purchase of liquefied natural gas assets in Peru and Trinidad and Tobago by the Anglo-Dutch company Royal Dutch Shell. The seller was also a European Union company: Spain's Repsol. The three largest transactions were in the brewery sector. This is an industry that is highly concentrated worldwide and where the three largest companies in the world are global conglomerates based in European countries: AB InBev (Belgium), SABMiller (United Kingdom) and Heineken (Netherlands).

Outward foreign direct investment from Latin America and the Caribbean totalled US\$29.2 billion in 2014, down $12 \%$ from 2013. FDI outflows have always been quite volatile because they are highly concentrated in few countries and a handful of large trans-Latins, which makes them very sensitive to individual acquisitions and large projects. FDI outflows from Latin America and the Caribbean are still concentrated in the region itself, but as companies grow and develop their capacities a significant number of them are beginning to invest in other regions. Mexico's largest 
trans-Latinas have investments in the United States, as do some of Brazil's and Colombia's largest corporations. In recent years, many companies in the region have boosted their investments in Europe. Since 2003, approximately 31\% of investment flows from Latin America went to Spain; Belgium and Luxembourg accounted for $25 \%$ and $15 \%$ respectively. The major source countries were Brazil and Mexico, albeit with substantial differences in recipient markets.

\section{PRODUCTIVITY AND INVESTMENT WITH A FAST-MOVING TECHNOLOGY FRONTIER}

In terms of productivity, the CELAC and European Union countries have not kept pace with the Asian economies or the United States

Latin America's economic growth has not come with a substantial productivity gain. In order to sustain growth, the region needs to focus on productivity in the coming years.

Tracking the productivity gap (with the United States) of a group of countries in the region compared with a group of South-East Asian countries reveals substantial differences (see figure 14). The productivity gap of the countries of Latin America and the Caribbean has fluctuated considerably, widening substantially in the 1980s and 1990s and then starting to narrow in the 2000s. In all cases the gap at the end of the period (2012) is larger than at the beginning (1980), with the exception of Chile, where the gap narrowed in the 1990s and remained stable in the 2000s.

Figure 14. Productivity gap index $(1980=100), 1980-2012$

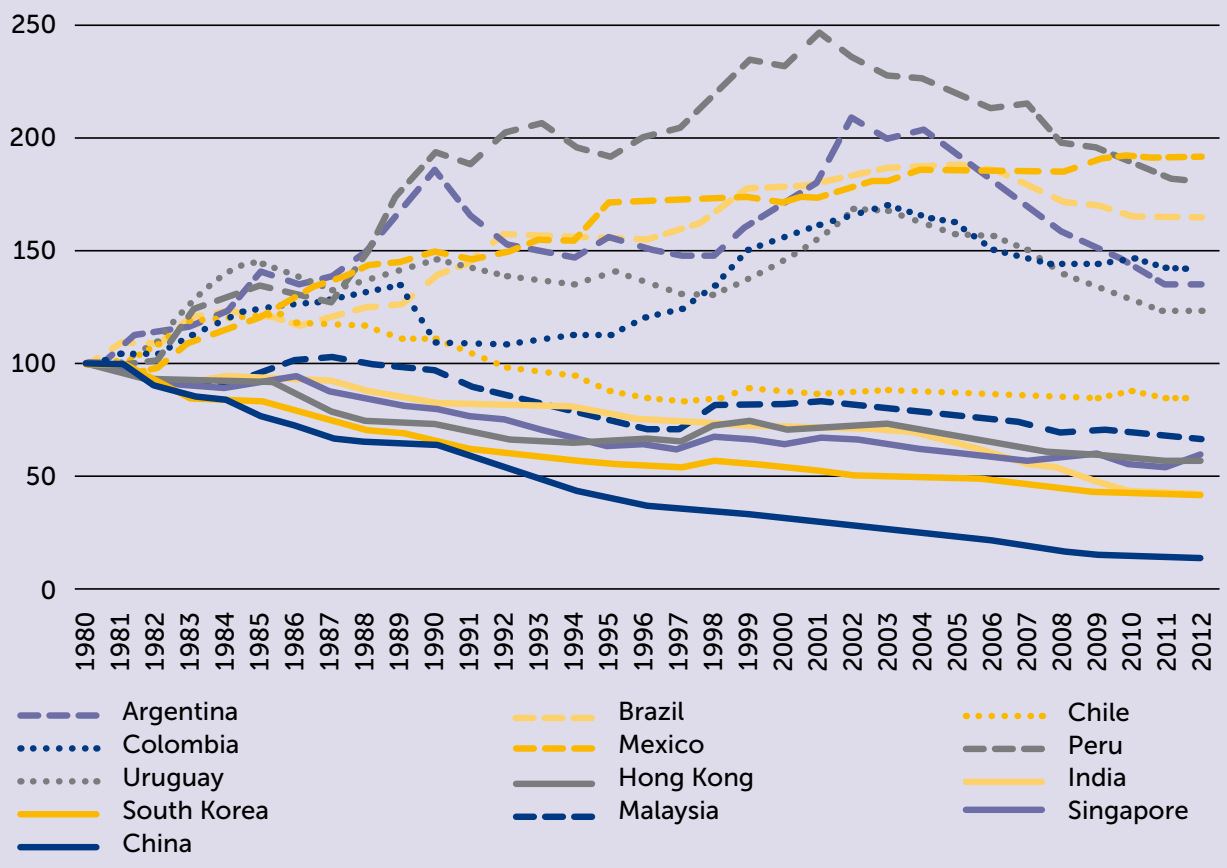

Source: Economic Commission for Latin America and the Caribbean (ECLAC), on the basis of data from the World Bank. 
in production patterns towards more knowledge-intensive sectors. Over the long term, dynamic comparative advantages (based on technological leadership or quick catch-up with new products or processes) prevail over static comparative advantages (which reallocate factors assuming a given technological level). This is particularly relevant in a world where the international frontier is moving at increasing speed. This movement is redefining productivity differentials between firms and sectors. Companies that fall behind technologically, and countries lacking policies for encouraging learning and structural change, tend to lose ground in the most dynamic sectors. The importance taken on by the debate over reshoring and global value chains, where developing countries are only able to enter the low-technology segments, confirms the dominance of dynamic advantages over static ones.

Figure 15 shows the relative productivity of Latin America and the Caribbean and Europe compared with United States productivity between 1991 and 2013. The former are both losing ground in productivity compared with the United States. Figure 16 shows the same variable for some of Europe's larger economies (France, Germany and the United Kingdom). France and Germany post declines; the relative productivity of the United Kingdom remains approximately the same at the beginning and at the end of the period. From a productivity standpoint, then, the past 20 years have not belonged to Latin America or Europe, but Asia. The former two regions and some of the principal countries are losing ground in terms of productivity compared with the United States.

Figure 15. Latin America and the Caribbean and Europe: relative productivity compared with the United States, 1991-2013 (Percentages)

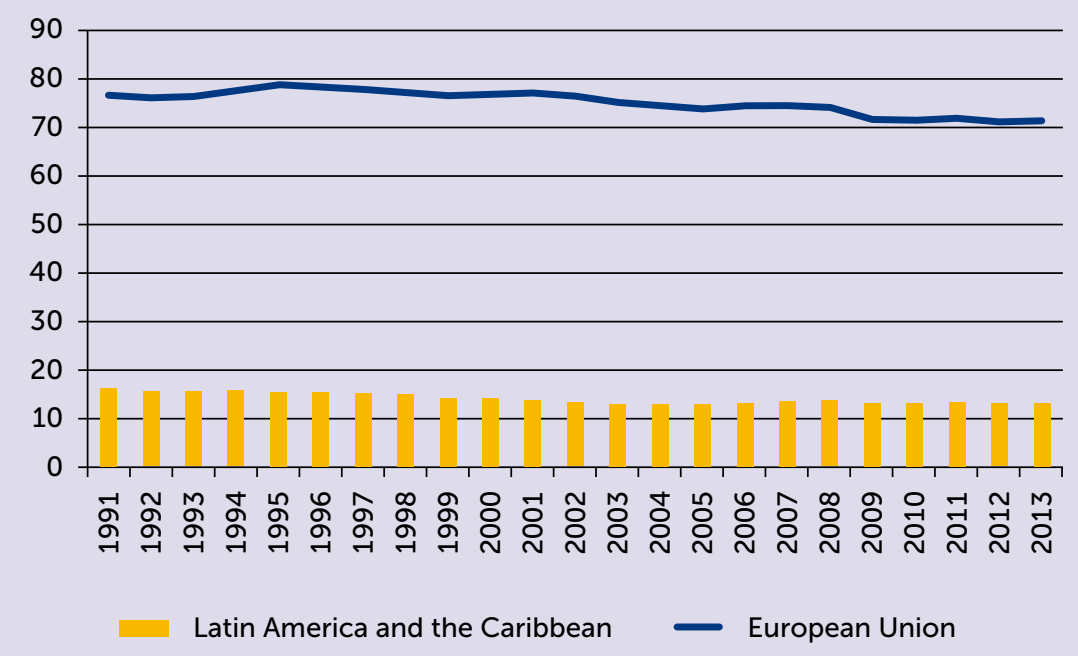

Source: Economic Commission for Latin America and the Caribbean (ECLAC), on the basis of data from the World Bank and the International Labour Organization (ILO). 
Figure 16. Relative productivity in Europe compared with the United States: selected economies, 1991-2013 (Percentages)

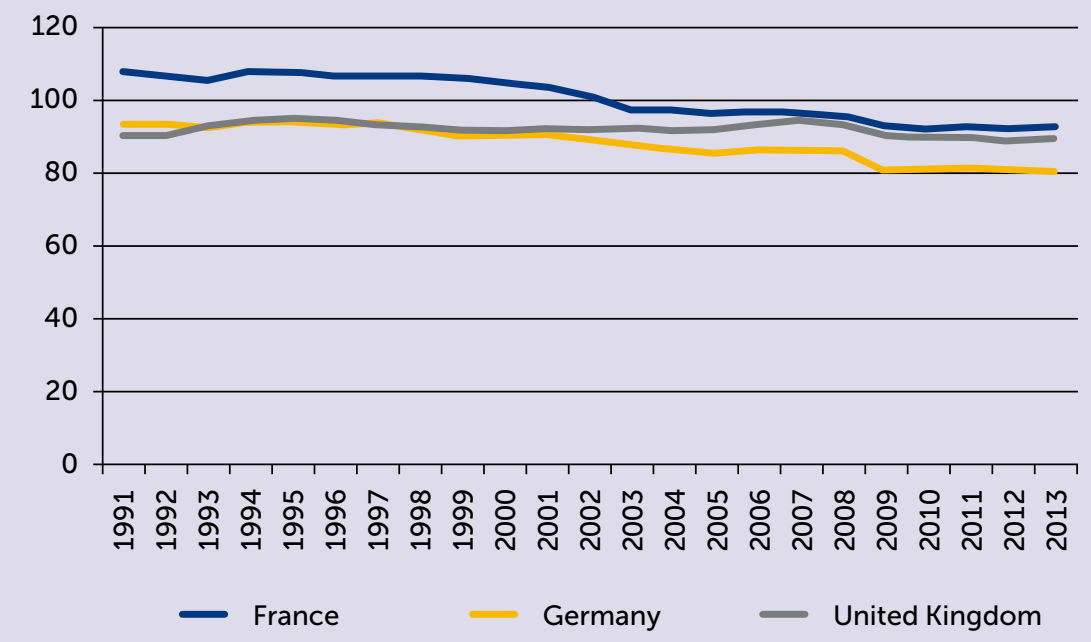

Source: Economic Commission for Latin America and the Caribbean (ECLAC), on the basis of data from the World Bank and the International Labour Organization (ILO).

Widening productivity gaps in Latin America and Europe are, in the former, due to erratic growth and incentives that work against more knowledge-intensive activities, and, in the latter, to failure to position themselves in the new technological paradigms.

Europe's productivity lag is rooted in different factors than Latin America's. Europe has not been on the leading edge of new technological paradigms that are revolutionizing production systems. While the advanced economies of Europe are drawing very close to the technology frontier, they have not managed to translate their technology efforts into productivity gains as the United States has done. The decade's recessionary context and uncertainty in the face of the financial crisis might explain this productivity lag. On the other hand, the scale of United States efforts in science and technology far outstrips what policies for the whole of Europe have so far been able to achieve. ${ }^{5}$

In Latin America and the Caribbean, although the commodity boom helped to narrow productivity gaps and higher growth rates fuelled an improvement in investment and technology dissemination, there were several other factors that did not help sustain this improvement in productivity. Unlike in the United States and the leading countries in Europe, learning and productivity gains were hobbled by the lack of industrial and technology policies, combined with erratic growth and the subsequent slowdown and incentives that work against greater knowledge intensity and in favour of commodities to meet international market demands. After all, he pattern of trade with China follows the classic lines of North-South trade. It has been said that

5 See Mazzucato, 2013. 
Latin America and the Caribbean reprimarized its trade during this decade. This had repercussions regarding the space for learning, especially because the lack of industrial policies meant failure to take advantage of potential complementarities between competitiveness in natural resources and capacity building in industry and services. The outcome was lost opportunities for promoting production structure diversification.

Latin America and the Caribbean has concentrated its manufacturing output in low-tech sectors, unlike in Europe and Asia, where high-tech industries today account for about $40 \%$ of manufacturing-sector value added (see figure 17). So, even though Europe has lost ground in productivity compared with the United States, it still has a production and trade structure where medium- and high-tech sectors carry substantial weight.

Figure 17. Manufacturing sector technology intensity in Europe, Asia and Latin America, 1980-2010 (Percentages)

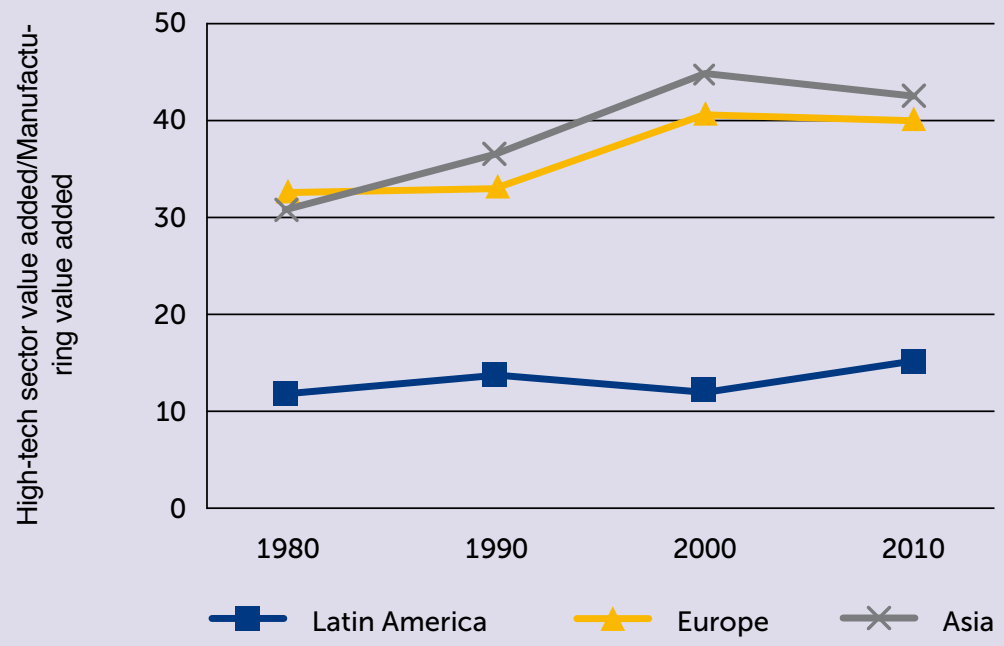

Note: Regions are simple averages of country data for 1980, 1990, 2000 and 2010 or the latest available year. For Latin America they comprise Argentina, Brazil, Chile, Colombia, Costa Rica, Ecuador, Mexico, Panama, Peru, the Plurinational State of Bolivia and Uruguay. For Europe: Austria, Belgium, Denmark, Finland, France, Germany, Greece, Ireland, Italy, the Netherlands, Norway, Portugal, Spain, Sweden and the United Kingdom. For Asia: China, Hong Kong Special Administrative Region of China, Japan and the Republic of Korea.

Source: Economic Commission for Latin America and the Caribbean (ECLAC), on the basis of data from the United Nations Industrial Development Organization (UNIDO).

Gradually, Latin America and the Caribbean is returning to industrial policies that seek to correct or reduce the region's technology lag. These policies will likely have to be implemented in a more challenging external environment and with fewer resources. As seen above, the fiscal space has shrunk, reducing the posibility of using more public investment and supporting private investment in new sectors. 
Weak investment and the high concentration of Latin America's production structure in low-tech sectors are behind an environment that is not very conducive to investment in research and development

Both Latin America and the Caribbean and the European Union have levels of investment that fall below those of other regions as well as the global average (24.5\% of GDP in 2013). The international crisis that broke out in 2008 and deepened in 2009 adversely impacted levels of investment in both regions. While their investment rates were similar until 2007, starting then gross fixed capital formation as a percentage of GDP declined in the European Union and dropped below $20 \%$. After recovering slightly in 2010 and 2011, this indicator fell again in the context of the crisis that has impacted the eurozone above all.

The export boom spurred an increase in investment, which had been very low in the two previous decades. Nevertheless, rates of investment remained below those of the Asian economies and also below the levels needed to achieve sustainable progress towards closing the gap. Furthermore, the rising investment trajectory seemed to stall or reverse in some countries, bringing down the regional average. This was to be expected given that investment levels move on growth and earnings expectations, which have deteriorated in response to changing conditions in the international environment and domestic challenges in some countries (such as Brazil and Mexico, which account for most of Latin America's GDP).

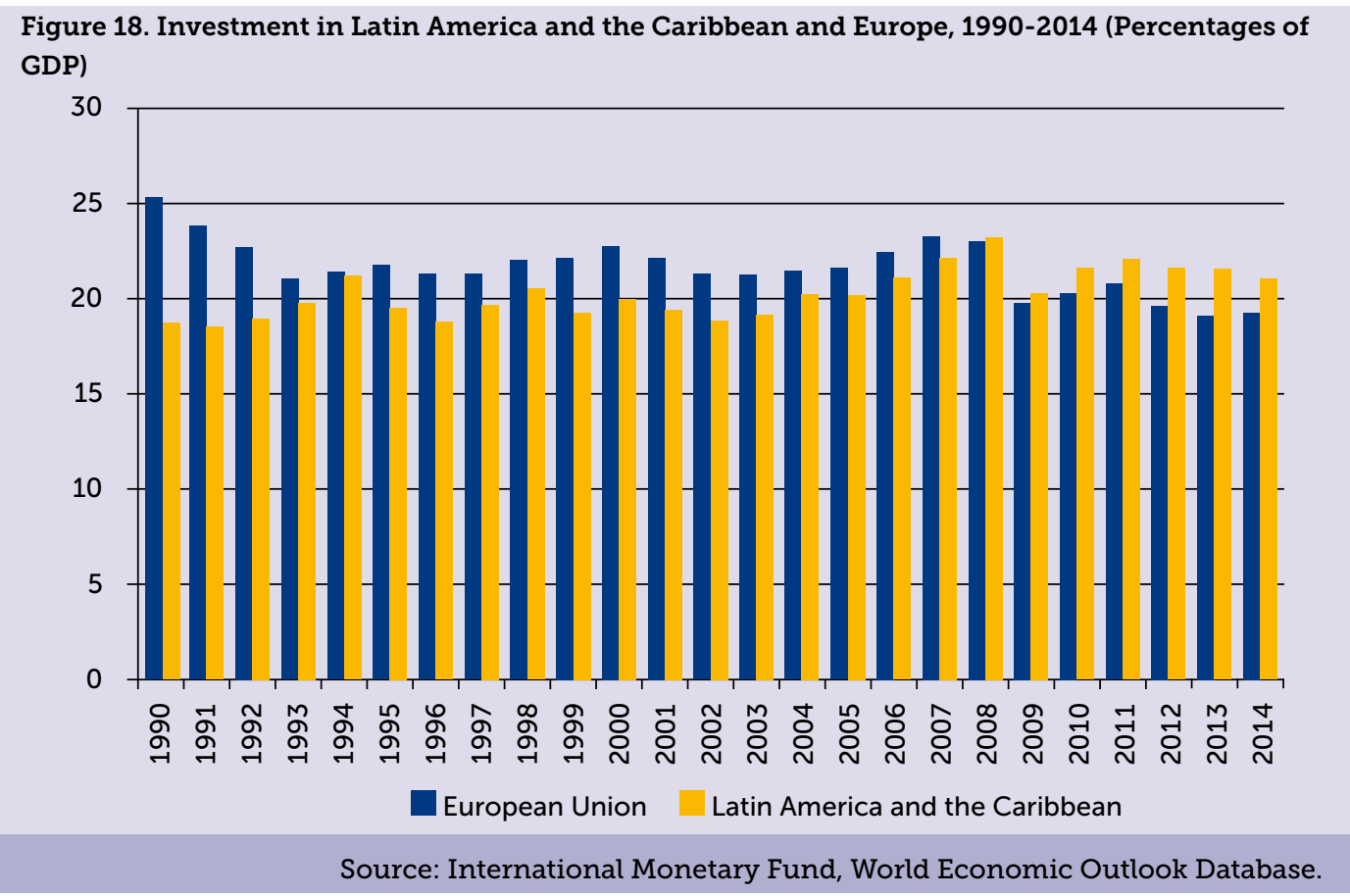


As a result, the regional investment rate (measured as a percentage of GDP in 2010 constant dollars), fell to $21.1 \%$ of GDP in 2014 , even lower than the 2010 level (21.7\%). As with other economic variables in the region, the outlook varies considerably from one country to another: investment as a percentage of GDP has climbed in Central America and in Colombia, Ecuador and the Plurinational State of Bolivia, but fallen in Argentina, the Bolivarian Republic of Venezuela, Brazil and Chile.

Productivity and investment patterns are directly linked to the generation, dissemination and appropriation of knowledge. Weak investment and a production structure that is highly concentrated in low-tech sectors make for an environment that is not very conducive to investment in research and development $(R \& D)$.

Latin America and the Caribbean has made progress in building and strengthening its scientific and technological capacities, and new science and technology institutions have emerged. But the region still presents major lags in this area, especially in comparison with developed countries and with emerging countries in Asia. The pattern of specialization in Latin America and the Caribbean is characterized by a high proportion of exports in low technology-content sectors and little involvement of the production sector in innovation. All of this means a high degree of dependence in terms of science, technology and innovation, and low intensity in technology learning and dissemination (see figure 19).

Latin America and the Caribbean lags far behind Europe in terms of research and development, where it invests on average less than $0.8 \%$ of GDP; in the countries of the European Union (28) the figure tops $1.9 \%$. Even in Brazil, the country of the region that invests the most in research and development (around 1.2\% in 2012), levels of investment are much lower than in the European countries. For example, France invests $2.2 \%$ of GDP, Germany $2.9 \%$ and Finland 3.3\% (2013). And the sources of funding for research and development vary widely. In Latin America and the Caribbean most of the investment comes from the public sector; in developed countries the private sector leads investment in research and development. This confirms what was noted earlier about the region's pattern of specialization and the weak incentives for technological development of enterprises in Latin America and the Caribbean. 
Figure 19. Research and development expenditure by source of funds in Latin America and Europe, 2000-2012

a. Latin America

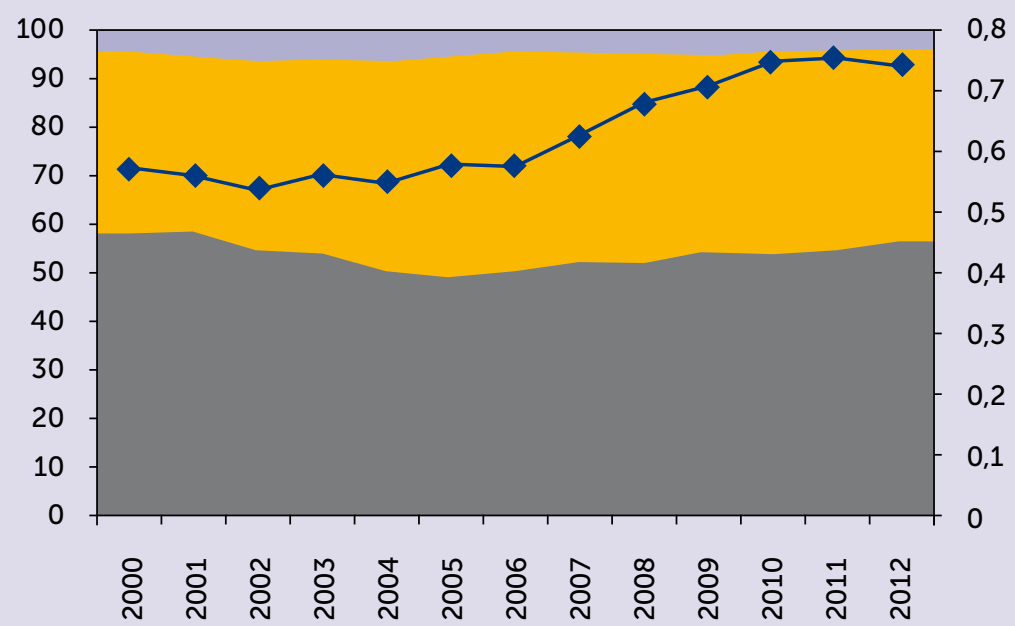

Total Government Total corporate Others - Expenditure on R\&D (\% of GDP)

b. European Union

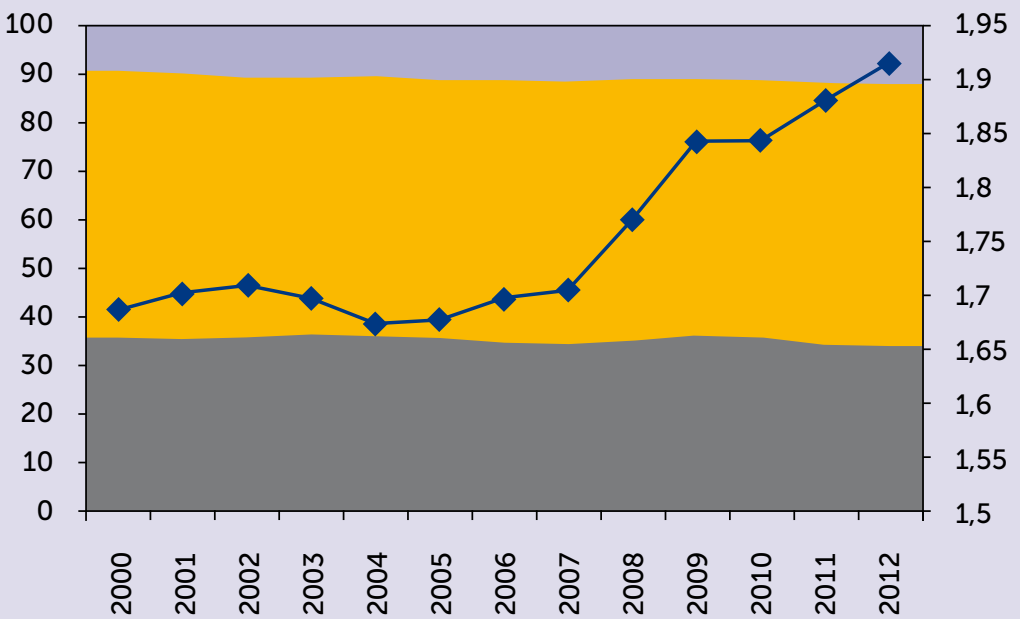

Total Government Total corporate Others - Expenditure on R\&D (\% of GDP)

Source: Economic Commission for Latin America and the Caribbean (ECLAC), on the basis of data from the OECD.Stat database and the Regional Network on Science and Technology Indica-

tors (RICYT). 


\section{SMES IN OPEN ECONOMIES: \\ OPPORTUNITIES FOR \\ INTERNATIONALIZATION AND PRODUCTION INTEGRATION}

Latin American and European SMEs will face a new trade, production and technological scenario in the coming years, with heightened competitive demand. Latin America and the Caribbean has strengthened its primary-export position without building significant technological capabilities at the same time. Europe has gone through a period with negative consequences for investment and innovation capacity. In a world where technological progress is gathering ever more speed, the decline in investment has high costs in terms of wider technology, productivity and income gaps. These gaps and competitive pressures are felt even more by SMEs, which usually have less financial and market leverage than large companies. The problem is particularly acute in Latin America, which lacks Europe's institutions for and experience with supporting SMEs, whose production structure lacks the technological intensity of the European network, and where -because of these factors- productivity differentials between SMEs and large enterprises are striking. This creates very high heterogeneity across firms and sectors in Latin America and the Caribbean.

The key to understanding the region's heterogeneity and the potential for moving towards more inclusive and sustainable development paths lies not only in understanding what is happening at the sector level but also analysing companies, particularly smaller enterprises.

\section{SMES IN CELAC AND THE EUROPEAN UNION: A STYLIZED OVERVIEW}

MSMEs are a key player in terms of the number of companies and persons employed in all of the countries, though not in terms of value-added generated

While the definition of SMEs varies from country to country, SMEs generally are defined as independent companies (not part of a business group) that employ up to a certain number of employees and/or whose turnover is below a certain limit. It is generally considered that an 
enterprise with up to 250 employees is medium-sized, with less than 50 employees it is small, and with fewer than 5 employees it is a microenterprise. ${ }^{6}$ In some definitions the limits (either for number of employees or for sales volume) vary depending on the sector, bearing in mind the higher per-employee turnover of marketing and service enterprises. Moreover, the operative definition of SMEs in each country is the result of a deliberative process or an administrative act. The legal value of this definition is rooted in the existence of a set of public policies aimed at this business segment. In this context, then, there is some room to expand or reduce the number of potential beneficiaries of these policies according to the established definition. Moreover, what is considered large or small may depend on the production context and therefore on the distribution of enterprise sizes in each country.

Different definitions of SMEs and the lack of data, especially in the case of developing countries, pose a challenge for gathering information and, above all, for carrying out an international comparison. Any comparisons should therefore be taken with caution.

Despite measurement and comparison issues, micro, small and medium-sized enterprises (MSMEs) are undeniably important. They represent the bulk of businesses and account for most of the jobs generated by the private sector. For both Latin America and Europe, MSMEs make up nearly $99 \%$ of the production structure and absorb between $40 \%$ and $80 \%$ of the total workforce. For this reason they have considerable impact on income and working conditions for much of the population, which depends on the performance of these companies (see table 1).

\begin{tabular}{|c|c|c|c|}
\hline \multirow[b]{2}{*}{ Country } & \multicolumn{3}{|c|}{ Enterprises } \\
\hline & Microenterprises & SMEs & Large enterprises \\
\hline Argentina & 69.7 & 28.4 & 1.9 \\
\hline Brazil & 90.1 & 9.3 & 0.6 \\
\hline Chile & 78.3 & 20.3 & 1.4 \\
\hline Colombia & 96.4 & 3.5 & 0.1 \\
\hline Ecuador & 95.4 & 4.4 & 0.2 \\
\hline El Salvador & 91.2 & 8.4 & 0.4 \\
\hline Mexico & 95.5 & 4.3 & 0.2 \\
\hline Peru & 94.5 & 4.9 & 0.6 \\
\hline Uruguay & 83.4 & 16.1 & 0.5 \\
\hline
\end{tabular}

6 This is the European Union's definition. In the United States, medium-sized enterprises can have up to 500 employees. 
Table 1. (continued)

\begin{tabular}{|c|c|c|c|}
\hline & \multicolumn{3}{|c|}{ Enterprises } \\
\hline Country & Microenterprises & SMES & Large enterprises \\
\hline UE (25) & 92.0 & 7.8 & 0.2 \\
\hline Germany & 82.0 & 17.5 & 0.4 \\
\hline Belgium & 93.7 & 6.2 & 0.1 \\
\hline Spain & 94.0 & 5.9 & 0.1 \\
\hline France & 94.7 & 5.1 & 0.1 \\
\hline Italy & 95.0 & 4.9 & 0.1 \\
\hline Czech Republic & 96.0 & 3.8 & 0.1 \\
\hline \multirow[t]{2}{*}{ United Kingdom } & 89.7 & 10.0 & 0.3 \\
\hline & \multicolumn{3}{|c|}{ Employment } \\
\hline Country & Microenterprises & SMES & Large enterprises \\
\hline Argentina & 11.5 & 39.6 & 48.9 \\
\hline Brazil & 13.7 & 28.3 & 58 \\
\hline Chile & 44.1 & 30.9 & 25 \\
\hline Colombia & 50.6 & 30.3 & 19.1 \\
\hline Ecuador & 47.3 & 29.8 & 22.9 \\
\hline El Salvador & 37.8 & 27.7 & 34.6 \\
\hline Mexico & 45.7 & 23.6 & 30.8 \\
\hline Peru & 48.5 & 19.2 & 32.4 \\
\hline Uruguay & 24.1 & 43.1 & 32.8 \\
\hline UE (25) & 31.5 & 38.3 & 30.2 \\
\hline Germany & 19.5 & 44.0 & 36.5 \\
\hline Belgium & 34.8 & 38.4 & 26.8 \\
\hline Spain & 41.5 & 35.1 & 23.4 \\
\hline France & 31.8 & 35.1 & 33.1 \\
\hline Italy & 48.5 & 33.4 & 18.1 \\
\hline Czech Republic & 32.8 & 37.6 & 29.6 \\
\hline United Kingdom & 19.8 & 37.0 & 43.2 \\
\hline
\end{tabular}

Note: For the countries of Latin America. For Argentina, 2012 data based on OECD (2013). For Brazil, 2010 data based on IBGE (2012). For Chile, data for companies based on ILO/SERCOTEC (2010) for 2008 and employment data based on CASEN for 2009. For Colombia, 2005 data based on DANE (2008). For Ecuador, 2009 data based on Chamber of Industries and Production (2011). For El Salvador, data for 2005 based on MINEC/DIGESTYC (2006). For Peru, 2007 data based on INEI (2011). For Mexico, 2009 data based on INEGI (2011). For Uruguay, 2012 data based on INE (2012).

EU-25 comprises Austria, Belgium, Bulgaria, the Czech Republic, Denmark, Estonia, Finland, France, Germany, Greece (2009), Hungary, Ireland, Italy, Latvia, Lithuania, Luxembourg, the Netherlands, Poland, Portugal, Romania, Slovakia, Slovenia, Spain, Sweden and the United Kingdom.

Source: Economic Commission for Latin America and the Caribbean (ECLAC), on the basis of P. Santoleri and G. Stumpo, 2014. For European Union countries: data from OECD, 2012. 
The substantial differences between MSMEs in Latin America and Europe have a lot to do with the sector to which they belong and to production development policies

Even if MSMEs make up a similar proportion of the production system from one country to another, in developing countries they have a very low level of professionalization. Microenterprises could in some cases be considered as precarious employment or hidden unemployment, and they often lack a true business culture. While smaller enterprises in the countries of Latin America have very low productivity (defined as value added per employee) compared with larger enterprises, the differences between enterprise strata are smaller in Europe (see figure 20). For example, while in countries like Brazil and Peru microenterprise productivity is $10 \%$ or $3 \%$ of large-company productivity, for some European countries like Germany and Spain the figure is $70 \%$ and $49 \%$ respectively.

Figure 20. Labour productivity compared with large companies, by size, 2011 or the latest available year (Percentages)

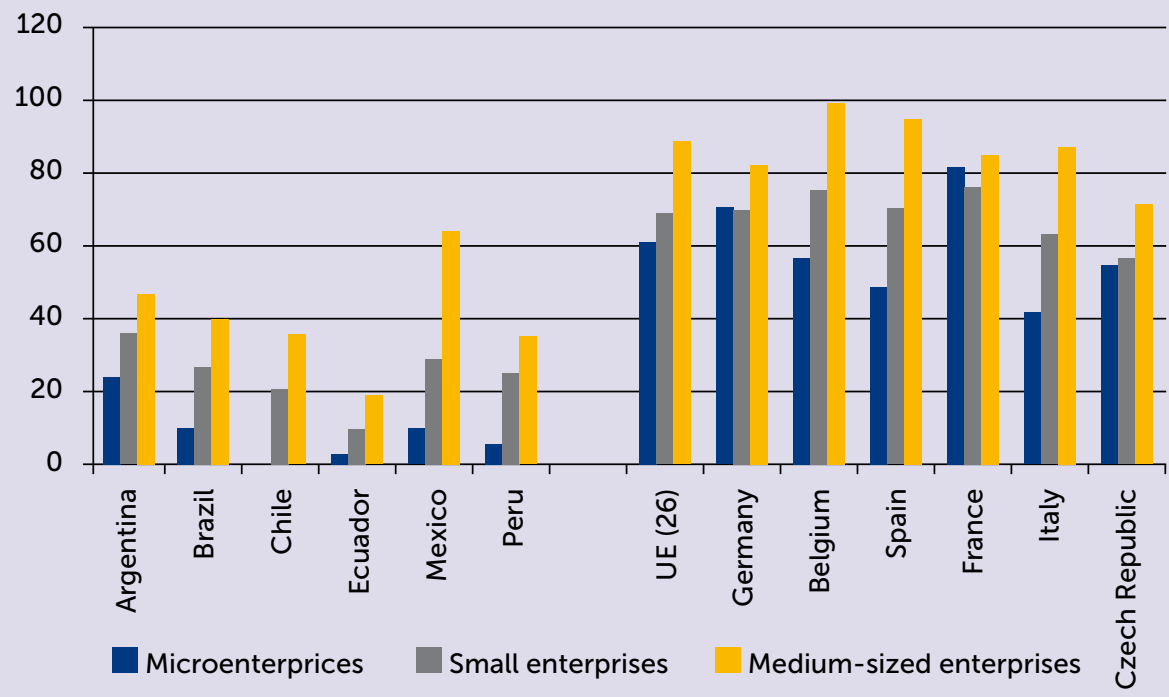

Note: For Chile, the figures include formal microenterprises with annual sales above 800 UF (approximately US\$39,000).

Source: Economic Commission for Latin America and the Caribbean (ECLAC), on the basis of P. Santoleri and G. Stumpo, 2014. For European Union countries: data from OECD, 2012.

Productivity differentials between micro, small, medium-sized and large enterprises are not determined by size alone, but rather by the sectors where they operate and the technology and production support policies in place in each country. In the countries of Latin America and the Caribbean, these enterprises usually operate in sectors with low technology intensity, low productivity, low wages and poor quality jobs and a high degree of informality. In Europe, by contrast, a significant percentage of these firms operate in high-productivity fields that are highly knowledge-intensive. Using the methodology developed by J. Katz and G. Stumpo to classify 
industries according to their degree of technological sophistication, it emerges that in countries like the Czech Republic, Germany and Italy more than $40 \%$ of SMEs are in engineering-intensive sectors (see table 2$)^{7}$.

Table 2. Contribution of sectors ranked by technology intensity to SME value added for a group of European countries, average 2008-2014 (Percentages)

\begin{tabular}{|l|l|l|l|l|l|l|l|}
\hline Sector & Hungary & Romania & Spain & $\begin{array}{l}\text { Czech } \\
\text { Republic }\end{array}$ & Germany & Italy & France \\
\hline 01 & 24 & 24 & 29 & 42 & 46 & 40 & 30 \\
\hline 02 & 4 & 4 & 4 & 4 & 3 & 3 & 5 \\
\hline 03 & 28 & 28 & 34 & 47 & 50 & 42 & 35 \\
\hline 04 & 17 & 17 & 20 & 11 & 11 & 11 & 23 \\
\hline 05 & 27 & 27 & 29 & 28 & 24 & 25 & 25 \\
\hline 06 & 44 & 44 & 49 & 39 & 35 & 36 & 48 \\
\hline 07 & 28 & 28 & 18 & 14 & 15 & 22 & 17 \\
\hline 08 & 100 & 100 & 100 & 100 & 100 & 100 & 100 \\
\hline
\end{tabular}

Note: The sectors are:

01. Engineering-intensive sectors, not including motor vehicles (NACE C25, C26, C27, C28)

02. Motor vehicles (NACE C29, C30)

03. Total engineering-intensive sectors $(01+02)$

04. Food, beverages and tobacco (NACE C10, C11, C12)

05. Other natural-resource intensive sectors (NACE C16, C17, C19, C20, C22, C23, C24)

06. Total natural-resource intensive sectors $(\mathrm{CO} 4+\mathrm{CO5})$

07. Labour-intensive sectors (C13, C14, C15, C18, C31, C32)

08. Total manufacturing

Source: Economic Commission for Latin America and the Caribbean (ECLAC), on the basis of data from the EUROSTAT database.

Achieving a higher level of development and social cohesion inevitably involves strengthening MSMEs through productivity gains that create good, higher-paying jobs. SMEs need to link with large companies, taking advantage of the latter's economies of scale and access to external markets. And at the local level, closer links with other SMEs are needed. This would also make it possible to contribute to region-wide development through the clustering of local production, thereby helping to narrow gaps between regions. The experience of developed countries confirms the importance of having a competitive SME segment, where business activity is focused on the creation of new knowledge- and innovation-intensive business models.

With both regions going through a period of slow growth, strong and competitively sustainable small and medium-sized enterprises are crucial for economic recovery (see box 1). These enterprises are weathering the crisis, but are taking a harder hit in terms of job losses and lower productivity.

7 See Katz and Stumpo, 2001. 


\section{BOX 1.}

\section{EUROPEAN SME RESILIENCE IN THE FACE OF THE CRISIS}

While the debate usually focuses on the percentage of total enterprises that are MSMEs, their contribution to value added and employment and their link to the external sector, there are other factors to consider in order to evaluate the role these enterprises play. Because they tend to be more heavily impacted by crises, policies geared to help them recover are important. A look at what has happened in the past six years in some European countries brings the following to light:

a.The only segment where the number of enterprises increased was microenterprises (2\%), so the overall increase was $1.7 \%$ despite a $2.5 \%$ decline in the number of medium-sized enterprises and a $2.8 \%$ drop for large enterprises.

b. The non-financial economy overall saw the number of employees decrease by $2 \%$; more jobs were destroyed in percentage terms in the microenterprise segment (3\%) because it is the largest source of employment, also in absolute terms.

c.In 2013 all segments, with the exception of small enterprises, topped the level of the value added generated in 2008 (2\% for the total number of companies). Medium-sized and large enterprises posted the best performance (3\%).

d. All segments of enterprises according to size boosted apparent labour productivity between 2008 and 2013. This is because they are producing the same level of value added (the small enterprises) or a higher one while sustaining fewer jobs. The largest productivity gains were among medium-sized and large enterprises (5.1\%), followed by microenterprises (4.1\%). Small enterprises performed the worst (1\%).

\begin{tabular}{|c|c|c|c|c|c|c|}
\hline \multicolumn{7}{|c|}{ Number of enterprises by enterprise size, $2008=100$} \\
\hline & 2008 & 2009 & 2010 & 2011 & 2012 & 2013 \\
\hline Micro & 100 & 97 & 103 & 103 & 103 & 102 \\
\hline Small & 100 & 98 & 97 & 98 & 99 & 98 \\
\hline Medium-sized & 100 & 99 & 97 & 98 & 98 & 98 \\
\hline Large & 100 & 97 & 96 & 98 & 97 & 97 \\
\hline Total & 100 & 99 & 102 & 103 & 103 & 102 \\
\hline \multicolumn{7}{|c|}{ Number of employees by enterprise size, $2008=100$} \\
\hline Micro & 100 & 100 & 100 & 99 & 96 & 97 \\
\hline Small & 100 & 100 & 99 & 100 & 100 & 99 \\
\hline Medium-sized & 100 & 98 & 98 & 98 & 98 & 98 \\
\hline Large & 100 & 96 & 97 & 98 & 98 & 98 \\
\hline Total & 100 & 98 & 98 & 99 & 98 & 98 \\
\hline \multicolumn{7}{|c|}{ Value added by enterprise size, 2008 $=100$} \\
\hline Micro & 100 & 88 & 94 & 98 & 99 & 101 \\
\hline Small & 100 & 91 & 94 & 97 & 99 & 100 \\
\hline Medium-sized & 100 & 92 & 96 & 101 & 102 & 103 \\
\hline Large & 100 & 90 & 98 & 101 & 103 & 103 \\
\hline Total & 100 & 90 & 96 & 100 & 101 & 102 \\
\hline \multicolumn{7}{|c|}{ Source: EUROSTAT } \\
\hline
\end{tabular}


In short, MSMEs proved to be quite resilient in that the number of them held steady (and even increased in the case of microenterprises) in spite of the crisis. The flip side of the coin is the less favourable performance they posted in terms of job destruction and productivity gains compared with medium-sized and large enterprises.

Source: own elaboration.

Productivity differentials are reflected in significant wage gaps between strata of enterprises; in Latin America they can be as much as double the differentials seen in the European Union.

These productivity differentials are reflected in wage differentials and thus affect the distribution of income and inequality (see table 3). In the countries of Latin America the wage gaps between workers in different enterprise segments are substantial (for example, a worker in a microenterprise earns some $20 \%-40 \%$ of what a worker in a large enterprise earns). In European countries wage gaps are much smaller; a microenterprise employee earns more than $60 \%$ of what a worker in a large enterprise earns.

\section{Table 3. Salary gaps compared with large enterprises, 2011 (Percentages)}

\begin{tabular}{|l|l|l|l|l|l|l|l|l|l|l|}
\hline & Argentina & Brazil & Chile & Ecuador & Mexico & Peru & Germany & Spain & France & Italy \\
\hline Micro & 46 & 43 & - & 20 & 30 & 21 & 69 & 63 & - \\
\hline Small & 56 & 49 & 52 & 31 & 45 & 49 & 73 & 74 & 88 & 69 \\
\hline $\begin{array}{l}\text { Medium- } \\
\text { sized }\end{array}$ & 65 & 74 & 69 & 44 & 66 & 67 & 81 & 89 & 91 & 79 \\
\hline
\end{tabular}

Note: For Argentina, 2012 data based on OECD (2013). For Brazil, 2010 data based on IBGE (2012). For Chile, 2007 data based on INE (2009). For Ecuador, 2009 data based on Chamber of Industries and Production (2011). For Mexico, 2009 data based on INEGI (2011). For Peru, 2007 data based on INEI (2011). For France, Germany, Italy and Spain, 2006 data based on Eurostat.

Source: P. Santoleri and G. Stumpo, 2014.

Smaller enterprises in CELAC countries have considerable scope for progress in international integration

Latin American MSMEs account for a small share of total exports in each of the economies reviewed (see figure 21). In most cases the figure is less than $10 \%$ (with the sole exception of Costa Rica); this stands in sharp contrast to European MSMEs, whose share of total exports ranges from $30 \%$ to $50 \%$ (except for Ireland, where the figures are well above the average for Europe). 
Figure 21 Share of total exports by enterprise group, 2011 or most recent year available (Percentages)

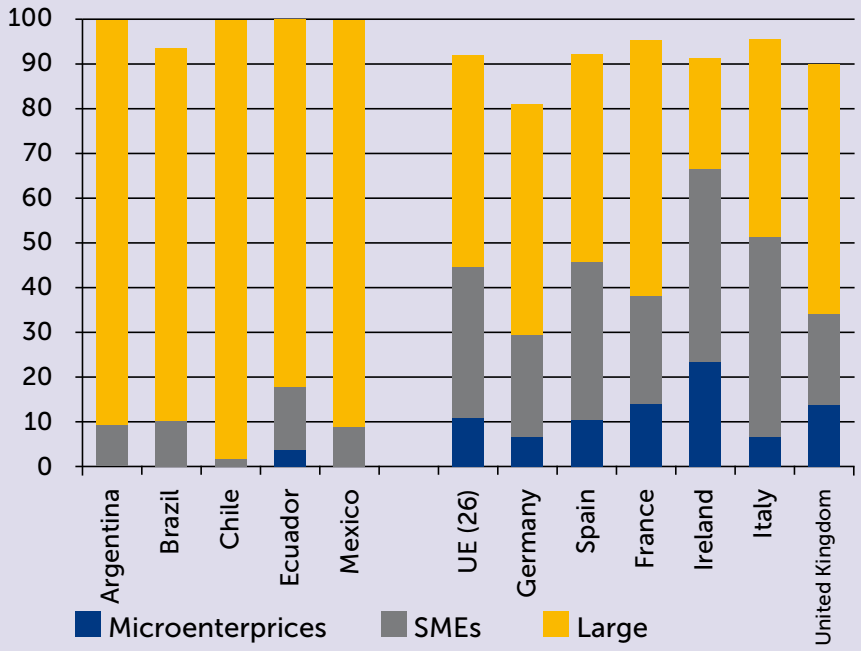

Note: For Argentina, industrial exports based on Argentine Chamber of Exporters (2013). For Brazil, based on SEBRAE (2011); does not include micro and small enterprises, which account for $6.6 \%$ of total exports. For Chile, based on ILO/SERCOTEC (2010). For Mexico, data on the manufacturing sector for 2007-2010 based on INEGI (2011).

EU-17 comprises Austria, Denmark, Estonia, Finland, France, Germany, Greece, Ireland, Italy, Latvia (2010), Lithuania (2010), Poland, Portugal, Slovakia, Spain, Sweden and the United Kingdom.

Source: For Latin American countries: P. Santoleri and G. Stumpo, 2014; for European Union countries: OECD, 2012.

European SMEs, particularly in smaller countries, have achieved a high degree of internationalization, including technological cooperation with foreign countries. This helps explain the aforementioned differences in productivity and exports between Latin American SMEs and their European counterparts (see box 2).

\section{BOX 2.}

\section{EXPORT INTENSITY OF EUROPEAN SMES}

A recent (2010) European Commission study on internationalization based on a survey of 9,500 SMEs in a grouping of European countries for 2006-2008 yielded useful findings as to the export capacity of European SMEs:

a.Twenty-five percent of SMEs within the EU-27 had exports during the three-year period, but just $50 \%$ did so outside the internal market (13\%).

b. Forty-four percent of SMES in the EU-27 have some level of internationalization (foreign direct investment, exports, imports, subcontracting and international technical cooperation). The larger the enterprise size, the larger the percentage: microenterprises (43\%), small enterprises (58\%) and medium-sized enterprises (73\%).

c. Seven percent of SMEs within the EU-27 are involved in technological cooperation with a foreign partner; $7 \%$ are a subcontractor to a foreign partner; $7 \%$ have foreign subcontractors; $2 \%$ of EU-27 SMEs are active in foreign direct investment. 
d. There is a direct link between enterprise size and level of internationalization: $24 \%$ of microenterprises, $38 \%$ of small enterprises and $53 \%$ of medium-sized enterprises were active in exports.

e. There is a negative correlation between country size (according to population and territory) and the level of international activity of its SMEs. Estonia, the Czech Republic, Denmark, Slovenia and Sweden have a much higher percentage of exporting SMEs than the EU-27 average of 25\%. Germany, France and the United Kingdom had the lowest scores.

$f$. The two sectors with the highest percentage of exporting SMEs are manufacturing (56\%) and wholesale trade (54\%). Transport and communications rank third (39\%).

g. The two sectors with the highest share of importing SMEs are wholesale trade (71\%) and manufacturing (49\%), followed by retailing (39\%) and transport and communications (26\%).

h. SMEs in sectors that are not export-intensive contribute between $25 \%$ and $45 \%$ of total value added.

Source: Economic Commission for Latin America and the Caribbean (ECLAC),

on the basis of European Commission, 2010.

The few Latin American MSMEs that do export have a much lower level of capacities than ones in Europe, and they usually operate in standardized areas of production with low knowledge intensity, competing directly with large-scale producers and large corporations

In the countries of Latin America, the presence of exporting SMEs encourages production diversification at the country level. SMEs on average perform better in terms of production, quality certification and innovation. It is therefore crucial to promote the involvement of Latin American SMEs in the international market.

The universe of MSMEs is made up of a set of widely different agents with marked asymmetries in terms of capacities. ${ }^{8}$ Within this universe some small and medium-sized enterprises have a distinct set of trade and production behaviours that enable them to access foreign markets. Successful exporting MSMEs usually have a sales and management structure (not necessarily with many people: usually two to four) devoted exclusively to foreign trade. This structure enables them to develop useful business intelligence. Successful firms consistently differ from unsuccessful ones in knowledge of the target market in terms of size, customer segments, type of competitors and regulations that impact their business. ${ }^{9}$

8 See Infante, 2011.

9 These enterprises are proactive in their search for opportunities and devote more effort to promotion, including visits and regular invitations to current and potential customers and systematic participation in international fairs related to their products. 
Another distinguishing feature is the greater involvement of exporting MSMEs with other firms through informal arrangements (consultations and joint participation in sector-based initiatives, among others) and formal ones (especially trade cooperation agreements). As a rule, successful exporting firms are more innovative than unsuccessful ones; this is reflected, among other things, in the regular addition of new or improved products to their export mix. In addition, successful exporting MSMEs generate more backward linkages, because their operations tend to be based on a group of stable domestic suppliers and have more positive impacts, both internal and external social ones (for their workers and for the community, respectively) and environmental ones.

Overall, the considerable heterogeneity among Latin American MSMEs is rooted in several factors. In the case of microenterprises, many come into being when people are forced to start a small business because they cannot find a better job in the formal labour market or have no guaranteed basic income from the State. Microenterprises (where the entrepreneur tends to have a low level of education and great difficulty in accessing external financing) only manage to enter sectors with low technical capacities where business operations are largely unregulated. Generally speaking, microenterprises are concentrated especially in commerce and in some low value-added services. Therefore, the concentration of enterprises in these areas with lower entry barriers generates a steady supply of labour and products; this negatively impacts sales margins and, thus, their capacity to invest and to increase wages. The large number of such enterprises in Latin America's production network is one of the factors that make these economies different from more developed ones and has a negative impact on aggregate productivity of the economy.

A second set of enterprises are small and medium-sized ones that, unlike the informal microenterprises described above, usually grow out of a lucrative business idea (on the part of a founder with certain technical or business skills). SMEs of this type are managed with a high degree of economic rationality, are organized in keeping with the division of labour, are (in part) officially registered, and differ from informal microenterprises in their higher productivity and higher-quality products and services.

In terms of sector distribution, small Latin American enterprises are concentrated in retail, manufacturing (to a lesser extent) and, in some cases, construction. Medium-sized manufacturing enterprises are likely to have more employees; although the commerce sector accounts for a substantial share it is generally lower than in manufacturing). Large manufacturing enterprises and some higher value-added services (telecommunications and financial intermediation) account for the bulk of jobs.

This sector breakdown varies across countries, which fall into three groups in terms of the relationship between the size of their economies and the sectors that are predominantly MSMEs. In larger countries with more developed industrial structures (Argentina, Brazil and Mexico), the main SME sectors are food, textiles and clothing, chemicals and plastics, and 
metalworking. In mid-sized economies (the Bolivarian Republic of Venezuela, Chile, Colombia, Ecuador and Peru), MSMEs are mostly found in the food and chemical industries; unlike larger economies, very few are involved in metalworking. In smaller countries (Costa Rica, Nicaragua and Uruguay) MSMEs clearly dominate the food industry.

However, these more modern Latin American SMEs do not play the same role in national production systems as do SMEs in European Union member countries. In the latter, SMEs can only survive the process of industrial development if they provide specific goods and services that do not compete with the mass-produced products of large manufacturers. These goods and services are normally designed specifically for their customers' needs. They are produced in small runs for market niches or are closely related to customer service (for example, installation, customization or maintenance). These SMEs also produce services for large firms or to complement their catalogue of services. Economies of scale play a minor role in these areas, pushing the benefits of the flexibility and customer proximity offered by SMEs to the fore. This kind of specialization demands greater technical and business qualifications, and one particular prerequisite is the capacity to innovate continuously.

Most SMEs in Latin America do not have these qualifications. Almost all of them operate in areas of standardized production with low knowledge intensity in direct competition with large-scale producers or large corporations. One example is the production of mass-market consumer goods such as clothing, footwear and food staples. In these areas, SMEs do not have competitive advantages; most of them have been hard-put to respond to the new competitive environment.

\section{Main challenges for making SMEs more competitive}

To turn Latin American SMEs into true agents of change that are engines of growth, competitiveness, structural change and external integration, it is important to identify the main factors limiting their development and productive upgrading. Among these are human capital and training, financing, innovation and technology transfer, institutional environment and capacities, territorial and/or production linkages and access to value chains.

\subsection{Human capital and SMEs in Latin America}

One of the basic dimensions for understanding the productivity of an economy is related to the stock of human capital and the capacities of its enterprises and workers. The low productivity of SMEs is therefore linked to some of the major education and training challenges facing the region. 
SMEs in Latin America and the Caribbean must address the challenge of improving worker education and training if they are to improve their situation

Latin America has progressed in recent years in terms of access, coverage and number of years of schooling of the population, but it still lags behind in this area compared with developed regions such as Europe. This lag is reflected in the low education levels of the region's workforce, which are substantially below those seen in more advanced regions. This trait is accompanied by high dropout rates in Latin America, which translate into lower wages for low-skilled young workers in the region's labour market. ${ }^{10}$

There is another side to the link between human capital and the labour market, namely the gap between the training provided by the education system and the skills that the production sector requires. One factor that acts as a barrier to increasing SME productivity in the region is the lack of a labour supply with the right skills. Depending on its size, sector and location, an enterprise can encounter serious difficulties in finding workers with the skills needed for the production process. This mismatch between the training provided by the education system and the skills demanded by the production sector makes an economy less competitive in an international context in which knowledge is increasingly crucial for conquering markets.

The shortcomings of SMEs in the region are reflected not only in the mismatch between the supply of and the demand for skills in the labour market. Many small and medium-sized enterprises are limited by their own management's inability to lead development, technology adoption, innovation, and expansion into new sectors and markets.

Nonetheless, more people spending more time in the education system in Latin America and the Caribbean does not necessarily mean that skills are being taught and learned effectively, or that students are being trained in skills and abilities needed to enter the labour force. These considerations are part of the qualitative side of education, a field in which Latin America is facing its toughest challenges.

International comparisons reveal a particularly worrying gap in the quality of education. According to the PISA report, ${ }^{11} 15$-year-old Latin American students scored far below those in OECD countries in the three subject areas covered by the study. The PISA assessments for mathematics and reading show that Latin American students are highly concentrated in the lower levels of the distribution of competencies, that is below level 1, at level 1 and at level 2 (see figures 22.a and 22.b). This is unlike the more advanced economies, where there is more concentration in the upper levels of the distribution of competencies, at levels 3 and 4. By contrast, Latin America has a very low distribution at high levels such as 4, and practically none at the highest levels (5 and 6). This shows that young people in the region have trouble performing skills that are basic for participating in the workforce and society.

10 See ECLAC/OECD, 2012.

11 See OECD, 2012 and Education GPS [online] http://gpseducation.oecd.org/. 
Figure 22. PISA assessment: distribution of students according to performance, 2012

a. Mathematics

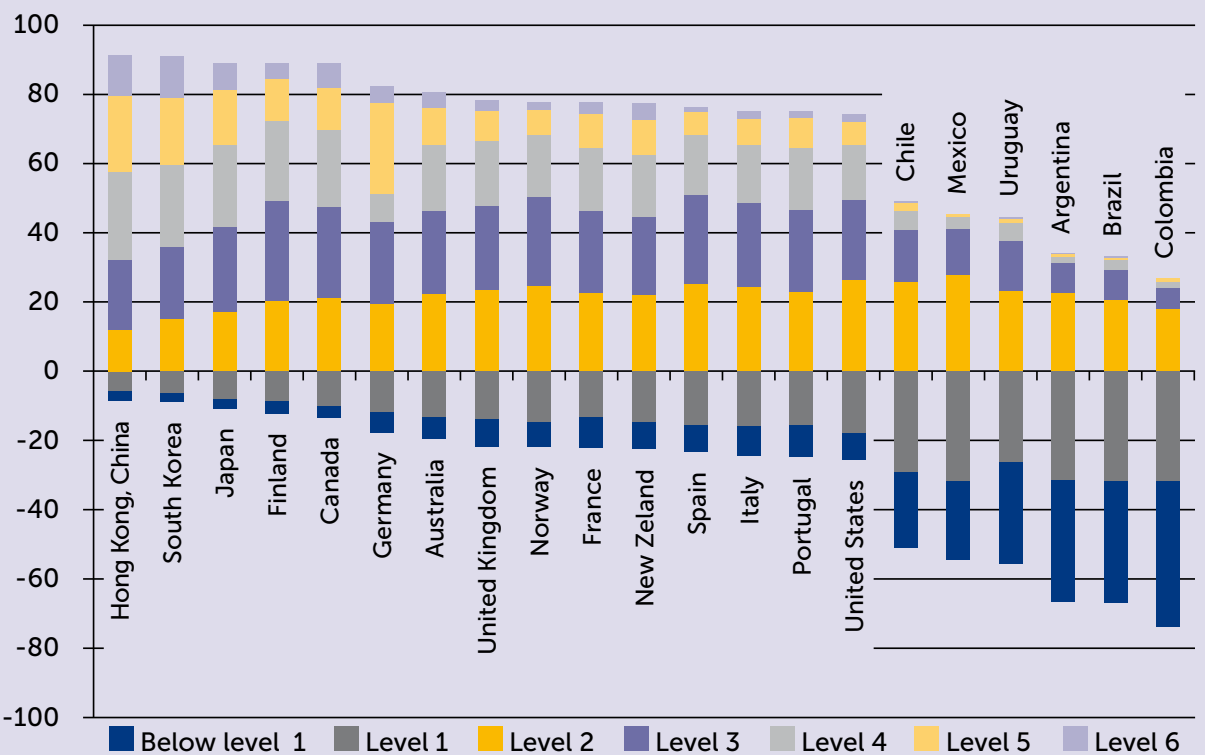

b. Reading

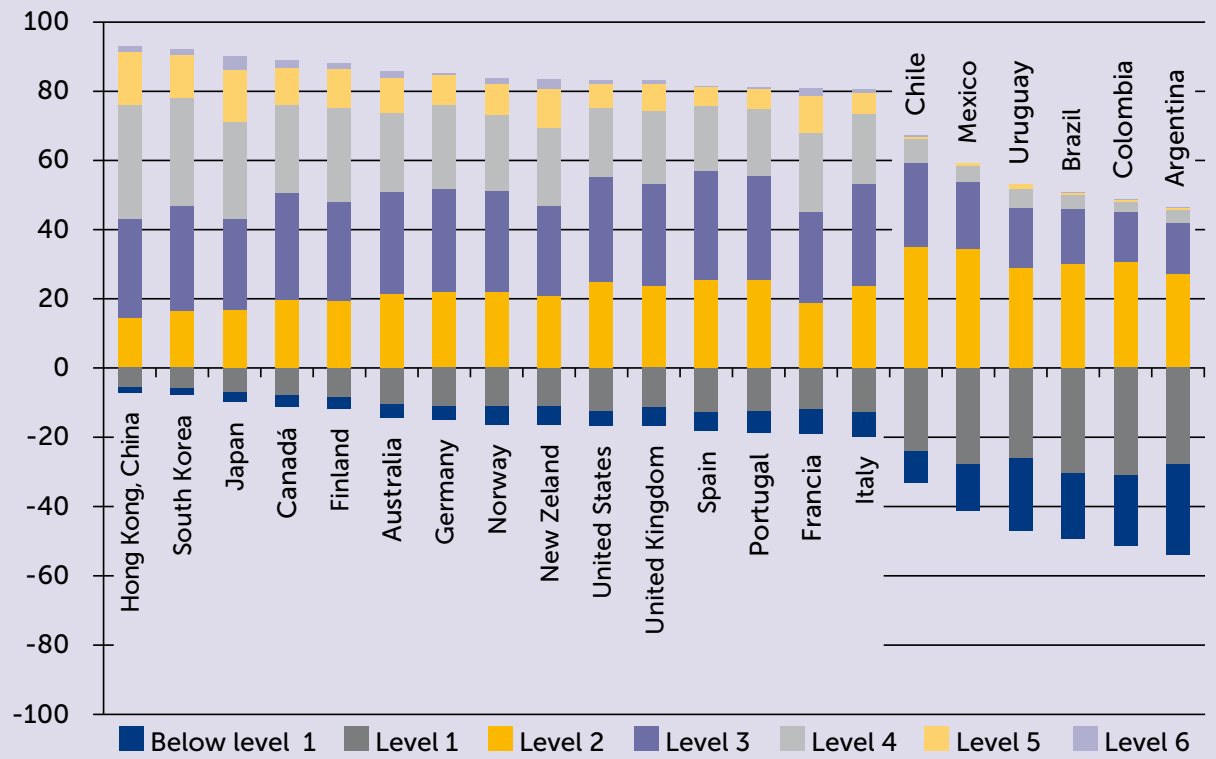

Note: For mathematics, levels are classified according to the following scores: below level 1 (a score less than or equal to 357.77); level 1 (a score greater than 357.77 and less than or equal to 420.07); level 2 (a score greater than 420.07 and less than or equal to 482.38); level 3 (a score greater than 482.38 and less than or equal to 544.68); level 4 (a score greater than 544.68 and less than or equal to 606.99); level 5 (a score greater than 606.99 and less than or equal to 669.30); and level 6 (a score greater than 669.30). Reading: levels are classified according to the following scores: below level 1 (a score less than or equal to 334.75); level 1 (a score greater than 334.75 and less than or equal to 407.47); level 2 (a score greater than 407.47 and less than or equal to 480.18); level 3 (a score greater than 480.18 and less than or equal to 552.89); level 4 (a score greater than 552.89 and less than or equal to 625.61); level 5 (a score greater than 625.61 and less than or equal to 698.32); and level 6 (a score greater than 698.32). 
Latin America and the Caribbean is the region with the highest"skills gap"between the education system and the needs of the production sector

Economic globalization has fostered a profound transformation of the production model, largely defined by sweeping technological change. The nature of the skills demanded by the production sector has therefore changed over time. This has created a gradual move away from the training traditionally offered by education systems, a phenomenon known as "skills gap". To the extent that it limits businesses' ability to find the skills they need, this skills gap impedes productivity growth. This is why it is important to understand its impact on Latin America and how it affects SMEs.

As shown in figure 23, the percentage of enterprises that consider the lack of a properly trained workforce as one of their main constraints came to $36 \%$ in Latin America and the Caribbean. This is well above the average for OECD countries (17\%) and the average for other emerging regions such as East Asia and the Pacific (21\%). This pattern especially impacts SMEs, which also face considerable difficulty in finding the workforce they need. Throughout the region a high percentage of SMEs consider that this factor represents one of the main obstacles to their operations (see figure 24).

Figure 23. Enterprises that see the lack of an appropriately trained labour force as one of their main constraints, 2009-2015 (Percentages)

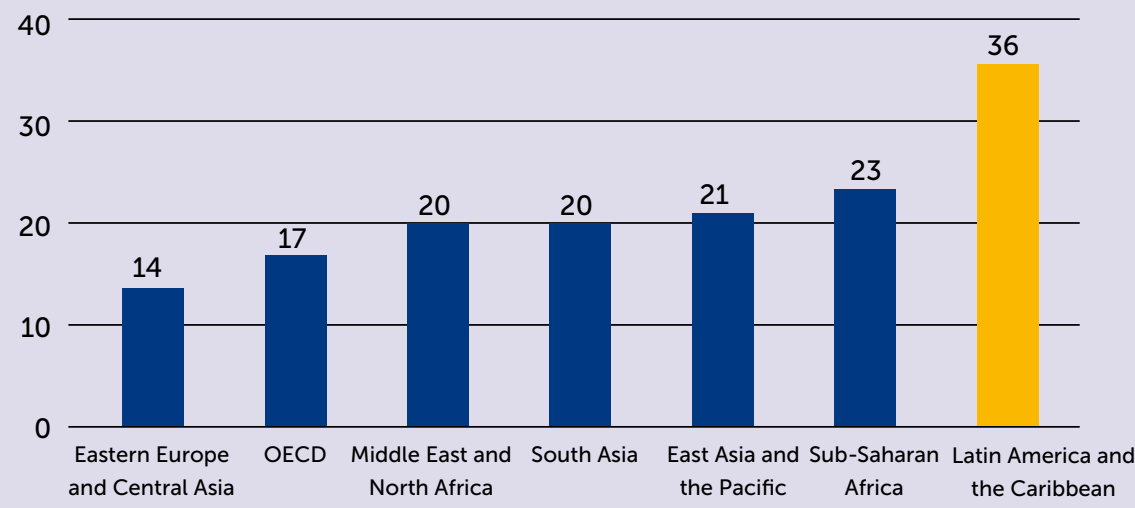

Source: Economic Commission for Latin America and the Caribbean (ECLAC), on the basis of World Bank, "Enterprise Surveys" [online] http://www.enterprisesurveys.org. 
Figure 24: SMEs that regard the difficulty of finding a properly trained workforce in Latin America as one of their main obstacles, 2010 (Percentages)

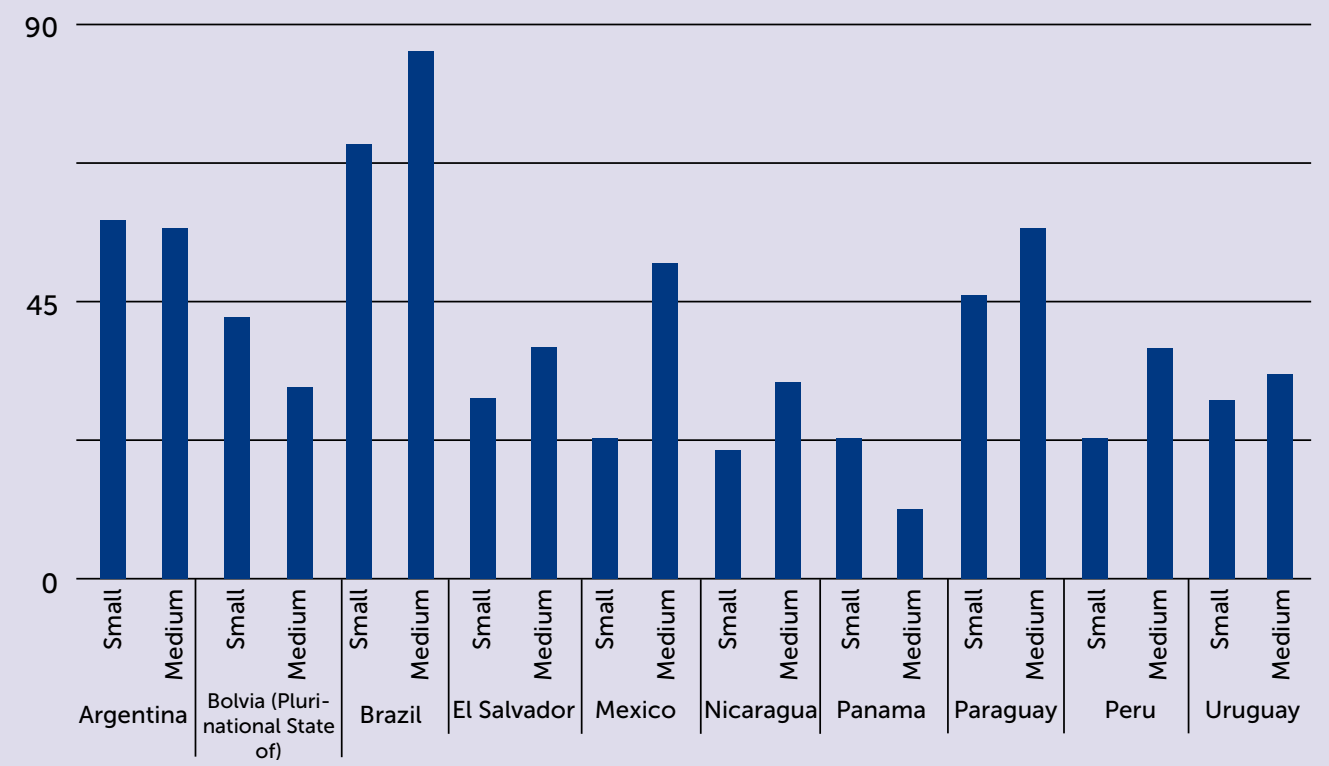

Note: Data for 2010 except in the case of Brazil (2009). According to the Enterprise Survey, a business is small if it has between 5 and 19 employees and medium-sized if it has between 20 and 99 employees.

Source: Economic Commission for Latin America and the Caribbean (ECLAC), on the basis of World Bank, "Enterprise Surveys" [online] http://www.enterprisesurveys.org.

There are significant differences among the countries of Latin America and the Caribbean. They reflect not only structural differences among their economies, but also the wide variety of SMEs in the region. Factors such as the production sector they belong to, how extensively they have adopted technology, their participation in global value chains, and how export-focused they are help determine what type of skills SMEs need and therefore the challenges they face in finding a properly trained workforce.

SMEs in different sectors face differing problems in finding a suitably trained workforce. On the one hand, there are sectors such as computer technology services in which $80 \%$ of SMEs say they have from moderate to severe or very severe problems finding the workers they need, and other sectors, such as machinery and equipment, textiles and chemicals, in which the percentage of businesses with severe or very severe problems is also very high. On the other hand, there are areas such as the hotel and restaurants sector and the wholesale and retail sectors, where the requisite skill set is not as specialized; some $40 \%$ of these businesses report no problem in finding the workforce they seek, and only around a third say they face severe or very severe problems. ${ }^{12}$ 
Figure 25: Percentage of SMEs in Latin America that face difficulties in finding a properly trained workforce, by sector and degree of difficulty, 2010

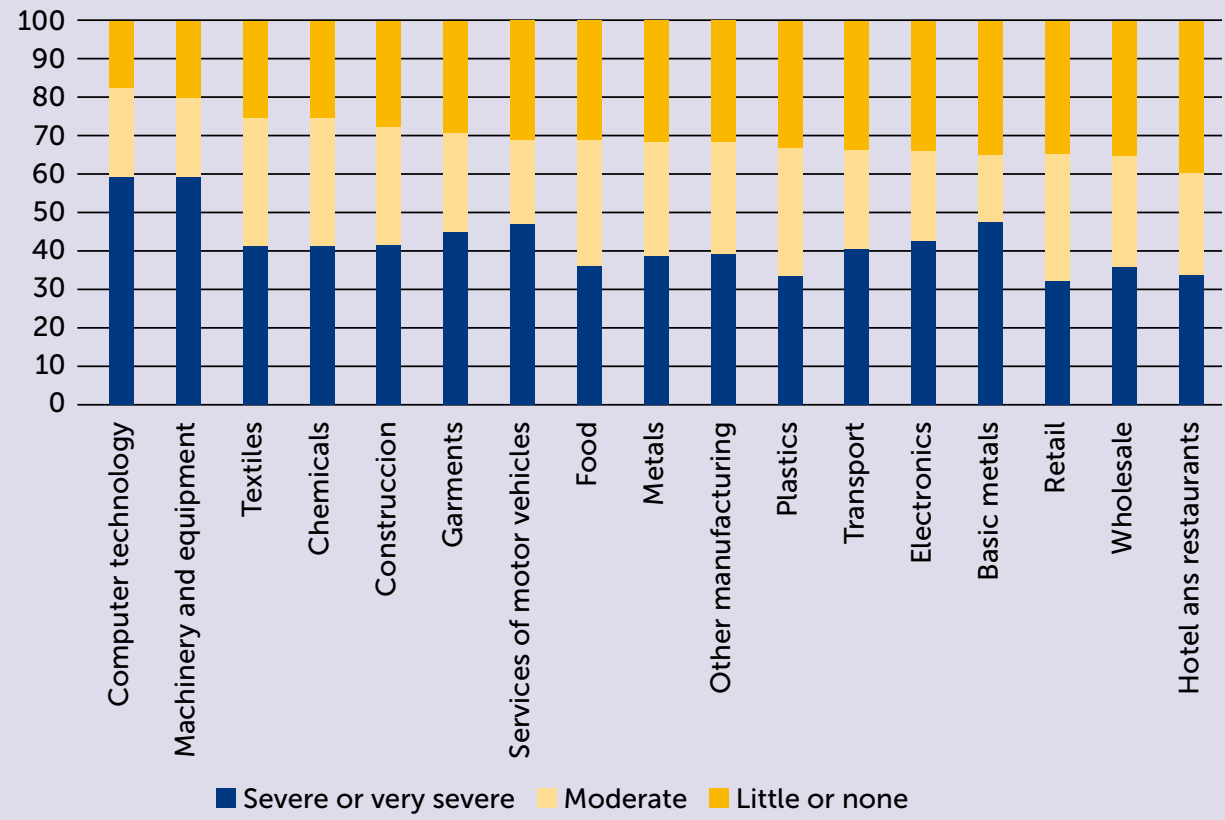

Source: ECLAC/OECD, 2012.

It is useful to understand what kind of skills SMEs seek, to better understand both the areas where their operations are concentrated and the constraints encountered by sectors that are key for the economic development of the region. It is also important to understand what these enterprises need, so as to identify gaps and implement policies to correct what the education system provides. Latin America has recently made great strides in this direction. For example, recent years have brought a change in the skills the production sector needs. Repetitive activities traditionally performed by workers with secondary education have gradually been replaced by advanced technologies requiring other skills and competencies. Among them are those associated with occupations in the new economy, which place a premium on knowledge of foreign languages or the use of computer operating systems. ${ }^{13}$

The lack of an appropriate supply of skills can adversely interact with the demand for such skills. Many SMEs operate in areas that contribute little value added and whose production processes make little use of technology. Some evidence indicates that businesses' demand for skills sometimes adapts to the limited supply of skills, meaning investment decisions are made based on the limited availability of human capital. This compromises diversification into sectors that are more closely linked with the global economy and have higher growth potential. At the 
same time, the low demand for skills enhances the disincentive for education and for building new competencies. This can create a kind of vicious circle that makes it increasingly difficult to diversify and boost the productivity of companies, sectors and the economy as a whole.

In short, the wide variety of SMEs in Latin America makes it particularly important to bolster institutions and the design of policies to promote technology diffusion and a better match between the supply of and the demand for skills. Efforts to fill gaps in basic education, to boost the educational level of management and to develop a supply of increasingly advanced skills should be accompanied by policies that encourage innovation and the integration of SMEs in increasingly more complex value chain activities. This matter will be taken up again later in this report.

\subsection{Financing for SMEs}

Financing gaps between SMEs and large companies in Latin America are still an obstacle and a public policy challenge

Latin America has historically lagged behind developed economies in terms of depth and financial development. This lag explains, in part, the gap in coverage and the cost of credit for the production sector, especially for SMEs. ${ }^{14}$ As the banking system's business model for SMEs transitions from relationship banking to a multiservice banking model, the constraints in financing for this business segment become more entrenched. Relationship banking has been associated with a personal link between a financial institution and its client. Multiservice banking introduced more functional lending technologies focused on solvency and payment capacity, with implications for small businesses. This transition has resulted in less-flexible financing schemes, high collateral requirements, greater reliance of banks on fees and high borrowing costs for SMEs. These factors still make it harder for SMEs to borrow. ${ }^{15}$

Access to financing by the business sector in Latin America is closely linked to insertion in the international economy, enterprise size and export capacity, among other variables. As a result, a higher percentage of large companies and exporters can benefit from access to financing. Financing gaps between SMEs and large companies in Latin America are still a public policy challenge. As shown in figure 26, limited access to financing is a major obstacle for enterprises; this is true not only in Latin America and the Caribbean but in other regions as well.

14 Credit has expanded in a number of countries of the region in recent years, but it has tended to focus on consumer loans and mortgages.

15 See ECLAC/OECD, 2012. 
Figure 26. Firms identifying access to financing as a major obstacle, by region, 2009-2015 (Percentages)

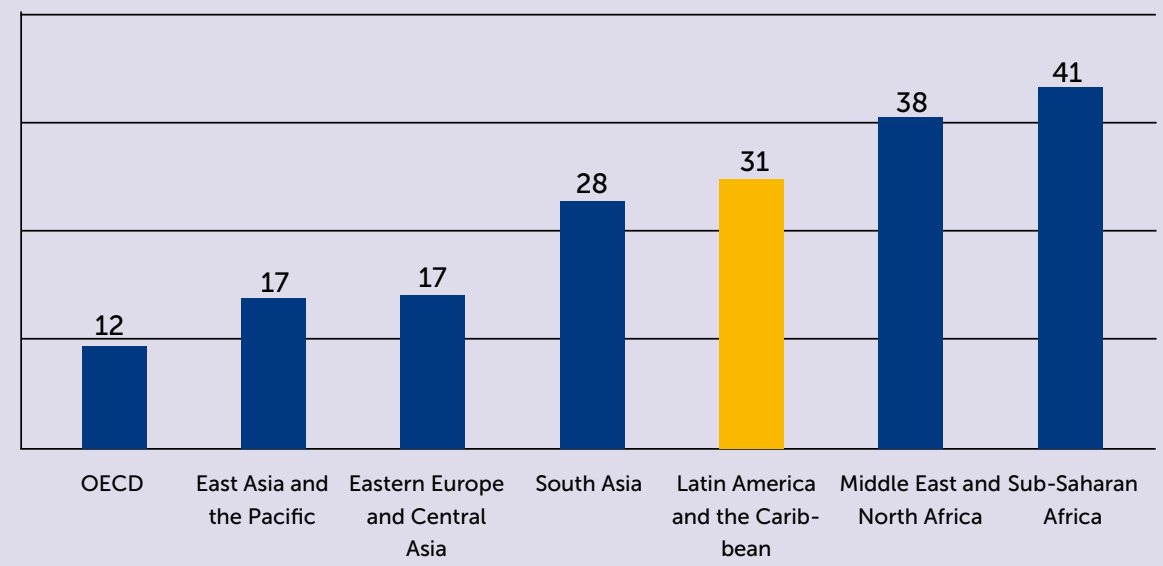

Source: Economic Commission for Latin America and the Caribbean (ECLAC), on the basis of World Bank, "Enterprise Surveys" [online] http://www.enterprisesurveys.org.

A very high percentage of Latin American SMEs have savings accounts or checking accounts in banks. A smaller share of SMEs have credit lines or bank loans (see table 4). And an even smaller percentage of this business segment taps banks to finance their investments.

Table 4. Financial profile of SMEs in Latin America and the Caribbean, 2010

\begin{tabular}{|c|c|c|c|c|c|}
\hline Country & $\begin{array}{l}\text { Enterprise } \\
\text { size }\end{array}$ & $\begin{array}{l}\text { Percent of } \\
\text { firms with } \\
\text { savings or che- } \\
\text { cking account }\end{array}$ & $\begin{array}{l}\text { Percent of } \\
\text { firms with bank } \\
\text { loan/line of } \\
\text { credit }\end{array}$ & $\begin{array}{l}\text { Percent of } \\
\text { firms using } \\
\text { banks to } \\
\text { finance invest- } \\
\text { ments }\end{array}$ & $\begin{array}{l}\text { Percent of firms } \\
\text { identifying access } \\
\text { to finance as a } \\
\text { major constraint }\end{array}$ \\
\hline \multirow[t]{3}{*}{ Argentina } & Small & 94 & 38 & 23 & 49 \\
\hline & Medium & 99 & 59 & 33 & 40 \\
\hline & Large & 100 & 75 & 41 & 26 \\
\hline \multirow{3}{*}{$\begin{array}{l}\text { Bolivia (Pluri- } \\
\text { national State } \\
\text { of) }\end{array}$} & Small & 93 & 33 & 14 & 31 \\
\hline & Medium & 98 & 60 & 38 & 26 \\
\hline & Large & 100 & 79 & 36 & 29 \\
\hline \multirow[t]{3}{*}{ Brazil } & Small & 99 & 58 & 32 & 46 \\
\hline & Medium & 99 & 59 & 60 & 46 \\
\hline & Large & 100 & 80 & 55 & 37 \\
\hline \multirow[t]{3}{*}{ Colombia } & Small & 94 & 51 & 21 & 52 \\
\hline & Medium & 100 & 64 & 29 & 16 \\
\hline & Large & 100 & 92 & 86 & 12 \\
\hline \multirow[t]{3}{*}{ Costa Rica } & Small & 96 & 41 & 14 & 40 \\
\hline & Medium & 99 & 72 & 25 & 45 \\
\hline & Large & 100 & 79 & 39 & 41 \\
\hline
\end{tabular}


Table 4. Financial profile of SMEs in Latin America and the Caribbean, 2010 (continued)

\begin{tabular}{|c|c|c|c|c|c|}
\hline Country & $\begin{array}{l}\text { Enterprise } \\
\text { size }\end{array}$ & $\begin{array}{l}\text { Percent of } \\
\text { firms with } \\
\text { savings or che- } \\
\text { cking account }\end{array}$ & $\begin{array}{l}\text { Percent of } \\
\text { firms with bank } \\
\text { loan/line of } \\
\text { credit }\end{array}$ & $\begin{array}{l}\text { Percent of } \\
\text { firms using } \\
\text { banks to } \\
\text { finance invest- } \\
\text { ments }\end{array}$ & $\begin{array}{l}\text { Percent of firms } \\
\text { identifying access } \\
\text { to finance as a } \\
\text { major constraint }\end{array}$ \\
\hline \multirow[t]{3}{*}{ El Salvador } & Small & 93 & 46 & 25 & 24 \\
\hline & Medium & 95 & 59 & 32 & 37 \\
\hline & Large & 100 & 73 & 45 & 19 \\
\hline \multirow[t]{3}{*}{ Guatemala } & Small & 54 & 34 & 17 & 19 \\
\hline & Medium & 70 & 64 & 27 & 25 \\
\hline & Large & 66 & 78 & 50 & 10 \\
\hline \multirow[t]{3}{*}{ Honduras } & Small & 79 & 24 & 8 & 33 \\
\hline & Medium & 78 & 56 & 26 & 26 \\
\hline & Large & 98 & 32 & 28 & 2 \\
\hline \multirow[t]{3}{*}{ Mexico } & Small & 59 & 27 & 15 & 27 \\
\hline & Medium & 67 & 37 & 18 & 39 \\
\hline & Large & 70 & 54 & 16 & 25 \\
\hline \multirow[t]{3}{*}{ Peru } & Small & 82 & 53 & 45 & 7 \\
\hline & Medium & 93 & 86 & 48 & 15 \\
\hline & Large & 100 & 93 & 44 & 5 \\
\hline \multirow[t]{3}{*}{ Paraguay } & Small & 82 & 55 & 22 & 21 \\
\hline & Medium & 96 & 63 & 30 & 20 \\
\hline & Large & 99 & 73 & 46 & 10 \\
\hline \multirow{3}{*}{$\begin{array}{l}\text { Dominican } \\
\text { Republic }\end{array}$} & Small & 100 & 50 & 38 & 30 \\
\hline & Medium & 95 & 65 & 34 & 19 \\
\hline & Large & 100 & 77 & 61 & 19 \\
\hline
\end{tabular}

Note: small enterprise: 5-19 employees; medium-sized enterprise: 20-99 employees; large enterprise: more than 100 employees. All of the data are for 2010, except for Brazil (2009).

Source: World Bank, "Enterprise Surveys" [online] http://www.enterprisesurveys.org.

Lending to SMEs in the countries of Latin America still accounts for a far smaller percentage than in Europe

The recent expansion of SME-targeted instruments in Latin America and the Caribbean points to a trend among financial institutions as they increasingly tailor their products to the specific needs of SMEs. In several of the countries of the region instruments that seek to take into account the heterogeneity of the SME universe are being introduced, with some success. They 
hold out innovative solutions customized to the needs of different enterprises and taking into account factors such as sector, stage of development and strategic potential (like guarantee companies in Argentina, the national guarantee fund in Colombia and Brazil's BNDES card).

SMEs are more fragile and vulnerable to the need for traditional financing than large enterprises, which can obtain financing through other sources such as the capital market. Table 5 shows lending to SMEs as a percentage of total lending and the importance that the credit market has attached to this business segment. There is a striking difference between the average for the countries of the European Union (approximately 45\%) compared with the percentages in some of the countries of Latin America (around 20\%).

\begin{tabular}{|c|c|c|c|c|c|c|}
\hline & 2007 & 2008 & 2009 & 2010 & 2011 & 2012 \\
\hline European Union & 45 & 44 & 44 & 44 & 45 & 46 \\
\hline Chile & 17 & 15 & 18 & 18 & 18 & 19 \\
\hline Colombia & 33 & 31 & 29 & 27 & 27 & 27 \\
\hline Mexico & 13 & 12 & 12 & 13 & 13 & 16 \\
\hline
\end{tabular}

Public and private financial institutions have a crucial role to play regarding SME access to financing

Historically, public financial institutions have played an important role in lending to SMEs. These institutions range from agencies that support SMEs, to guarantee companies, public banks and development banks. Development banks in particular play a crucial role in financing the production sector and, especially, SMEs, promoting projects in strategic areas as well as the development of innovative businesses and projects. Financial institutions in Latin America play a crucial, special role, which is described below.

\section{a) Development banks}

In recent years, development banking has gained renewed momentum in the region after losing some ground in the 1990s, when the role of the public sector in the economy was cut back in favour of a more prominent role for the private sector. Currently, development banks are a key industrial policy tool and a source of credit for small and medium-sized enterprises. There are marked differences between public and private banks in terms of target population and the type of project they finance, so their roles are now complementary. Most Latin American countries have development banks, including the Brazilian Development Bank (BNDES) in Brazil; Nacional Financiera (NAFIN) and the Foreign Trade Bank (BANCOMEXT) in Mexico; the Colombian Development Bank (BANCOLDEX), a mixed development bank; Corporación Financiera de Desarrollo 
S.A. (COFIDE) in Peru; and Corporación Financiera Nacional (CFN) in Ecuador. Where there are no development banks, first-tier public banks usually take on this role. ${ }^{16}$

Financing programmes for SMEs are normally run by promotion agencies in coordination with development banks; they tend to use second-tier systems or mechanisms for channeling direct loans. The main purposes of these financing programmes are acquisition of capital assets, working capital and, to a lesser extent, investments. But public financial institutions in Latin America are diversifying their financing schemes for SMEs compared with previous decades, thanks to the implementation of new support programmes that include more targeted lines of credit, such as for introducing productivity gains to improve environmental sustainability and supporting specific production sectors. An interesting development is the growing trend among development banks to promote the use of financial-service packages that go beyond lending and guarantees to include products such as credit cards and online and e-transaction systems. The BNDES card in Brazil has meant an improvement in facilitating, streamlining and promoting the granting and management of loans to SMEs in that country.

While the region has made substantial progress, development bank financing programmes for SMEs still face some constraints. Lending is skewed towards the short term and is somewhat concentrated in working capital. Paperwork slows funding lines between first- and second-tier institutions, which can make them less effective. For example, requiring approval by a second-tier bank can add to the waiting time and make this option less attractive, both for the enterprise and for the first-tier entity or bank that would use the funding line. And funding programmes should be enhanced in order to achieve greater additionality and impact for SMEs. ${ }^{17}$

\section{b) Guarantee systems in Latin America}

Commercial banks' strict guarantee requirements for SMEs when applying for and granting loans are a major obstacle for SMEs. Generally, guarantees must partially or completely cover the loan, almost always with assets. Table 6 shows the high percentage of loans that require collateral, in several countries in the region.

Requiring collateral for bank loans, coupled with SMEs being less able to provide collateral, limits their entry into the credit system. In Latin America, as in other regions, the main sources of collateral are fixed assets such as machinery and equipment. Not only do SMEs face a higher cost of credit, but it is harder for them to provide the necessary collateral. In the region there are guarantee funds consisting mainly of public capital. Some examples are NAFIN in Mexico; the National Guarantee Fund in Colombia; the FOGAPE fund for small-business owners and FOGAIN fund for investments in Chile; Brazil's Micro and Small Enterprise Support Service (SEBRAE) and the Brazilian Development Fund (BNDES); and the FOGABA fund for the province of Buenos Aires in Argentina.

16 See ECLAC, 2012 and ECLAC/OECD, 2012

17 See ECLAC/OECD, 2012. 
Table 6. Percentage of loans requiring collateral, by enterprise size and country, 2010

\begin{tabular}{|c|c|c|}
\hline Country & Enterprise size & Loans requiring collateral \\
\hline \multirow[t]{3}{*}{ Argentina } & Small & 66 \\
\hline & Medium-sized & 70 \\
\hline & Large & 49 \\
\hline \multirow[t]{3}{*}{ Brazil } & Small & 17 \\
\hline & Medium-sized & 34 \\
\hline & Large & 41 \\
\hline \multirow[t]{3}{*}{ Chile } & Small & 59 \\
\hline & Medium-sized & 62 \\
\hline & Large & 29 \\
\hline \multirow[t]{3}{*}{ Colombia } & Small & 65 \\
\hline & Medium-sized & 64 \\
\hline & Large & 39 \\
\hline \multirow[t]{3}{*}{ Costa Rica } & Small & 97 \\
\hline & Medium-sized & 89 \\
\hline & Large & 97 \\
\hline \multirow[t]{3}{*}{ Ecuador } & Small & 77 \\
\hline & Medium-sized & 81 \\
\hline & Large & 95 \\
\hline \multirow[t]{3}{*}{ Honduras } & Small & 85 \\
\hline & Medium-sized & 80 \\
\hline & Large & 71 \\
\hline \multirow[t]{3}{*}{ Mexico } & Small & 66 \\
\hline & Medium-sized & 66 \\
\hline & Large & 73 \\
\hline \multirow[t]{3}{*}{ Peru } & Small & 40 \\
\hline & Medium-sized & 54 \\
\hline & Large & 56 \\
\hline
\end{tabular}

Note: small enterprise: 5-19 employees; medium-sized enterprise: 20-99 employees; large enterprise: more than 100 employees. All of the data are for 2010, except for Brazil (2009).

Source: World Bank, "Enterprise Surveys" [online] http://www.enterprisesurveys.org.

Guarantee companies have gained a higher profile in Latin America. They can be funded with public and private resources. Generally, it is the guarantee company itself that analyses and assesses the risk associated with the transaction. The benefits of these companies for SMEs are better access to credit and better loan conditions, including longer maturities. 
For SMEs, credit guarantee schemes provide guarantees, short-term loans and countercyclical loans as well, guaranteeing risk capital, among other factors. Such schemes can leverage access to financing for smaller enterprises. ${ }^{18}$ Public guarantee schemes are the main credit guarantee instruments in emerging and developing economies. One of the major guarantee funds in Latin America and the Caribbean is Fundo de Aval às Micro e Pequenas Empresas (FAMPE) run by Brazil's SEBRAE. And there are mutual guarantee schemes, where the private sector has a very important role, for example, through partnerships with SME and banking associations. They generally have a thorough knowledge of the businesses, and participants continuously monitor each other. This prevents firms that need credit from taking excessive risks and increases the likelihood of loan repayment. ${ }^{19}$

\section{c) Private banks in Latin America}

Private banks are a major player in financing SMEs. Data from the seventh Regional Survey of SMEs and Banks in Latin America and the Caribbean ${ }^{20}$ show that in $201490 \%$ of banks surveyed in the region indicated that SMEs are a strategic part of their business. Twenty-eight percent of the banks surveyed said that one of the main reasons they work with this business segment is to boost the profitability of their operations; $24 \%$ were looking to diversify their portfolio.

Private banks in the region have identified barriers to SME financing: 56\% of the banks surveyed said that there are internal barriers to financing this business segment. They include the lack of staff training for serving SMEs, and inadequate credit scoring systems to measure risk. Seventy-two percent of the banks surveyed said that there are external barriers having to do with business climate that hamper lending. SME informality makes it difficult for banks to perform credit assessments, due to lack of collateral, a credit history or audited financial statements. Many of these factors are included in bank procedures for evaluating loans to SMEs. Of the banks surveyed, $91 \%$ use financial statement analysis, $87 \%$ use cash flow analysis, $84 \%$ look at owner's equity and $71 \%$ review asset quality. ${ }^{21}$ SMEs are highly vulnerable in all of these areas.

In short, despite the strides Latin America has made in terms of financial depth and development, access to financing is still a major constraint for the development of small and medium-sized enterprises in the region. Many SMEs cannot meet formal credit requirements because of factors such as the high cost of interest rates, high collateral requirements, technicalities and red tape owing to information asymmetry issues. These constraints become even more obvious when compared with the conditions that apply to large companies, which benefit from better access to commercial credit. In the case of Latin America, difficulty in accessing credit on fair terms translates into a source of inequality for the region's production sector.

18 The financial additionality of such schemes depends largely on firms tapping the credit market when they do not need the former, and for high-risk firms to turn to them if they do not have collateral.

19 See ECLAC/OECD, 2012.

20 See FOMIN, 2014.

21 See FOMIN, 2014. 


\subsection{Small and medium-sized enterprises and their capacity for innovation}

The capacity for innovation of SMEs is influenced by a number of micro-, meso- and macroeconomic factors.

The innovative behaviour of enterprises is crucial for understanding an economy's capacity for growth and development. A company's access to and use or development of new technologies are influenced by several factors: first, at the microeconomic level, by its internal capacities (absorptive capacities) and by its own efforts to advance in this regard; second, at the mesoeconomic level, by the characteristics of the sector of activity in which the company is engaged and its linkages with other companies in the same or other sectors, which together make up a complex system of interactions. Lastly, at the macroeconomic level, the behaviour and innovation capacity of companies depend on another series of variables, notably, the institutional environment and macro-prices, such as interest rates and exchange rates, trade agreements and linkages with the global economy and other factors (some of which have already been discussed).

In seeking to innovate this business segment, smaller enterprises face tighter restrictions than larger companies. Investment in R\&D entails a high risk, with significant levels of uncertainty as to the expected outcomes and benefits, and heavy outlays of money. While not a major obstacle for large companies, such outlays will certainly pose a problem for small companies. As already discussed, access to financing, whether internal or external is not easy for SMEs; for example, they are required to pay steep interest rates or to provide higher collateral, which is a hindrance to the absorption of technology or innovation. Innovations generate, but also demand, economies of scale and scope, which makes it all the more difficult and complex for SMEs to take part in these processes. Large companies are better placed not only to assume the high risks associated with innovation activities, but also to take possession of the returns of these processes.

Thus, it is important for SMEs to pursue cooperation and linkages with other companies and agents of National Innovation Systems (NIS), which can enable them to foster and facilitate the incorporation of learning and knowledge. In some cases, SMEs find themselves in an advantageous position. Their more flexible organization structure and ability to respond rapidly to change can contribute to the malleability of the innovation processes, enhancing active participation by their workers and quick decision-making.

Differences in innovative behaviour occur not only between companies of different sizes but also among SMEs. SMEs that are integrated in international markets or that operate in high-technology or knowledge-diffusion sectors display a greater capacity for innovation and for the incorporation of knowledge in their production processes. Linkages with international markets provide access to other technologies while helping to deepen technological competencies as well as the organization and business model of companies, factors that broaden the scope for innovation. 
While the focus of Latin American SME innovation is on the procurement of machinery and equipment, European SMEs display a more consistent pattern, investing higher percentages in $R \& D$.

In terms of the innovative capacity of SMEs, three key elements should be borne in mind:

- The informality of the innovation strategies pursued by small and medium-sized enterprises compared with the formal strategies of larger companies. These differences are also observed between the different sectors of the economy (on the whole, companies belonging to knowledge-intensive sectors adopt more formal strategies, with higher and more stable levels of investment in R\&D over time).

- As regards their relationship with their economic environment, SMEs generally interact little with their peers or with other institutions and stakeholders, which limits the scope of their innovation strategies.

- Access by SMEs to formal innovation strategies can be enhanced through ties with other economic stakeholders, such as large corporations which do not have to contend with the same problems of scale as small and medium-sized enterprises

Innovation surveys relating to selected countries of Latin America and the European Union reveal some similarities and differences in terms of their capacity for innovation and highlight some of the obstacles faced by companies seeking to innovate as well as the relationships they have formed.

As regards investment in innovation, Latin American companies, especially small businesses, most of which are engaged in non-knowledge-intensive and low-technology branches of economic activity, focus on informal and incremental innovation activities, with emphasis on technology transfer and imitation, as reflected in the high percentage of investments in machinery and equipment, compared with the smaller investments in radical innovations or R\&D (see table 7).

European SMEs are seen to invest heavily in innovation activities whether it be R\&D or in procurement of machinery and equipment. However, unlike Latin American SMEs, which focus on acquiring machinery and equipment at the expense of efforts at endogenous innovation, European SMEs invest more in both internal and external R\&D (although internal $R \& D$ accounts for a higher proportion).

With respect to the trend towards innovation, a strong link is observed between the size of a business and the results of innovation activities. This is true in Europe as well as in selected Latin American countries, with significant gaps noted between small and large enterprises. 
Table 7. Investment in innovation activities: investment in capital assets versus R\&D by firms size (Percentage of the group)

\begin{tabular}{|c|c|c|c|c|c|}
\hline Region & Country & Size of business & In-house R\&D & External R\&D & $\begin{array}{l}\text { Acquisition of machinery } \\
\text { and equipment }\end{array}$ \\
\hline \multirow{9}{*}{$\begin{array}{l}\text { Latin } \\
\text { America }\end{array}$} & \multirow{3}{*}{ Brazil } & Small & 4 & 2 & 26 \\
\hline & & Medium & 15 & 5 & 35 \\
\hline & & Large & 34 & 13 & 38 \\
\hline & \multirow{3}{*}{ Chile } & Small & 2 & 1 & 10 \\
\hline & & Medium & 11 & 4 & 32 \\
\hline & & Large & 23 & 7 & 31 \\
\hline & \multirow{3}{*}{ Uruguay } & Small & 5 & 0 & 9 \\
\hline & & Medium & 12 & 4 & 25 \\
\hline & & Large & 23 & 9 & 46 \\
\hline \multirow{15}{*}{$\begin{array}{l}\text { European } \\
\text { Union }\end{array}$} & \multirow{3}{*}{ Germany } & Small & 52 & 16 & 64 \\
\hline & & Medium & 69 & 31 & 74 \\
\hline & & Large & 89 & 61 & 79 \\
\hline & \multirow{3}{*}{ Spain } & Small & 36 & 17 & 26 \\
\hline & & Medium & 62 & 32 & 21 \\
\hline & & Large & 75 & 50 & 29 \\
\hline & \multirow{3}{*}{ France } & Small & 63 & 26 & 65 \\
\hline & & Medium & 84 & 45 & 67 \\
\hline & & Large & 90 & 67 & 75 \\
\hline & \multirow{3}{*}{ Italy } & Small & 37 & 9 & 73 \\
\hline & & Medium & 59 & 24 & 69 \\
\hline & & Large & 79 & 41 & 71 \\
\hline & \multirow{3}{*}{ Sweden } & Small & 66 & 25 & 78 \\
\hline & & Medium & 80 & 40 & 80 \\
\hline & & Large & 91 & 65 & 84 \\
\hline
\end{tabular}

Note: Brazil: the size classification used is that of the SEBRAE, based on the number of employees: microenterprises: up to 19 employees; small enterprises: 20-99 employees; medium-sized enterprises: 100-499 employees; and large enterprises: 500 or more employees. "Small" enterprises include micro and small enterprises. The percentages are for the period 2009-2011. The values correspond to the total companies surveyed for each business segment. The companies taken into consideration are those that attach high or average importance to innovation. Chile: the percentages are for the period 2011-2012. The values correspond to the total companies surveyed for each business segment. "Acquisition of machinery and equipment" also includes software. Uruguay: the percentages are for the period 2010-2012. European Union "Acquisition of machinery and equipment" also includes software. The values are percentages of the businesses introducing product and/or process innovations (that is, those engaged in innovation activities, whether or not they obtain results). The percentages are for the period 2010-2012.. In all the countries, the data correspond to the manufacturing industry, except in the case of Brazil where they correspond to the extractive and processing industries. Owing to differences in the periods covered as well as in the definitions and methodologies applied in the different surveys, the results are not comparable between countries.

Source: Brazil: IBGE, Pesquisa de Inovação, PINTEC, 2011; Chile: Ministry of Economy, Development and Tourism, Octava Encuesta de Innovación en Empresas, 2013; Uruguay: ANII/INE, V Encuesta de Actividades de Innovación en la Industria, 2013; European Union: EUROSTAT, Community Innovation Survey, 2012. 
Table 8. Innovating and innovative companies, by size (Percentage of the group)

\begin{tabular}{|l|l|l|l|}
\hline & Small & Medium-sized & Large \\
\hline Germany & 18 & 30 & 54 \\
\hline Belgium & 18 & 31 & 49 \\
\hline Denmark & 9 & 20 & 53 \\
\hline Spain & 5 & 22 & 48 \\
\hline France & 13 & 27 & 48 \\
\hline Finland & 18 & 26 & 67 \\
\hline Ireland & 16 & 32 & 62 \\
\hline Italy & 21 & 39 & 55 \\
\hline Portugal & 16 & 31 & 68 \\
\hline Sweden & 14 & 20 & 39 \\
\hline Brazil & 34 & 45 & 56 \\
\hline Chile & 19 & 33 & 51 \\
\hline Uruguay & 15 & 33 & 58 \\
\hline
\end{tabular}

Note: Brazil: the size classification used is that of the SEBRAE, based on the number of employees: microenterprises: up to 19 employees; small enterprises: 20-99 employees; medium-sized enterprises: 100-499 employees; and large enterprises: 500 or more employees. "Small" enterprises include micro and small enterprises. The data relate to the extractive and processing industries. The percentages correspond to businesses engaged in product and/or process innovation for the period 2009-2011. Chile: the percentages correspond to rates of innovation in the manufacturing industry during the period 2011-2012. Uruguay: the percentages correspond to businesses engaged in product, process, organisational and marketing innovation of the manufacturing industry. The percentages are for the period 2010-2012. European Union: the percentages relate to businesses that are introducing product and/or process innovations (including those engaged in innovation activities as well as those that have suspended or discontinued such activities). The percentages are for the period 2010-2012. Owing to differences in the periods covered as well as in the definitions and methodologies applied in the different surveys, the results are not comparable between countries.

Source: Brazil: IBGE, Pesquisa de Inovação, PINTEC, 2011; Chile: Ministry of Economy, Development and Tourism, Octava Encuesta de Innovación en Empresas,, 2013; Uruguay: ANII/INE, V Encuesta de Actividades de Innovación en la Industria, 2013; European Union: EUROSTAT, Community Innovation Survey, 2012.

\section{Obstacles to innovation include barriers peculiar to the company and country barriers.}

Businesses (especially small businesses) seeking to innovate find their attempts hampered by certain common barriers, which should be borne in mind when designing and implementing policies and instruments for the promotion of science, technology and innovation. Some of the major constraints already cited, especially for SMEs, are credit access difficulties and the lack of skilled personnel and these are compounded by the high risk associated with innovation. There is no shortage of examples in this regard.

In addition to the obstacles common to all Latin American countries, other factors peculiar to individual countries come into play. In the case of the smaller economies, the small size of the domestic market and absence of economies of scale can be an obstacle to innovation. 
In some European Union countries, innovative small and medium-sized companies are hindered by the high cost of compliance with regulations, the lack of skilled personnel, the high cost of accessing new markets, stiff price competition and lack of adequate financing. These factors affect small businesses in particular, their impact being less significant for mediumsized companies and still less for large establishments (see table 9b).

Table 9. Principal factors that hinder business innovation in the manufacturing industry in selected countries of Latin America and the European Union, by size

a. Latin America, selected countries

\begin{tabular}{|c|c|c|c|c|c|c|c|}
\hline Country & $\begin{array}{l}\text { Size of } \\
\text { business }\end{array}$ & $\begin{array}{l}\text { Organizati- } \\
\text { onal rigidity }\end{array}$ & $\begin{array}{l}\text { Lack of/ } \\
\text { insufficient } \\
\text { information } \\
\text { on markets }\end{array}$ & $\begin{array}{l}\text { Lack of/ } \\
\text { insufficient } \\
\text { information } \\
\text { on techno- } \\
\text { logies }\end{array}$ & $\begin{array}{l}\text { Few oppor- } \\
\text { tunities for } \\
\text { cooperation } \\
\text { with other } \\
\text { businesses/ } \\
\text { institutions }\end{array}$ & $\begin{array}{l}\text { Lack/ } \\
\text { shortage } \\
\text { of skilled } \\
\text { personnel }\end{array}$ & $\begin{array}{l}\text { Shortage } \\
\text { of/ difficul- } \\
\text { ties of } \\
\text { appropriate } \\
\text { sources of } \\
\text { financing/ } \\
\text { access } \\
\text { constraints } \\
\text { to finance }\end{array}$ \\
\hline \multirow[t]{3}{*}{ Brazil } & Small & 14 & 13 & 16 & 21 & 51 & 44 \\
\hline & Medium & 17 & 15 & 16 & 18 & 37 & 31 \\
\hline & Large & 12 & 10 & 12 & 11 & 24 & 24 \\
\hline \multirow[t]{3}{*}{ Chile } & Small & - & 27 & 27 & 39 & 39 & 42 \\
\hline & Medium & - & 19 & 19 & 35 & 36 & 29 \\
\hline & Large & - & 15 & 15 & 24 & 23 & 16 \\
\hline \multirow[t]{3}{*}{ Uruguay } & Small & 9 & 11 & 7 & 18 & 21 & 24 \\
\hline & Medium & 12 & 12 & 6 & 20 & 19 & 19 \\
\hline & Large & 12 & 2 & 2 & 4 & 13 & 11 \\
\hline
\end{tabular}

Note: Brazil: the percentage relates to innovative businesses during the reference period (2009-2011); the size classification used is that of the SEBRAE and is based on the number of employees: microenterprises: up to 19 employees; small enterprises: 20-99 employees; medium-sized enterprises: 100-499 employees; and large enterprises: 500 or more employees. In the table, "small" enterprises include micro and small enterprises. The data correspond to the extractive and processing industries and to obstacles identified as highly important. The percentages correspond to businesses that implemented product and/or process innovations during the period 2009-2011. Chile: the percentages relate to all companies in the manufacturing industry during the reference period 2011-2012 which identify those obstacles that were highly important. In the survey, "Shortage of appropriate sources of financing/access constraints" was listed as "Lack of external financing for the company". Uruguay: the data corresponds to the manufacturing industry and the obstacles identified as highly important. The percentages correspond to total companies by size during the period 2010-2012. The category "Shortage of appropriate sources of financing/access constraints" appears in the survey, as "Difficulty in accessing financing". Owing to differences in the periods covered as well as in the definitions and methodologies applied in the different surveys, the results are not comparable between countries.

Source: Brazil: IBGE, Pesquisa de Inovação, PINTEC, 2011; Chile: Ministry of Economy, Development and Tourism, Octava Encuesta de Innovación en Empresas,, 2013; Uruguay: ANII/INE, V Encuesta de Actividades de Innovación en la Industria, 2013. 
b. European Union, selected countries

\begin{tabular}{|c|c|c|c|c|c|c|c|}
\hline Country & $\begin{array}{l}\text { Size of } \\
\text { business }\end{array}$ & $\begin{array}{l}\text { Enterprises } \\
\text { considering } \\
\text { high costs } \\
\text { of access to } \\
\text { new mar- } \\
\text { kets highly } \\
\text { important }\end{array}$ & $\begin{array}{l}\text { Enterpri- } \\
\text { ses con- } \\
\text { sidering } \\
\text { a lack of } \\
\text { adequate } \\
\text { finance } \\
\text { highly } \\
\text { important }\end{array}$ & $\begin{array}{l}\text { Enterpri- } \\
\text { ses con- } \\
\text { sidering } \\
\text { a lack of } \\
\text { demand } \\
\text { highly } \\
\text { impor- } \\
\text { tant }\end{array}$ & $\begin{array}{l}\text { Enterprises } \\
\text { considering } \\
\text { strong pri- } \\
\text { ce compe- } \\
\text { tition highly } \\
\text { important }\end{array}$ & $\begin{array}{l}\text { Enterprises } \\
\text { considering a } \\
\text { lack of quali- } \\
\text { fied personnel } \\
\text { highly impor- } \\
\text { tantCompanies } \\
\text { that consider } \\
\text { lack of skilled } \\
\text { personnel as } \\
\text { very important. }\end{array}$ & $\begin{array}{l}\text { Enterprises } \\
\text { conside-- } \\
\text { ring high } \\
\text { costs of } \\
\text { meeting } \\
\text { regulati- } \\
\text { ons highly } \\
\text { important }\end{array}$ \\
\hline \multirow{3}{*}{$\begin{array}{l}\text { Germa- } \\
\text { ny }\end{array}$} & Small & 19 & 15 & 15 & 63 & 21 & 23 \\
\hline & Medium & 12 & 9 & 22 & 66 & 19 & 14 \\
\hline & Large & 13 & 5 & 22 & 76 & 10 & 13 \\
\hline \multirow[t]{3}{*}{ Italy } & Small & 21 & 27 & 45 & 56 & 6 & 45 \\
\hline & Medium & 12 & 14 & 41 & 61 & 3 & 24 \\
\hline & Large & 8 & 9 & 46 & 58 & 3 & 18 \\
\hline \multirow[t]{3}{*}{ Austria } & Small & 23 & 13 & 14 & 67 & 27 & 34 \\
\hline & Medium & 20 & 9 & 16 & 76 & 19 & 26 \\
\hline & Large & 13 & 4 & 18 & 78 & 13 & 18 \\
\hline \multirow[t]{3}{*}{ Portugal } & Small & 37 & 34 & 36 & 63 & 15 & 36 \\
\hline & Medium & 34 & 29 & 37 & 70 & 8 & 31 \\
\hline & Large & 21 & 21 & 38 & 68 & 7 & 14 \\
\hline
\end{tabular}

Note: European Union: the percentages relate to manufacturing businesses that have introduced product and/or process innovations (including those engaged in innovation activities as well as those that have suspended or discontinued such activities). The percentages are for the period 2010-2012.

Source: EUROSTAT, Community Innovation Survey, 2012.

Linkages and cooperation between the productive sector and other agents of the National Innovation Systems are a determining factor in businesses' capacity to innovate.

Collaboration and multidisciplinary linkages through liaison with NIS agents generate opportunities to address, diffuse, transfer and appropriate knowledge, information and technology. Given the constraints faced by small businesses, their ability to innovate and upgrade their technology depends crucially on opportunities to liaise and interact with other businesses, academic institutions and science, technology and innovation institutes. These linkages would reduce many of the high costs as well as the uncertainty associated with the innovation process and provide access to new knowledge while helping to boost their internal capacities. 
There is significant scope for promoting cooperation between the stakeholders who make up the innovation systems in Latin America and the Caribbean. On the whole, Latin American companies have little interaction with the various actors in the respective national innovation systems. Coordination between the production sector and academia has not tended to be virtuous; the smaller the business the more acute the problem. Universities have not played a significant role or done much to boost innovation in businesses. As a result, levels of coordination between these agents are weak, and little scientific and technological knowledge has been introduced or technology transferred either in the production sector or in corporate innovation strategies.

Table 10 shows the linkages between companies and various National Innovation System agents in selected Latin American and European countries, by size. In all the economies under consideration, the larger the business the greater the degree of interaction with the different agents. Although the data between the two regions are not really comparable, significant contrasts may be observed between them. In all business segments in Europe the rates of interaction between companies and NIS agents are, on the whole, considerably higher than in the Latin American countries.

\begin{tabular}{|c|c|c|c|c|c|c|c|}
\hline Country & $\begin{array}{l}\text { Size of } \\
\text { business }\end{array}$ & Universities & $\begin{array}{l}\text { Research } \\
\text { centres }\end{array}$ & Clients & Suppliers & $\begin{array}{l}\text { Competi- } \\
\text { tors }\end{array}$ & $\begin{array}{l}\text { Other com- } \\
\text { panies of the } \\
\text { same group }\end{array}$ \\
\hline \multirow[t]{3}{*}{ Brazil } & Small & \multicolumn{2}{|c|}{5} & 9 & 11 & 5 & 1 \\
\hline & Medium & \multicolumn{2}{|c|}{12} & 18 & 18 & 10 & 2 \\
\hline & Large & \multicolumn{2}{|c|}{29} & 32 & 30 & 15 & 9 \\
\hline \multirow[t]{3}{*}{ Chile } & Small & 1 & 1 & 10 & 8 & 6 & - \\
\hline & Medium & 4 & 3 & 21 & 22 & 13 & - \\
\hline & Large & 8 & 7 & 33 & 30 & 25 & - \\
\hline \multirow[t]{3}{*}{ Uruguay } & Small & 5 & 1 & 13 & 69 & - & 0 \\
\hline & Medium & 8 & 5 & 19 & 62 & - & 3 \\
\hline & Large & 12 & 9 & 14 & 41 & - & 13 \\
\hline \multirow[t]{3}{*}{ Germany } & Small & 10 & 7 & 6 & 8 & 3 & 4 \\
\hline & Medium & 21 & 16 & 12 & 15 & 4 & 11 \\
\hline & Large & 51 & 35 & 35 & 36 & 12 & 37 \\
\hline \multirow[t]{3}{*}{ Spain } & Small & 5 & 7 & 6 & 9 & 3 & 3 \\
\hline & Medium & 11 & 17 & 11 & 17 & 7 & 14 \\
\hline & Large & 31 & 34 & 22 & 34 & 17 & 39 \\
\hline \multirow[t]{3}{*}{ Finland } & Small & 24 & 22 & 27 & 31 & 25 & 12 \\
\hline & Medium & 37 & 33 & 39 & 40 & 29 & 32 \\
\hline & Large & 76 & 74 & 77 & 76 & 61 & 77 \\
\hline
\end{tabular}


Table 10. Linkages with NIS agents by country and company size (Percentage of the group) (continued)

\begin{tabular}{|c|c|c|c|c|c|c|c|}
\hline Country & $\begin{array}{l}\text { Size of } \\
\text { business }\end{array}$ & Universities & $\begin{array}{l}\text { Research } \\
\text { centres }\end{array}$ & Clients & Suppliers & $\begin{array}{l}\text { Competi- } \\
\text { tors }\end{array}$ & $\begin{array}{l}\text { Other } \\
\text { companies } \\
\text { of the same } \\
\text { group }\end{array}$ \\
\hline \multirow[t]{3}{*}{ France } & Small & 7 & 5 & 9 & 17 & 4 & 7 \\
\hline & Medium & 15 & 11 & 14 & 26 & 6 & 20 \\
\hline & Large & 37 & 27 & 25 & 43 & 15 & 46 \\
\hline \multirow[t]{3}{*}{ Italy } & Small & 4 & 2 & 4 & 4 & 3 & 1 \\
\hline & Medium & 6 & 2 & 4 & 9 & 4 & 4 \\
\hline & Large & 30 & 13 & 15 & 23 & 12 & 25 \\
\hline \multirow[t]{3}{*}{ Portugal } & Small & 4 & 3 & 7 & 7 & 3 & 2 \\
\hline & Medium & 15 & 9 & 14 & 16 & 5 & 9 \\
\hline & Large & 43 & 26 & 37 & 48 & 18 & 40 \\
\hline \multirow{3}{*}{$\begin{array}{l}\text { United } \\
\text { Kingdom }\end{array}$} & Small & 15 & 8 & 45 & 36 & 15 & 24 \\
\hline & Medium & 20 & 9 & 46 & 44 & 14 & 35 \\
\hline & Large & 25 & 15 & 48 & 49 & 16 & 44 \\
\hline
\end{tabular}

Note: Brazil: the percentage relates to businesses engaging in product and/or process innovation during the reference period (2009-2011); the size classification used is that of the SEBRAE based on the number of employees: microenterprises: up to 19 employees; small enterprises: 20-99 employees; medium-sized enterprises: 100-499 employees; and large enterprises: 500 or more employees. „Small” enterprises include micro and small enterprises. The percentages refer to the linkage within Brazil. "Universities" and "Research centers" are grouped together as this is the variable presented in PINTEC 2011. The category "Clients" corresponds to the category "Clients and customers" of the survey. Chile: the percentages relate to innovative companies, during the reference period 2011-2012, which identify sources of information and cooperation as being of high and average importance. The category "Universities" corresponds to the category "Universities or other institutions of higher education"; the category "Research centres" corresponds to the category "Public or government research institutes"; the "Competitors" category corresponds to the survey category "Competitors or other companies in the same sector". Uruguay: the percentages relate to the innovative companies in the manufacturing industry during the period 2010-2012. The category "Laboratories" was used for "Research centres" and "Parent company" for "Other companies of the same group". European Union: in the Community Innovation Survey (CIS) 2012, the full name of the categories "Universities" is "Enterprises co-operating with universities or other higher education institutions", Research centres are "Enterprises co-operating with Government, public or private research institutes". "Competitors" are "Enterprises co-operating with competitors or other enterprises of the same sector". "Clients" are "Enterprises co-operating with clients or customers from the private sector"; "Suppliers" are "Enterprises co-operating with suppliers of equipment, materials, components or software". The percentages relate to manufacturing businesses that are introducing product and/or process innovations (including those currently engaged in innovation activities and those that have suspended or discontinued such activities) and correspond to the period 2010-2012. The percentages for the category "Clients" correspond to clients or customers from the private sector. In all countries, the data relate to the manufacturing industry, except in the case of Brazil where they correspond to the extractive and processing industries. Owing to differences in the periods covered as well as in the definitions and methodologies applied in the different surveys, the results are not comparable between countries.

Source: Brazil: IBGE, Pesquisa de Inovação, PINTEC, 2011; Chile: Ministry of Economy, Development and Tourism, Octava Encuesta de Innovación en Empresas,, 2013; Uruguay: ANII/INE, V

Encuesta de Actividades de Innovación en la Industria, 2013; European Union: EUROSTAT, Community Innovation Survey, 2012. 
The purpose of the interaction between the companies and these agents may be to request information, technical assistance, training or financing or some other form of assistance. This diversity in the size of companies applies equally to the human resources they employ and the sources of financing available for supporting innovation activities. These two factors are key to understanding the innovative behaviour of companies.

In terms of linkages and cooperation between universities and companies, SMEs are seen to be at a disadvantage. Table 10 shows that relationships with universities have not played a significant role in boosting innovation in Latin American or European SMEs, except in the cases of SMEs in the Nordic countries and in the United Kingdom, where substantial differences do exist. This suggests that there is ample scope for policies geared to building cooperation between NIS and other innovation agents, on the one hand, and national stakeholders and those of other countries and regions, on the other.

Foreign direct investment (FDI) can be a key vehicle for innovation and for incorporating small and medium-sized enterprises in the technological upgrading process and in strengthening their absorptive capacity. To the extent that the rules for competitiveness, quality and prices are more stringent, FDI can provide linkages with external markets which can further the adoption of new technologies and transfer know-how of new processes and methodologies for managing production and production processes. The FDI in question must have a greater R\&D component. In terms of the R\&D projects announced in the different regions, CELAC countries have seen a slight improvement over the past few years but still lag far behind Asia.

Figure 27. R\&D projects announced by region, 2003-2007 and 2008-2012 (Millions of dollars)

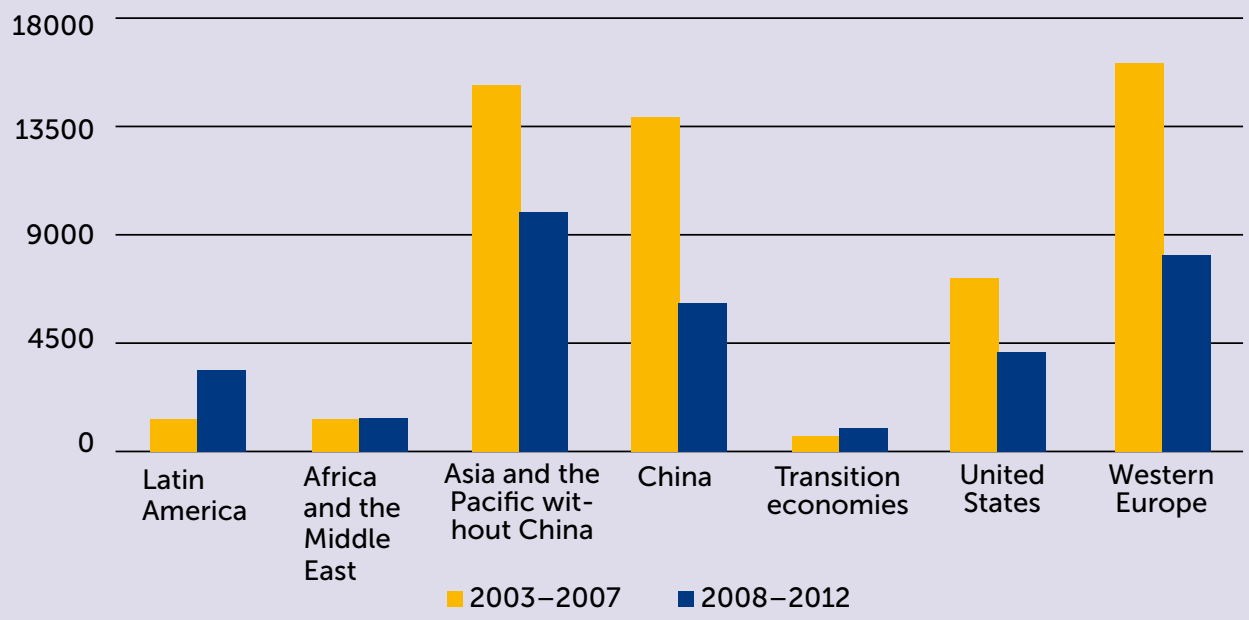

Source: ECLAC/CAF/OECD, 2014. 
In short, although some companies and production sectors in Latin America are close to the international technological frontier, they are considered to be "technological islands" in a production structure characterized by a high degree of structural heterogeneity. If Latin American countries are to move towards the path of inclusive long-term development, investment in innovation and R\&D must be increased across the entire production network to boost productivity substantially and enhance the position of businesses in international markets. This underscores the urgent need to establish industrial policies for SMEs, in tandem with science, technology and innovation policies, so as to promote complementarity between agents and facilitate linkages with the rest of the production and innovation system. Furthermore, the value of promoting and strengthening ties with companies in other countries and regions must not be overlooked as these relationships will facilitate technology transfers and knowledge spillover. Every effort must be made to include all companies, from microenterprises to medium-sized companies, in order to improve their productivity and competitiveness while reducing structural heterogeneity.

\subsection{Environment and institutional framework for the support of SMEs}

Setting up a business in Latin America is a slow process involving numerous and time-consuming procedures.

The regulatory and institutional framework is another factor that has a significant impact on the scope for developing a dynamic and integrated MSME sector. A first approach to assessing the business climate in order to determine how conducive it may or may not be to the generation of new businesses is to use the World Bank's "ease of doing business" indicator, which covers, and ranks countries in 10 areas of interest. The rankings go from 1 to 189 and the lower the value the easier it is to do business. Although some countries in the region have a similar ranking to that of the European Union countries, on the whole, Latin America is in a much less favourable position than the European economies. This applies especially to MSMEs as businesses less able to afford to pay for technical assistance and with more limited management capacity find it more difficult to cope with regulatory barriers.

A more detailed analysis of the main indicators used to prepare this ranking reveals that in most cases, procedures for business registration and operation are among the greatest obstacles to the establishment of companies and are considered by entrepreneurs to be complex, costly and lengthy. Setting up a business in Latin America is a slow process involving numerous (8.7) and time-consuming procedures (on average, 34 days). Within the region, wide differences have been observed: in Brazil, for example, the average time frame for establishing a company is almost 3 months (83 days), while in Ecuador the average is 55 days, in the Plurinational State of Bolivia 49 days, in Mexico 6,3 days and in Chile 5.5 days. These contrast, in most cases, with the data for the developed countries; for example, in France, incorporation of a new company takes 4.5 days, in Norway 5 days, and in the United Kingdom 6 days. This stresses the restrictions and bureaucracy that still apply to the formal establishment of a business in several of the Latin 
American countries. The time wasted on these procedures has negative repercussions on the economies of the region, since economic growth is held back by the failure to establish potential businesses and the positive benefits that such businesses would bring in terms of employment are constrained, resulting in higher levels of informality among SMEs.

\section{Figure 28. Ease of doing business index, average for 2013-2014}

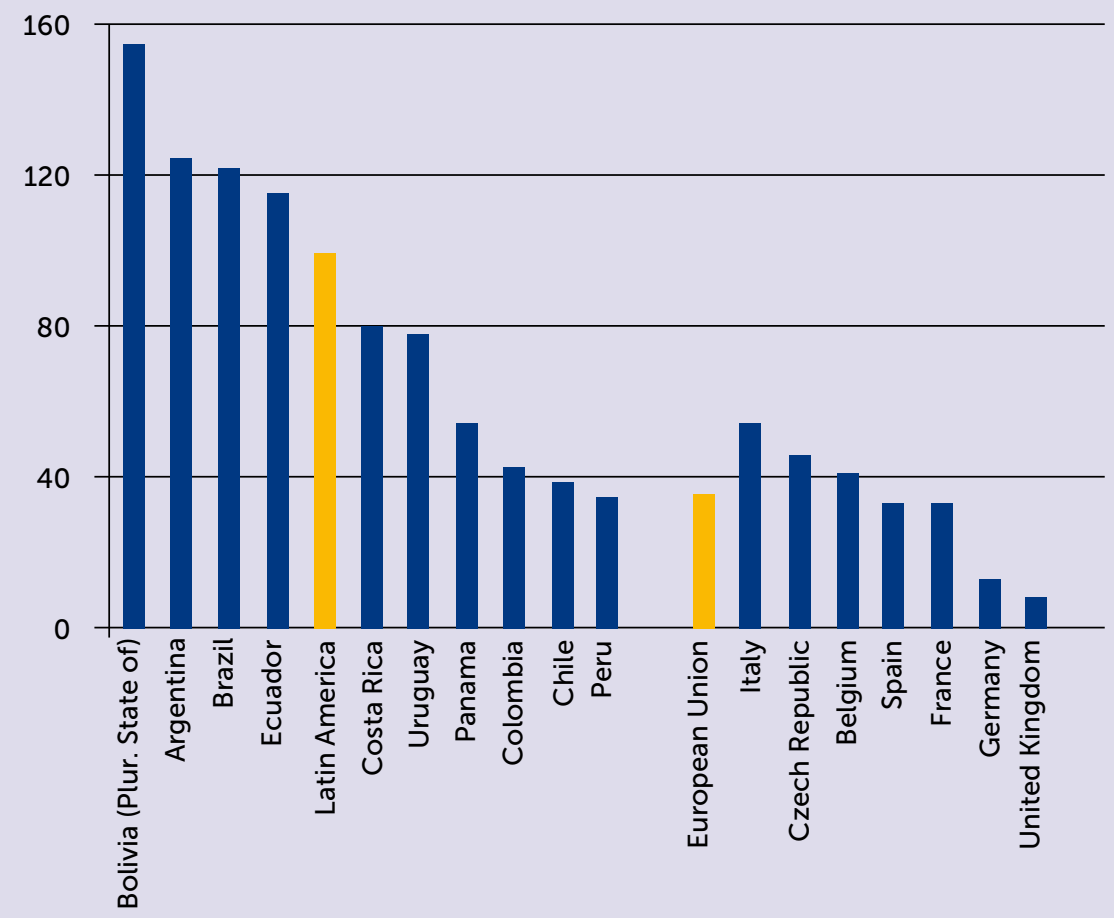

Source: World Bank, Doing Business, 2015.

A comparison of the data of 2005 with those of 2015 for the three indicators presented below reveals a trend towards more streamlined procedures for setting up companies in Latin America (see figure 29).

Although the indicators for Latin America and the Caribbean show a substantial improvement, they still lag far behind those of other geographical areas: each of the three indicators proves to be higher than the world average. In the Latin American countries, the procedures for establishing a new company are lengthier and more complex than in other regions of the world. This situation has an impact especially on the creation of new companies, the vast majority of which are microenterprises and SMEs. This difference in waiting and processing times has negative effects on corporate expenses, which, as a percentage of per capita income, are more than 9 times higher in Latin America than in the European Union. This situation has a negative impact on the creation of businesses and their integration into the formal sector. 
Figure 29. Procedures for setting up a business in Latin America, Europe and the world, 2005 and 2015

90

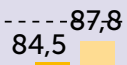

68

72,9

45

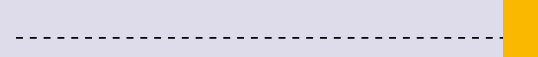

48,0

23

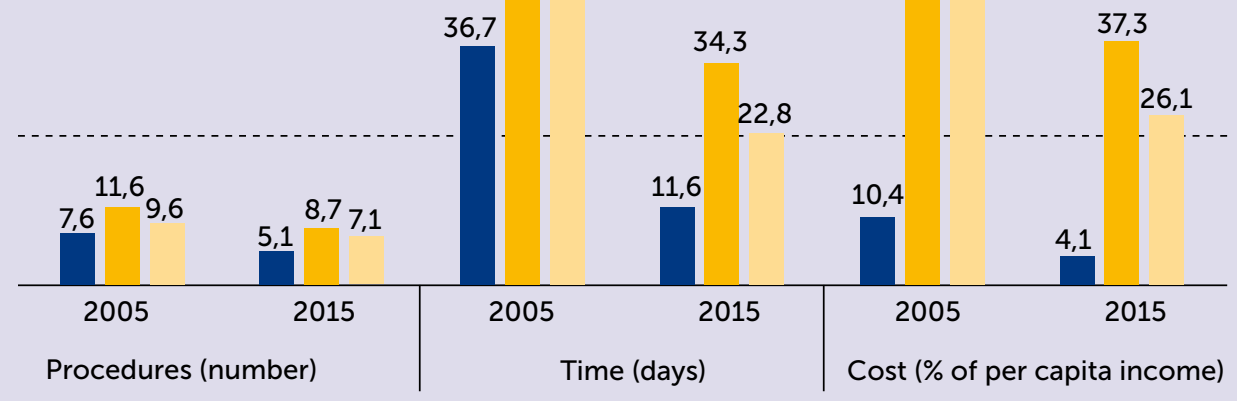

European Union Latin America and the Caribbean World

Source: World Bank, Doing Business, 2015.

Winding down of companies is also an obstacle in the countries of the region, because of regulations concerning the time required to close down a business and liquidate its assets. According to data from the International Labour Organization (ILO), it takes on average about four years for a company in Latin America to wind down or receive a discharge under bankruptcy proceedings and the percentage of debt recovery by creditors stands at $17 \%$, whereas in European countries such as Ireland, this procedure takes less than six months and creditors manage to recover approximately $87 \%$ of their debt. ${ }^{22}$

Norms, standards, certifications and accreditations are essential factors for innovating and integrating into national or international production chains.

The regulatory framework is not the only factor that has a direct impact on the competitiveness of SMEs and their chances of integrating into the world economy. Another key element is quality infrastructure (QI). This concept encompasses standards and standardization, tests, certifications and accreditation. All these elements are interrelated and must - up to a certain point - give the buyer, user or authorities, the appropriate assurance that the product, process or service complies with expectations. This point is particularly important for MSMEs, since a consolidated system of certifications and standards enables them to enter more demanding markets, eliminates fixed costs and reduces transaction costs, which are a heavier burden for small businesses. 
Quality assurance of industrial products depends on measuring, standardizing and testing, which are the technical basis for marketing merchandise and goods and for consumer, public health and environmental protection. The elements that ensure a given quality generally act invisibly, as manufacturers and consumers use components of this system on a daily basis without being fully conscious of it. For example, screws can be tightened properly in their nuts, mobile phones work and medicines contain the correct dosage of the active ingredients.

In a globalized world where huge volumes of goods and services are flowing constantly, the measurement, standardization and testing of products are increasingly important in international trade and indeed play a vital role in facilitating integration into global value chains. However, more and more reliable standards, measurements and tests are required for environmental protection, health services and food security. Standards support compatibility and can reduce costs through the use of common components, specifications and methodologies; they are essential for developing new industries and tapping the potential of new technologies; and they are crucial for securing and maintaining market access. Being able to quantify and verify the characteristics of the products or services that a country offers or can offer is important not only for more effective and efficient policymaking overall but also for defining and implementing various policies and instruments for the promotion of specific production sectors, for example, export policies, consumer protection policies, environmental protection policies and policies relating to science, technology and innovation.

QI is a network of many elements that are crucial in several areas of economic social and scientific development. It is a system consisting of a vast number of actors, stakeholders or interested parties, including the following:

- The government with its regulatory agencies.

- Micro, small, medium-sized and large goods-producing enterprises.

- Testing and calibration laboratories, clinical laboratories.

- Consumers and non-governmental organizations (NGOs) that work for consumer and environmental protection.

- The academic world.

- Research, development and innovation institutions.

Numerous public and private stakeholders participate in this network of institutions and are involved in QI development and services. Testing and calibration laboratories, for example, are a component of the system, and through their own networks and associations work to improve the development of the system. They normally have a clear understanding of the problems affecting their clients (companies, the State, NGOs), hence their technical competence is indispensable. Consumer and environmental protection agencies are other entities that must be taken into account and which have gained in strength and technical competence over the past few years. 
The private business sector is a very important stakeholder within the system. The development of the different components of QI depends to a large extent on its demands and specific requirements. The greater the number of local businesses that have access locally to an internationally recognized QI, the more they will be able to benefit from the impetus given by global trade to economic development. In this context, it should be recalled that lack of sustainability in the development of MSMEs is often due to the fact that this essential part of business management has been overlooked and that these companies do not have a solid relationship with QI development.

Policies that encourage international competitiveness must promote the introduction of quality management systems in companies. A case study of Uruguay's dairy sector shows that joint action by these institutions, agencies and companies have had a very positive impact on producers, the industry and the national economy of the country. Coordinated systemic action by the different QI stakeholders was instrumental in boosting quality at the national level throughout the production chain and in reviving a sector that had become depressed, resulting in significant productivity gains and success in repositioning Uruguayan dairy products in the international market. Moreover, small producers benefited from inclusion in the dairy chain. In this case study, policies to improve the quality of crude milk, through microbacterial and somatic cell counts, combined with a policy for upgrading cattle and pastures, enabled producers, especially small and medium-sized milk producers, to boost their production, income and wellbeing, and the country to penetrate external markets (milk production in Uruguay increased 2,4 times, from 900 million in 1990 to over 2.1 billion in 2011; products and destination markets were diversified and in 2006-2008 exports of dairy products accounted for more than $65 \%$ of the country's milk equivalent production). ${ }^{23}$

Thus, quality infrastructure is another of the enabling environment factors, which, together with other factors such as human resources, financing, technological capacities, production chains and access to global value chains, determine the productivity, competitiveness and innovativeness of companies, especially small businesses; thus, a host of different factors must be taken into account when defining and promoting strategies for sustainable and inclusive productive development.

\subsection{Clusters, production integration and access to global value chains}

Interaction with other companies and science and technology institutes is crucial for the advancement of SMEs towards more complex stages of the production process

For small businesses, collaboration with other companies and institutions is essential. The creation of mechanisms for cooperation between companies is vital as it helps to generate competitive advantages and externalities that will spur modernization. The concept of production integration encompasses different terms and conditions for collaboration between

23 See Gothner and Rovira, 2011 
economic stakeholders, geared to boosting the competitiveness of businesses and the efficiency of support institutions.

In practice, a variety of experiences exist ranging from business networks to production clusters, industrial districts, supplier development, trailblazing companies, production chains and global value chains. ${ }^{24}$ Amid financial constraints that limit the scope of public policy, adding partnership projects to SME development schemes offers a chance to reduce the programme's operating costs, since the fixed cost of the support activities is spread among more beneficiaries and increases the programme's efficiency and reach. Clusters afford the advantage of common infrastructure, the development of a pool of professionals in science and engineering, as well a pool of workers skilled in specific technologies. They are also a tool for sharing know-how acquired through the solution of technical problems between suppliers and users, among others.

Over the past 30 years, new technologies and increasing globalization have generated various changes in production methodologies, marketing channels and global financial markets. These changes had different impacts on Latin American SMEs and their integration in the world economy. As regards the organization of production, the new information and communication technologies (which facilitated control and coordination from a distance) have led to the further decentralization of networks of suppliers, users and subcontractors. These organizational changes have in turn led to the emergence of new and differentiated marketing channels which have enabled businesses to pursue new forms of integration in international markets. Although these forms were spearheaded by multinational corporations, they have also given rise to the integration of SMEs in global value chains (GVCs). In most cases, SMEs have been on the defensive in their response to this new situation, but there has been evidence of strategic responses that go beyond the embryonic responses observed in the early years of the twenty-first century. Indeed, these responses have consisted mainly in greater SME integration in external markets, an increasing recognition of the importance of cooperation with other companies, and the development of innovation activities designed to boost competitiveness. At the same time, more intense competition in the global market prompted the use of local arrangements to enhance competitiveness, by taking advantage of external economies and by generating collective efficiency.

Currently, the consensus is that GVCs control an increasingly significant proportion of international trade and, in the case of export SMEs, are (directly or indirectly) one of the most frequent ways of integrating into world markets. It is also recognized that these chains are an opportunity for successful international integration. There are risks, however; in some cases, GVCs can restrict access to international markets. This is because global buyers insist on more stringent product and process standards, and because increasingly the goods being traded in international markets consist of sub-assemblies and integrated sets of components from very different geographical origins. This makes it more difficult for SMEs to modify the 
type of integration in these chains. In spite of this, SMEs that operate in and belong to dynamic local groups, such as clusters or local production and innovation systems are partially able to withstand the prohibitions and restrictions imposed by the new global conditions, especially if their previous development path did not follow the pattern of the typical Latin American SME (characterized by a limited capacity in terms of technology, production and trade, concentration of management and ownership, relative isolation within the production system, problems in competing in open economies and in identifying opportunities, among others). In fact, in terms of policies, the past few years have seen a proliferation of territorial development programmes designed to enable SMEs to improve their competitiveness and attain the more complex phases of global value chains.

\subsubsection{Brief overview of the strengthening of global value chains}

Global value chains account for an increasing proportion of world trade and Latin American and Caribbean trade, although the region lags behind in its integration in these chains

Global value chains have gained greater significance in international trade, as indicated by the OECD-WTO Trade in Value Added (TiVA), which presents the share of domestic value added in the exports of selected countries and regions and in world total during the period 1995-2008 (see figure 30). A lower share of domestic value added (VA) means that imports of intermediate goods have a greater weight per export unit hence global value chains play a greater part. Figure 30 shows a clear downward trend in this share in the different countries and selected regions, that is to say, an increasing role for GVCs. This pattern goes hand in hand with the global trend in which domestic value added declined from $78 \%$ of total world exports in 1995 to $73 \%$ in $2008 .{ }^{25}$ The variation in this indicator is particularly striking in the case of the People's Republic of China, India and, to a certain extent, the Republic of Korea. These countries experienced the highest rate of variation, which suggests that they are the countries where the role of CGVs has grown the most.

Figure 30 also shows that both the levels and the downtrend in this indicator differ for the different countries and regions. Thus, while the lowest levels were recorded in the countries of South-East Asia (Cambodia, Indonesia, Malaysia, the Philippines, Singapore, Thailand and Vietnam), where domestic value added accounted for $67 \%$ of exports, the highest levels occurred in the United States, where the percentage stood at $91.5 \%$ on average. The weight of the chains is high in the European countries (72\%) owing to strong intraregional trade, while Latin American countries included in the TiVA base recorded average levels (85\%), which mask wide variations between countries. In Argentina and Brazil, domestic value added carries greater weight, while in Chile and Mexico imported intermediate inputs are more significant (see figure 30).

25 Although data are available up to 2009 , this study examines data up to 2008 only owing to the distortion in trade flows caused by the crisis. The data suggest that the crisis put a damper on the fragmentation process. 
Figure 30. Value added in the exports of different countries, 1995, 2000, 2005 and 2008

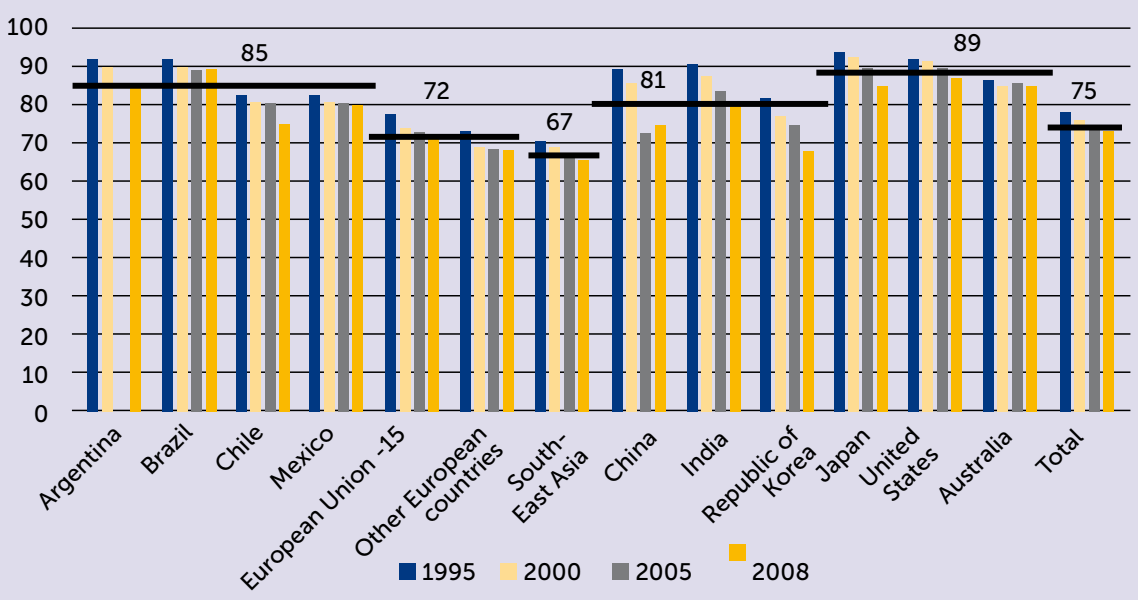

Source: Economic Commission for Latin America and the Caribbean (ECLAC) on the basis of information from OECD-WTO Trade in Value Added (TiVA).

These results are consistent with the indicator of re-exported intermediate products over total intermediate product imports, presented in table 11, which increased from $33 \%$ to $41 \%$. ${ }^{26}$ The figures for the Latin American countries were below or close to these levels. Argentina and Brazil recorded values that were significantly lower than the world average; those recorded for Chile and Mexico, were lower than, but closer to, the world average. In the case of Mexico, this is due to the important role played by maquila activities. In 1995, the weight of re-exported intermediate products was already very significant in Mexico, reflecting the importance of these activities even before the establishment of the North American Free Trade Agreement (NAFTA). In the case of Argentina, the weight of re-exported intermediate products doubled between 1995 and 2008. This is due in part to the increase in the weight of global chains, but above all to integration with Brazil, particularly in the automotive sector.

Table 11. Intermediate products re-exported as a percentage of total intermediate product imports, selected countries of Latin America and world total, 1995-2008

\begin{tabular}{|l|l|l|l|l|}
\hline Countries & 1995 & 2000 & 2005 & 2008 \\
\hline Argentina & 15 & 16 & 29 & 29 \\
\hline Brazil & 14 & 14 & - & 16 \\
\hline Chile & 24 & 27 & 32 & 33 \\
\hline Mexico & 35 & 35 & 37 & 38 \\
\hline World total & 33 & 38 & 40 & 41 \\
\hline
\end{tabular}

Source: Economic Commission for Latin America and the Caribbean (ECLAC), on the basis of information from OECD-WTO Trade in Value Added (TiVA)

26 The production of iPods and iPads in China is a case in point. While Chinese exports of these products account for most of global sales thereof, they generate only $5 \%$ of value added (Milberg y Winkler, 2013). 
At the sectoral level, the branches where GVCs are dominant differ from one country to another. Table 12 shows that while in the group of Latin American countries, the role of GVCs is particularly significant (albeit with differences between countries) in transport equipment (basically because of the automotive industry in Mexico, Brazil and Argentina) and in chemicals, in the countries of South-East Asia, the sectors which they dominate are electrical equipment and optics (electronics) as well as machinery and equipment. This reflects an increasing weight of GVCs that are intensive in the new technological paradigm.

At the sectoral level, the branches where GVCs are dominant differ from one country to another. Table 12 shows that while in the group of Latin American countries, the role of GVCs is particularly significant (albeit with differences between countries) in transport equipment (basically because of the automotive industry in Mexico, Brazil and Argentina) and in chemicals, in the countries of South-East Asia, the sectors which they dominate are electrical equipment and optics (electronics) as well as machinery and equipment. This reflects an increasing weight of GVCs that are intensive in the new technological paradigm.

\begin{tabular}{|c|c|c|c|c|c|c|c|c|c|}
\hline $\begin{array}{l}\text { Ran- } \\
\text { king }\end{array}$ & Latin American countries & Argentina & Brazil & Chile & Mexico & Total & & & \\
\hline 1 & Transport equipment & 65 & 84 & 68 & 63 & 70 & & & \\
\hline 2 & $\begin{array}{l}\text { Chemicals and non-metallic } \\
\text { minerals }\end{array}$ & 77 & 80 & 47 & 82 & 72 & & & \\
\hline 3 & Electrical and optical equipment & 72 & 82 & 95 & 43 & 73 & & & \\
\hline 4 & Machinery and equipment & 81 & 87 & 63 & 69 & 75 & & & \\
\hline \multirow[t]{2}{*}{5} & Textiles, clothing and footwear & 85 & 91 & 60 & 76 & 78 & & & \\
\hline & South-East Asia & Cambodia & $\begin{array}{l}\text { Indo- } \\
\text { nesia }\end{array}$ & $\begin{array}{l}\text { Malay- } \\
\text { sia }\end{array}$ & $\begin{array}{l}\text { The } \\
\text { Philip- } \\
\text { pines }\end{array}$ & $\begin{array}{l}\text { Sin- } \\
\text { ga- } \\
\text { pore }\end{array}$ & $\begin{array}{l}\text { Thai- } \\
\text { land }\end{array}$ & $\begin{array}{l}\text { Viet- } \\
\text { nam }\end{array}$ & $\begin{array}{l}\text { To- } \\
\text { tal }\end{array}$ \\
\hline 1 & Electrical and optical equipment & 35 & 70 & 43 & 47 & 36 & 41 & 33 & 43 \\
\hline 2 & Machinery and equipment & 42 & 59 & 44 & 62 & 40 & 54 & 42 & 49 \\
\hline 3 & Basic metals and metal products & 33 & 78 & 50 & 59 & 45 & 58 & 33 & 50 \\
\hline 4 & Textiles, clothing and footwear & 37 & 71 & 60 & 67 & 41 & 70 & 33 & 54 \\
\hline \multirow[t]{2}{*}{5} & Transport equipment & 44 & 80 & 52 & 63 & 50 & 52 & 39 & 54 \\
\hline & United States-Europe and Japan & $\begin{array}{l}\text { European } \\
\text { Union } 27\end{array}$ & Japan & $\begin{array}{l}\text { United } \\
\text { States }\end{array}$ & Total & & & & \\
\hline 1 & $\begin{array}{l}\text { Chemicals and non-metallic } \\
\text { mineral products }\end{array}$ & 73 & 68 & 72 & 71 & & & & \\
\hline 2 & Transport equipment & 84 & 81 & 77 & 81 & & & & \\
\hline 3 & Basic metals and metal products & 81 & 76 & 87 & 81 & & & & \\
\hline 4 & Electrical and optical equipment & 82 & 79 & 89 & 84 & & & & \\
\hline 5 & Textiles, clothing and footwear & 89 & 83 & 81 & 84 & & & & \\
\hline
\end{tabular}

Source: ECLAC, on the basis of information from OECD-WTO Trade in Value Added (TiVA). 
Latin American and Caribbean integration in value chains is based on the factor of production, capital, and on sectors with a high concentration of average skilled labour.

Data taken from the World Input-Output Database (WIOD) have been used to carry out a similar analysis, the interesting point being that this base can also distinguish between factors of production: capital, skilled labour and unskilled labour. The results of the estimate of the world input-output matrix may be summed up as four global trends. First, as already mentioned at the beginning of the document, there is a growing trend towards the international fragmentation of production. A total of 560 end products from 14 industries in 40 different countries were identified. In $85 \%$ of cases, domestic value added diminished between 1995 and 2008, which attests to the expansion of GVCs across the globe. However, this process was not onedimensional and various factors came into play with differences between periods. For example, regional global chains were the norm during the 1990s (owing to the proliferation of regional free trade agreements), but since the beginning of the twenty-first century, they have become internationalized, with fragmentation of production extending beyond the regional blocs.

The second trend identified concerns the greater value added provided by skilled labour and capital (see table 13). During the period 1995-2008, skilled labour accounted for a growing percentage of value added in most activities (92\%), while the share of unskilled labour fell in the vast majority of cases $(91 \%)$. Capital and average skilled labour grew in approximately half of all cases. Nevertheless, in terms of value, the data show that capital was the factor that contributed most to the increase in value added, rising from $40.9 \%$ in 1995 to $47.4 \%$ in 2008, while average- and low-skilled labour diminished by about 4 percentage points. These results point to the forms of integration in value chains in terms of the factors contributed at the domestic level. It can be seen that integration based on average- or low-skilled labour has been losing the capacity to generate value. ${ }^{27}$

Table 13. Share of factors of production in global value added, 1995-2008 (Percentages and billions of dollars)

\begin{tabular}{|c|c|c|c|c|}
\hline Value added & 1995 & 2008 & $\begin{array}{l}\text { Difference } \\
\text { 2008-1995 }\end{array}$ & $\begin{array}{l}\text { Chains in which } \\
\text { factor increases }\end{array}$ \\
\hline Capital & 41 & 47 & 7 & 64 \\
\hline Highly skilled labour & 14 & 15 & 2 & 92 \\
\hline Average skilled labour & 29 & 24 & -4 & 44 \\
\hline Unskilled labour & 17 & 13 & -4 & 9 \\
\hline Total (billions of dollars) & $\$ 6,586$ & $\$ 8,684$ & $\$ 2,098$ & \\
\hline
\end{tabular}


The third and fourth trends refer to deeper specialization based, on the one hand, on skilled-labour-intensive activities in high-income countries and, on the other, on increasing specialization in capital-intensive activities in middle-income countries. As shown in table 14, most of the value added in high-income countries is attributable to increases in the participation of highly-skilled labour. This applies especially to France, the Netherlands, the Republic of Korea, Spain and the United Kingdom. Meanwhile, capital is also a key factor in the increase in value added in Australia, Germany, the Netherlands and the Republic of Korea. Clearly, variations in the share of the four factors must amount to zero, ${ }^{28}$ in other words, a higher share of capital and skilled labour means a fall in the share of average and low-skilled labour. It is striking that for some of these high-income countries (in particular Canada, Germany and the United States) there has been a sharper decline in average-skilled labour than in unskilled labour. Italy and Spain share the distinction of having recorded an increase in value added based on average-skilled labour.

\section{Table 14. Increase in factor share of value added in the manufacturing industry, selected coun-} tries, 1995-2008 (Percentage points)

\begin{tabular}{|l|c|c|c|c|}
\hline Selected countries & Capital & Unskilled labour & $\begin{array}{l}\text { Average skilled } \\
\text { labour }\end{array}$ & $\begin{array}{l}\text { Highly skilled } \\
\text { labour }\end{array}$ \\
\hline United States & 3.9 & -1.9 & -5.9 & 4 \\
\hline Japan & 4.5 & -5.4 & -2.1 & 3.1 \\
\hline Germany & 6.8 & -2.8 & -7.4 & 8.4 \\
\hline France & 0.2 & -8.7 & 0.1 & 10.2 \\
\hline United Kingdom & -3.4 & -8.0 & 1.2 & 5.5 \\
\hline Italy & -1.1 & -14.8 & 10.4 & 8.1 \\
\hline Spain & 0.1 & -12.9 & 4.7 & 4.8 \\
\hline Canada & 1.8 & -2.0 & -4.6 & 3.3 \\
\hline Australia & 6 & -8.4 & -0.9 & 8 \\
\hline Republic of Korea & 9.3 & -11.6 & -5.6 & 8.9 \\
\hline The Netherlands & 5.5 & -7.3 & -7.1 & 2 \\
\hline China & 9.3 & -9.3 & -2.1 & 2.8 \\
\hline Russian Federation & 1.1 & -1.6 & -2.4 & 4 \\
\hline Brazil & -6.7 & -4.8 & 7.5 & 3.1 \\
\hline India & 4.5 & -5.9 & -1.7 & -1.7 \\
\hline Mexico & 6.4 & -4.2 & -0.5 & 3.1 \\
\hline Turkey & -12.7 & 4.5 & 5.2 & 1.6 \\
\hline Indonesia & 5.3 & -8.1 & 1.3 & 1.5 \\
\hline World total & 6.5 & -3.8 & -4.2 & \\
\hline Source: Timmer & & & & \\
\hline
\end{tabular}

Source: Timmer et al., 2014; and World Input-Output Database (WIOD) [online] http://www.wiod. org/new_site/home.htm.

28 In fact, it may not add up to zero owing to rounding. 
The lower part of table 14 shows that the share of unskilled labour in value added decreased in middle- and high-income countries. The share of skilled labour also shows a positive trend although less than in the case of high-income countries. In this group of countries, average skills also play an increasingly important role. Clearly, this global trend is due to the growing weight of services, as well as to technological changes, which call for more highly skilled workers. Furthermore, the growing role of capital in value added in countries such as China and India reflects this factor's precedence over labour in modern manufacturing.

From a policy perspective, these four trends identified on the basis of data from WIOD point to the importance of value chains in world production, as well as to new trends in international specialization, where unskilled labour loses some of its share at the global level and regions tend to specialize in average skilled labour, with capital carrying more weight in the case of manufacturing (China, India and Mexico), or in skilled labour with less weight for capital in the case of services (Turkey, Brazil).

Unskilled labour loses ground among the factors contributing to Latin American integration in GVCs.

These four trends affect SMEs in different ways. On the one hand, their relative disadvantage in terms of access to financing limits their scope for capital expansion. In that regard, there would be a minimum threshold in terms of size and access to financing, which would require SMEs to make more substantial efforts than in the past. Although this lack of capital could be offset by relatively high skills, international trends suggest these two factors (access to capital and the availability of skilled labour) are not interchangeable but rather complementary elements that develop side by side. Thus, the major challenge for SMEs is to overcome these constraints jointly, strengthening their presence in local and sectoral innovation systems that generate interactions and externalities. This, therefore, is a collective challenge and one that requires specific capacity-building policies and policies for improving connectivity in the systems and clusters in which these businesses operate.

On the whole, the strategies implemented by the countries that integrated into global value chains in the1980s and 1990s, based on low labour costs, no longer seem to be relevant. On average, Latin American SMEs have to cope with higher wages and lower productivity rates than the Asian economies. In addition, increasingly high levels of education are demanded of workers and greater levels of capitalization and goods and services certification are required. In spite of these difficulties, there could be room for a new strategy based on capacity-building and the accumulation of tacit knowledge. In this strategy, local businesses could assume a greater role in $R \& D$ and design activities in an upgrading process that will involve the development of endogenous capacities. 


\subsubsection{Towards greater SME integration in global value chains}

There are four key elements for understanding the chances of successfully integrating SMEs in GVCs: whether they belong to a cluster, the governance of the entities to which they belong, the sectoral specialization profile and whether or not there are specific SME policies for export promotion

Producers in local clusters that join multinational-led GVCs (in which the design, marketing, quality standards and access to demand are controlled by the multinational) have the option of engaging in different types of upgrade: (i) processing upgrades (transforming inputs into products more efficiently), (ii) product upgrades (based on differentiation), (iii) functional upgrades (designed to increase the functions of the cluster within the global chain) and (iv) intersectoral upgrades (whereby companies switch to a new activity in order to position themselves in another sector or another GVC and occupy a position that will allow them to generate and retain greater value added).

The chances of a small or medium-sized enterprise becoming integrated in a GVC are determined by a series of factors, some contextual, others microeconomic, and these must be taken into consideration when identifying potential partners with whom the business can form linkages and collaborate.

The contextual determinants include a series of elements which operate at the mesoeconomic level and which have an impact on the company's competitiveness. First, in order to determine what form of integration in a GVC may be possible, it is important to ascertain whether or not the business is part of a cluster and if so to establish the characteristics of that cluster. Clusters enable firms to boost their productivity through external economies, so as to obviate the disadvantages associated with the lack of economies of scale. However, the benefits of belonging to clusters may vary, depending on the characteristics of the latter. If the cluster emerges as the result of the endogenous interaction between local companies and institutions, the social and organizational distances are smaller, which facilitates internal flows of knowledge and enhances the competitiveness of the whole. On the contrary, if the formation of the cluster is the result of a deliberate public policy or of strategies adopted by a multinational corporation, then the barriers to knowledge flow can be greater, especially when the initial capacities are weak.

Second, one of the main features of value chains is the mode of governance, since this determines how resources and gains are distributed throughout the system. The governance or control model refers to the manner in which some segments of the chain exert control over the rest. The leading segment determines the division of labour within the chain and the type of activities carried out at each stage (including R\&D, design, marketing and brand positioning). This link will also determine the level of the barriers to entry and the competition 
system that will predominate between the different segments and stages. Generally speaking, the governance structure of the chains belongs to one of two broad categories: producerdriven and buyer-driven. ${ }^{29}$

Producer-driven chains are those in which the capital or technology is controlled by upstream production systems. In these cases, the stakeholder which organizes the production dominates both ends of the chain (design, innovation and development, directly linked to upstream production technologies, on the one hand, and distribution and marketing, on the other), leaving to the subcontractor the narrower area of manufacturing. Thus, companies that exercise control over the chain seek to protect technological innovation and avoid its diffusion by maintaining contractual relationships with specialized suppliers). In this model of governance, the role of SMEs is less important as these types of chains are usual in activities with a high technological content, where the margins are determined by taking advantage of economies of scale and by control of technology.

On the other hand, buyer-driven chains are those in which the strategic assets of the stakeholder that controls the chain stem from access to distribution channels. In this case, the chain is controlled by large wholesalers/retailers, distributors or brand owners. This kind of chain is typical of labour-intensive industries dedicated to the manufacture of consumer goods, such as textiles, footwear or electronics. The manufacturing process conforms directly to the specifications of the companies that exercise the control, which also maintain the functions of R\&D, design, brand management and logistics. In this case, SMEs can enter either as suppliers of specific inputs (for example, in the case of coffee, with chains of coffee shops) or else at some stage of the manufacturing process on the basis of a cost advantage (clothing and footwear for department stores with world-wide distribution).

Third, the sectoral specialization profile is another key factor to bear in mind when examining the dynamics of SMEs in the chain, on the basis of the scope for innovation and learning, which derive from the technological regime to which these SMEs belong.

Lastly, the presence of specific export promotion policies for SMEs (including sources of financing, public-private actions, trade missions, promoted nationally or locally on a public or private basis) is an important prerequisite for the successful integration of SMEs in these chains.

Microeconomic factors are other key elements of export integration. In other words, beyond the contextual advantages, minimum thresholds of endogenous development are required if a business is to enter into a global value chain, defend its position and, if possible, initiate upgrades within the chain. Thus, factors such as production efficiency, the presence of quality certifications and productive, technological, organizational and trade capacities are crucial for

See Gereffi, 1994. 
understanding the company's interaction within the cluster and its integration in clusters or a GVC.

Some examples from Latin America show the wide variety of sectors, technological processes and production categories involved in the international integration of Latin American SMEs in GVCs. The selected cases are examples of contrasting situations that may provide insight into the chances of upgrading depending on the characteristics of the case.

Table 15 provides a summary of the central elements that were analyzed in all cases under consideration. First, some of the clusters examined in this analysis emerged as a result of bottom-up processes (type 1), while others developed in response to a specific cluster promotion policy (type 2). In only one of the cases analysed (the software case in Argentina) does the cluster emerge as a result of a combination of endogenous and bottom-up factors associated with policy initiatives launched by entrepreneurs in the sector to promote software development in the region. Experience at the international level indicates that subsequent success with clusters is linked to the characteristics of the initial arrangement, in which bottom-up processes or a combination of the two types is usually associated with a better performance by the group of companies subsequently. This is due basically to the fact that many cases arise from previous experiences with associations and with sharing of information and knowledge between the companies that generate the social capital needed to achieve a given level of combined efficiency. In the case of SMEs, this previous experience determines, in part, the cluster's overall bargaining power when it joins a global value chain, especially a hierarchical one.

The selected cases are from diverse sectoral specializations that may be classified as: (a) natural-resource-based, (b) traditional manufacturing; (c) medium- and high-tech manufacturing; (d) design-intensive manufacturing; and (e) knowledge-intensive services. This sectoral classification is, to a great extent, linked to the operation of the value chains, the role played by SMEs and the potential for upgrading to more sophisticated levels.

Of the cases analysed, the natural-resource-based and traditional manufacturing categories are typical examples of global commodity chains. First, SMEs in the clusters analysed participate in activities whose competitiveness is based exclusively on price advantages, as a result of either low labour costs (as in the case of footwear in Brazil and jeans in Mexico) or the availability of natural resources (such as coffee). In some cases the experience of SMEs in the GVC has enabled them to move forward with functional and/or product upgrading; activities such as design, research, development and distribution are, however, usually in the hands of the large multinational corporations which control these chains. Thus, in these hierarchical networks the chances of upgrading are limited and in many cases SME competitiveness is threatened by products originating in China. 
As discussed earlier, SMEs that participate in clusters manage to overcome some of their weaknesses in terms of competitiveness thanks to the systemic advantages arising from the interactions, externalities and collective learning experiences within the cluster (as in the case of software, wine and, to a certain extent, the fourth generation maquila industry). Second, SMEs that participate in segments with the potential for differentiation are able to offer the GVC new competencies that will enhance their bargaining position in negotiations with buying companies. Examples of successful integration of this type include traditional manufactures that target niche segments (for example, clothing and footwear design) and some high generation maquila segments. Lastly, when businesses are already integrated in commodity chains and are able to develop complementary comparative advantages, they have a better chance of competing with new scale-intensive entrants who threaten their acquired position. The management and coordination capacities of the production processes within the local phase of the chain (for example, footwear and textiles) are a case in point; or the trading capacities developed by some coffee producers through linkages with marketing firms in a bid to obtain better prices than through mass marketing.

A final advantage in belonging to value chains is access to technology and knowledge thanks to linkages established by regional SMEs with corporations that control the chain and operate at the technological frontier. Examples of this include access to quality certifications, as in the case of the software cluster and third generation maquila businesses, and access to new production practices, as in the wine-making industry.

Table 15 suggests that opportunities for advancement do exist in the different types of GVCs identified, but these apply mainly to design-intensive manufacturing and knowledge-intensive services. In order to further advancement within the value chain in these areas, institutions are needed that facilitate coordination and cooperation between stakeholders - firms, universities, R\&D centres - and interaction with the leading sectors in the chain (whether buyer-driven or producer-driven) so as to generate virtuous producer-user interactions that will serve to build local capacity.

The challenges also depend on sectoral determinants since SME integration in relationships such as global commodity chains hinges almost exclusively on cost advantages based on low wages. Several examples of this attest to the difficulties that this type of cluster faced with the entry of new players, such as China, in the world arena. 


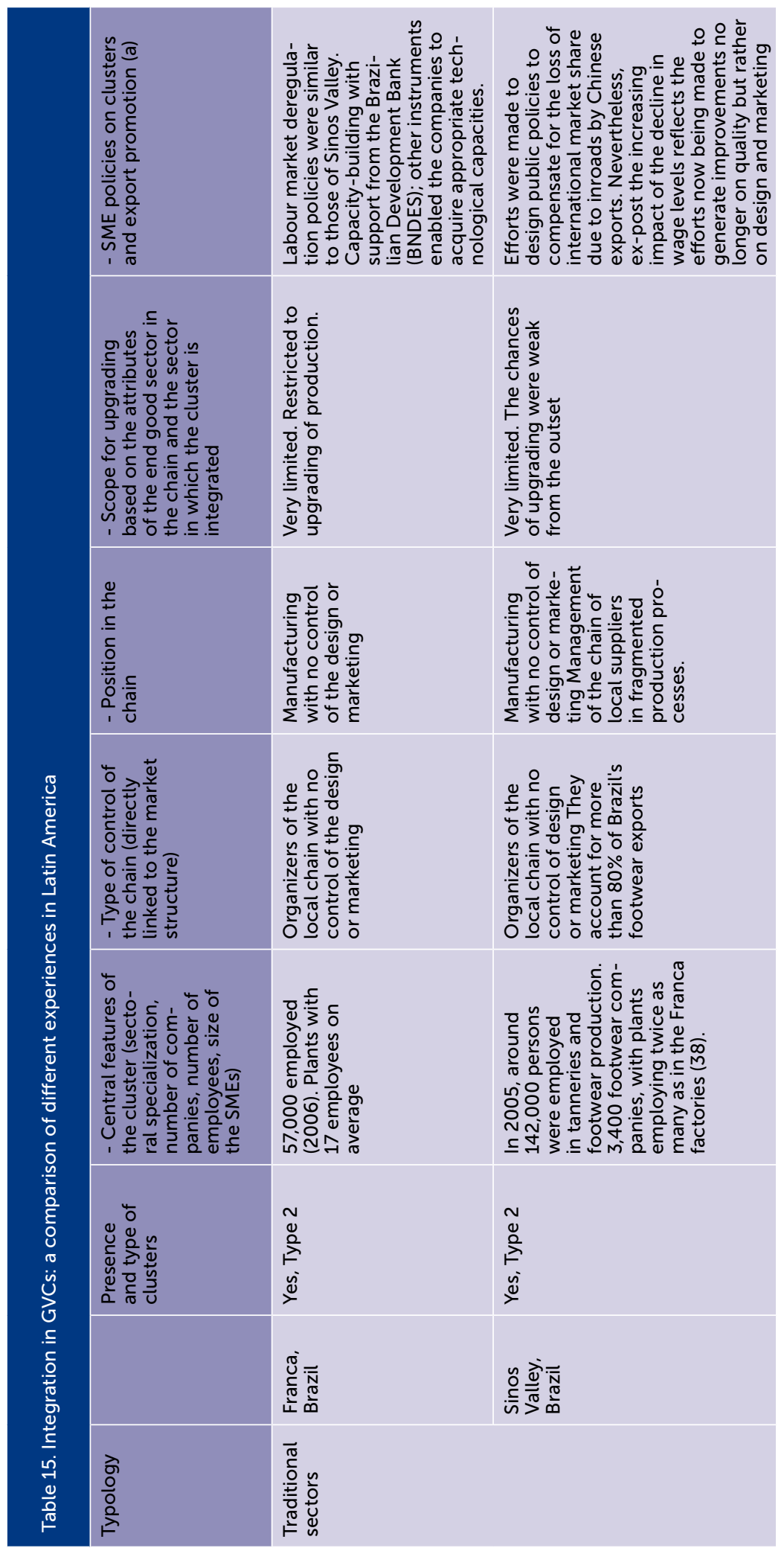




\begin{tabular}{|c|c|c|c|c|}
\hline & 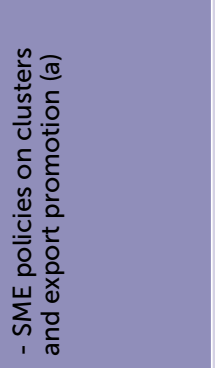 & 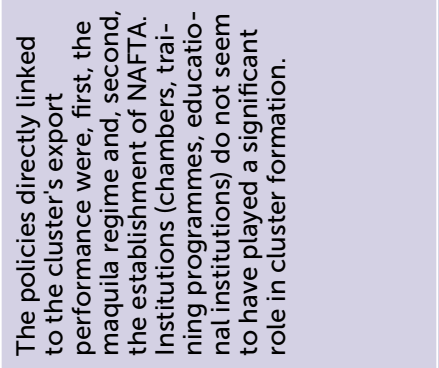 & 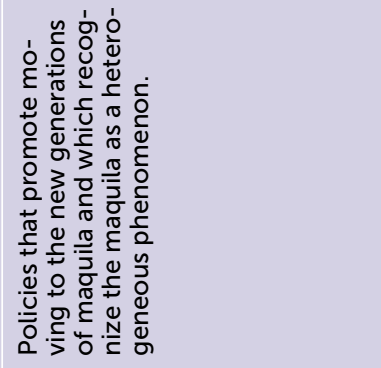 & 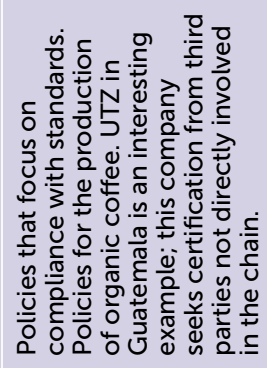 \\
\hline & 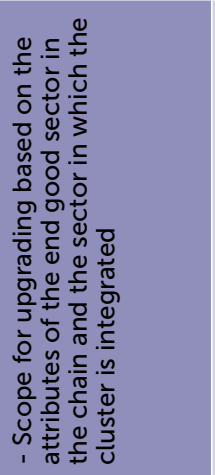 & 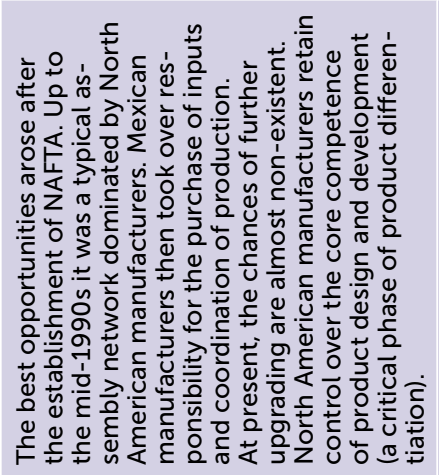 & 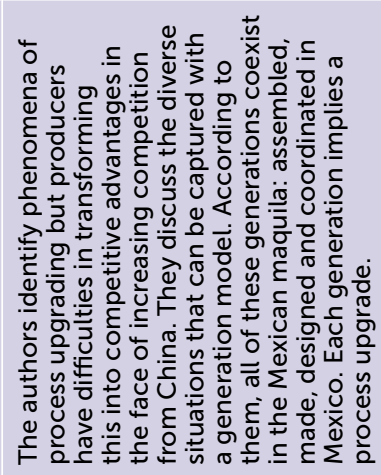 & 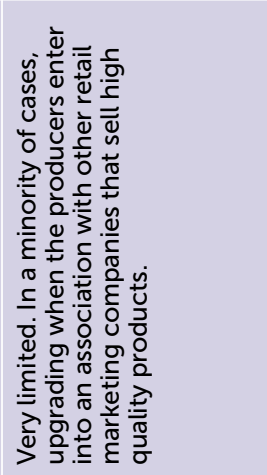 \\
\hline & 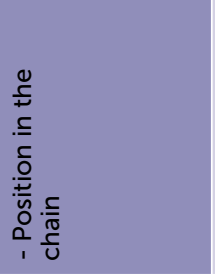 & 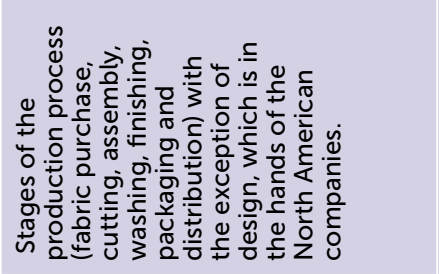 & 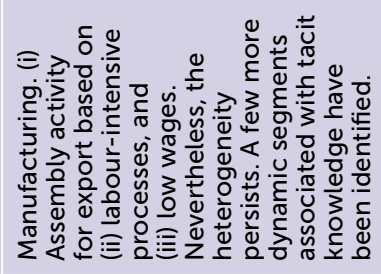 & 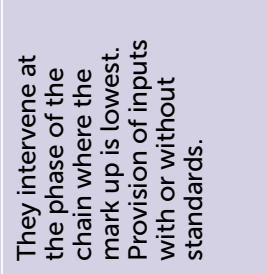 \\
\hline & 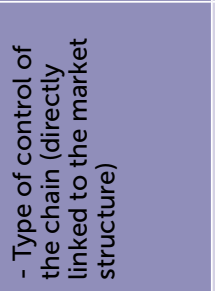 & 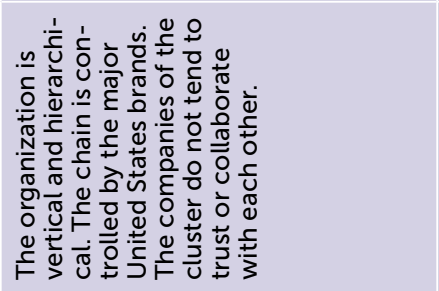 & 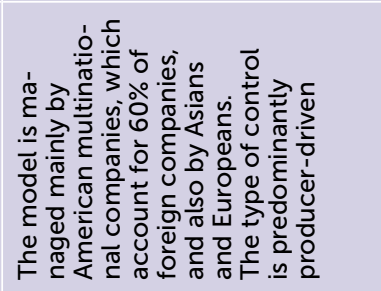 & 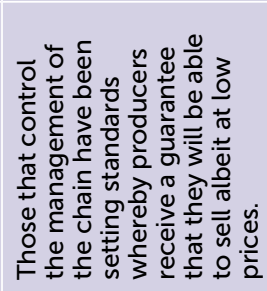 \\
\hline & 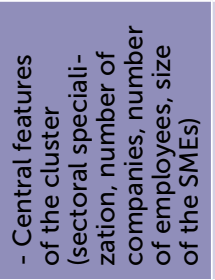 & 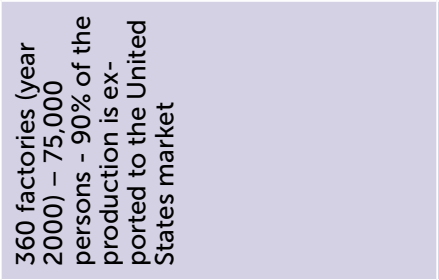 & 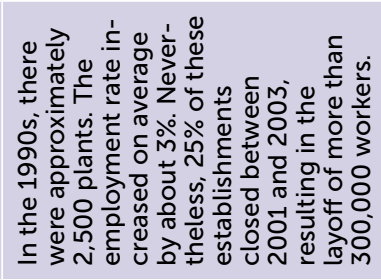 & 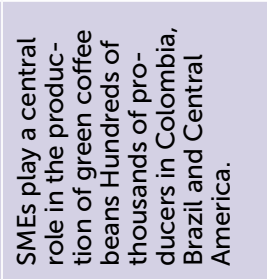 \\
\hline ริ & 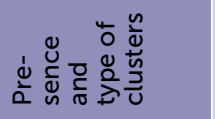 & 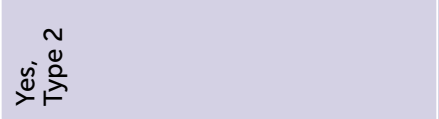 & 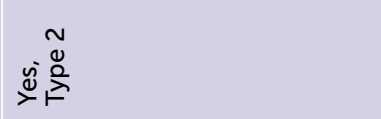 & $\stackrel{\circ}{z}$ \\
\hline & & 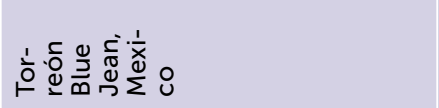 & 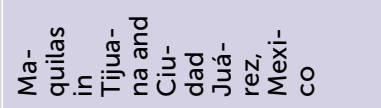 & 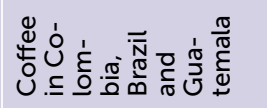 \\
\hline $\begin{array}{l}\stackrel{0}{\circ} \\
\frac{0}{0} \\
\frac{0}{\oplus}\end{array}$ & $\begin{array}{l}\frac{1}{0} \\
\stackrel{2}{2} \text { वे }\end{array}$ & 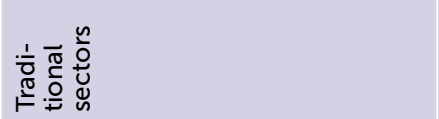 & 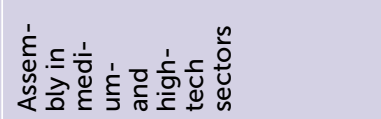 & 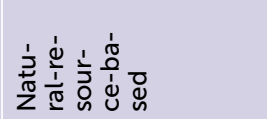 \\
\hline
\end{tabular}




\begin{tabular}{|c|c|c|c|}
\hline 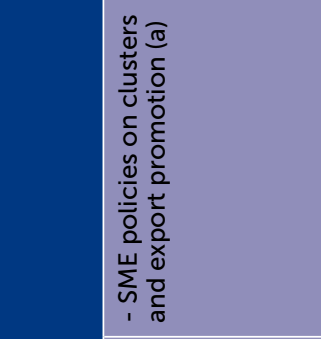 & 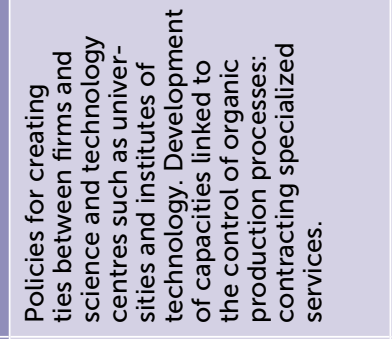 & 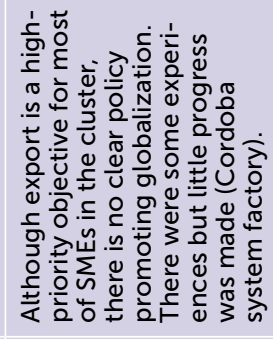 & 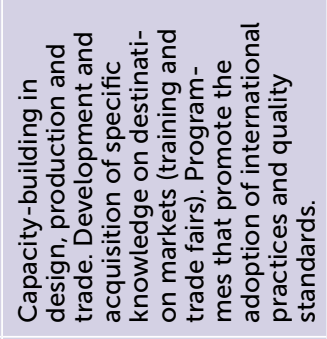 \\
\hline 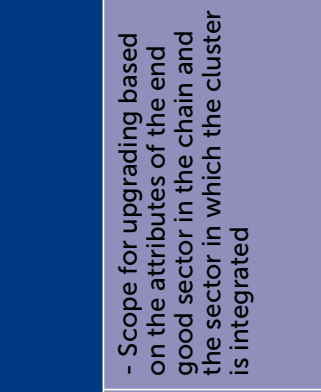 & 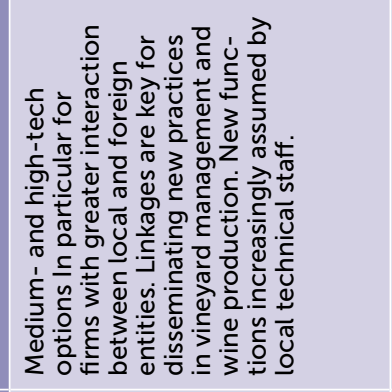 & 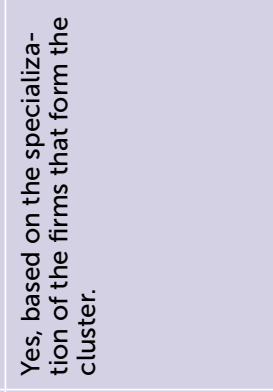 & 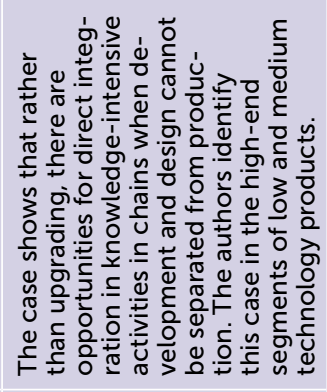 \\
\hline 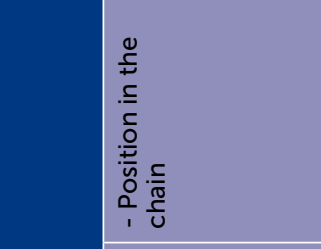 & 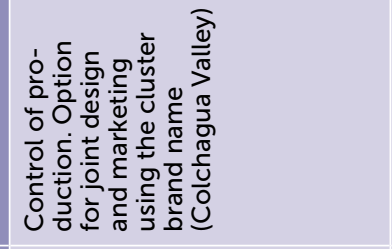 & 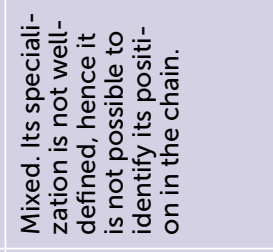 & 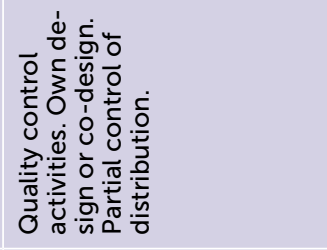 \\
\hline 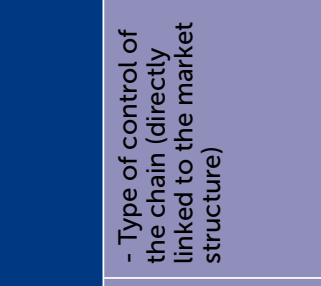 & 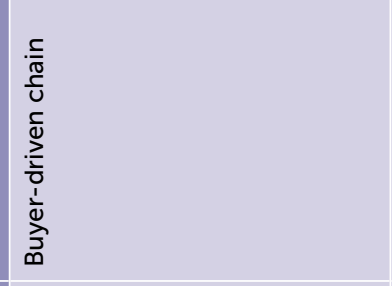 & 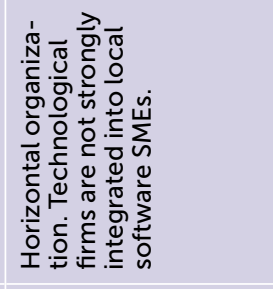 & 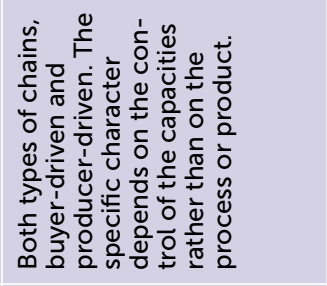 \\
\hline 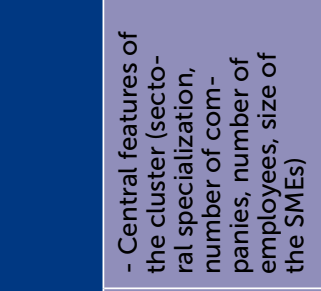 & 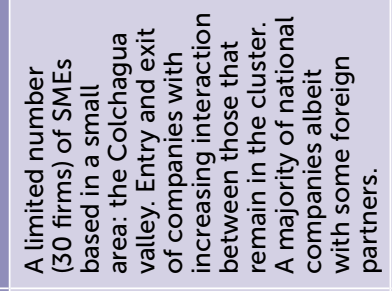 & 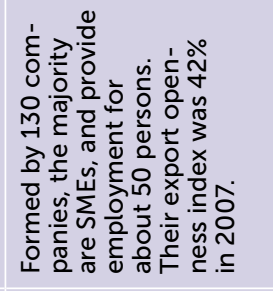 & 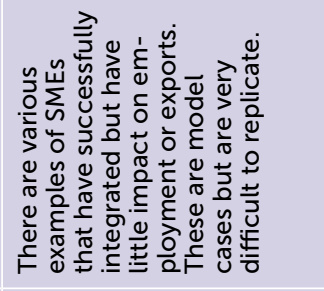 \\
\hline 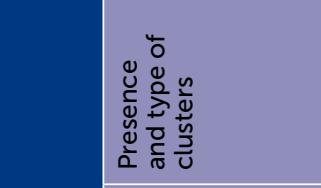 & $\begin{array}{l}\vec{y} \\
\stackrel{0}{\gtrless} \\
\stackrel{0}{y}\end{array}$ & 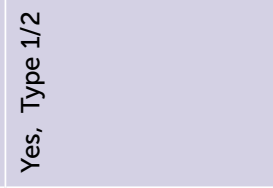 & 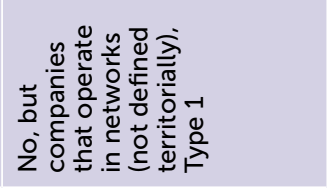 \\
\hline 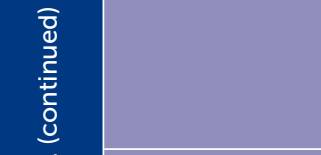 & 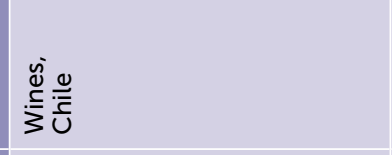 & 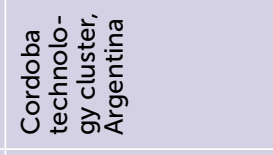 & 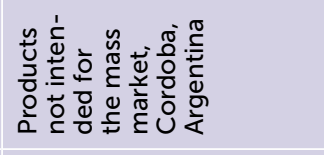 \\
\hline 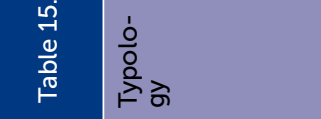 & 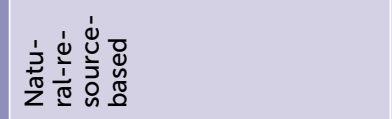 & 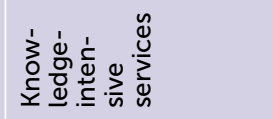 & 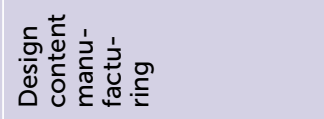 \\
\hline
\end{tabular}




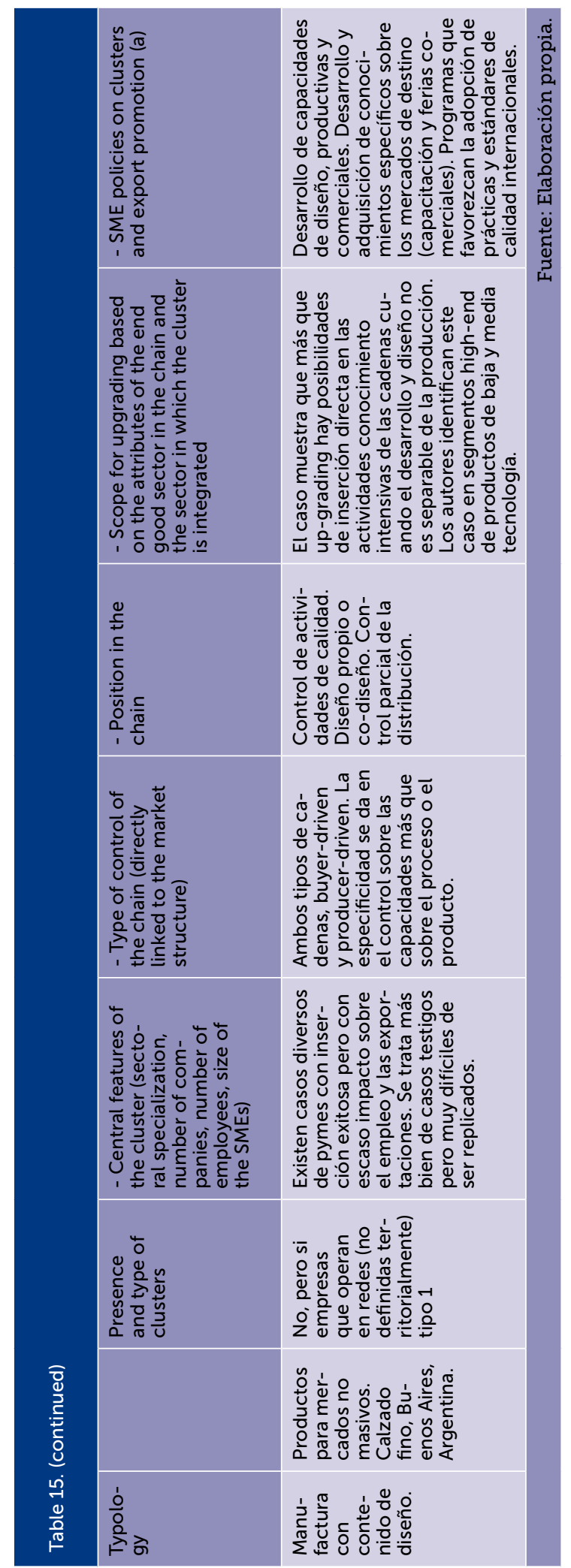




\section{TOWARDS CLOSER COOPERATION BETWEEN CELAC AND THE EUROPEAN UNION FOR THE PRODUCTIVE DEVELOPMENT OF SMES}

Two shocks of opposing signs had an impact on the climate in which SMEs performed in the previous decade and will have repercussions on the future scenario opening up for them. The first shock was the commodity boom. For the natural-resource-rich Latin American countries, this shock fuelled higher growth rates with external equilibrium and improvements at the fiscal level. Expansion of the domestic market and the rise of the new middle class generated a significant increase in aggregate demand. On the minus side, the currency appreciations jeopardized the integration of firms that produce tradable goods. The second shock was the Great Recession of 2008, which brought back the twin deficits and cast doubts on the possibility of growth continuing. While the recovery in the demand for commodities helped Latin America to emerge from the recession in 2010, there is growing concern as to whether growth in the international economy can be sustained in the coming years. Looking to the future, SMEs will probably have a less vibrant domestic market and less support from public policies, at least from those that call for higher fiscal spending.

Europe, meanwhile, has not fully recovered from the shock of 2008 . This region faces a deep crisis within the eurozone, linked to the problem of over-indebtedness in some economies (in particular, Greece). Although the European crisis resembles a financial crisis, its gestation was underway long before the shock of 2008. It was due to the current account deficits that mounted up, especially in the Southern European countries following currency unification. These deficits reflect asymmetries in technological and production capacities and wide differences in competitiveness between Northern, Eastern and Southern Europe.

In contrast with Europe's performance, the ten-year period from 2004 to 2013 was dubbed the "Latin American decade", as there was convergence with Europe in terms of per capita GDP. However, this convergence was very weak when compared with that of Asia. Moreover, the forces driving convergence in Latin America and the Caribbean seem to be losing steam, despite the fact that the situation within the region is very heterogeneous. The external disequilibrium 
has coincided with lower growth rates; a plateau has been reached in commodity prices and in some cases these have even started to fall off. Conversely, Europe is recording surpluses which, combined with a more flexible monetary policy and the decline in the value of the euro, could open up more favourable prospects for the recovery of aggregate demand.

One point that these two regions have in common is that both (but especially Europe) have seen their productivity decline in comparison with the United States. This is a disturbing sign insofar as it may reflect difficulties for technological catch-up in a world in which the technological frontier is moving very fast.

The challenges looming ahead for these two regions are different albeit just as complex. Europe must overcome the internal tensions generated by the financial crisis in Spain and Greece and seek higher levels of technological convergence and competitiveness between member countries. This is crucial not only for avoiding the emergence of unsustainable disequilibria within the zone but also in order to respond to the competitive challenge posed by Asia and the United States. Meanwhile, the Latin American and Caribbean region will once again have to find a way of redefining its position in the field of technology and production in a world where fiscal space and external space are shrinking. Major advances were achieved during the boom years; if these are to be maintained, the policy focus must be redirected towards productivity and structural change.

SMEs have a key role to play in promoting structural change and sustaining growth and equity. They account for a significant percentage of employment, but are not integrated into the more intensive innovation processes, the diversified production networks or export chains. This has a high cost for countries in terms of loss of efficiency, a lack of quality jobs and greater inequality.

The challenge for public policymakers is to disseminate best practices to SMEs and integrate them in increasingly complex activities within global value chains. SMEs suffer disproportionately more than large firms from problems of business and worker training, the barriers due to concentration of technological and market power in the hands of GVCs, regulation of competition and business activity and the weakness of clusters and local systems of innovation.

The starting point for public policies is to recognize the new context arising from the acceleration of technological progress and a world economy in which growth will probably be lower in the coming decade than it was in the previous one. In this context, GVCs have assumed a very important role. At present, policies that promote corporate training are necessary to enable firms to integrate successfully into global value chains (and upgrade their capacities). Concentrating only on tax benefits, a lax environmental legislation and/or cheap labour does not solve the main problem of capacities - and in some cases may prove to be counterproductive. 
Policy design must take into account the specificities of the country's production base, as well as the different stakeholders involved. In some cases, policies must seek to modify the incentives and behaviour of the subsidiaries of foreign corporations operating in the region. The aim is to ensure that these subsidiaries offer Latin American SMEs the opportunity to increase their participation and integration in more knowledge-intensive activities in their production chains. This will only be achieved if the training received by local businesses and the efficiency of the national innovation system are such that it is feasible to set up these activities in the country. Given the significant heterogeneity between firms, it is necessary to recognize the specific difficulties of SMEs (not only within individual sectors but also between sectors) and the key role of some major national or multinational firms in the control and governance of production chains.

In other cases, especially when businesses find themselves ousted by the increasingly stiff competition in the market, it is vital to generate cross-cutting competencies that facilitate restructuring. Such policies should favour those sectors which offer the most opportunities. Obtaining a movement of this type requires a constant forward-looking exercise in order to anticipate trends in production and the way they may change over time.

SME policies in Latin America and the Caribbean reveal very significant deficiencies especially when compared with the maturity and coverage achieved by such policies in Europe. Latin America has made strides in the implementation of SME policies in some respects: changes in the regulatory framework have been introduced, programme execution systems have been improved, and new instruments and services are being used to boost support for small businesses. But the results in terms of enhancing productivity and competitiveness have not been positive.

This has been partly due to problems with implementation or to the fact that the policies have not had sufficient time to mature. Some are old problems that relate to industrial policies in Latin America (and not just SME-related policies), such as the need to improve implementation systems, establish inter-agency coordination mechanisms, encourage linkages between businesses, universities and R\&D agencies and achieve continuity in the programmes. ${ }^{30}$ Other problems arise from the conceptual framework applied to policy analysis. It is necessary to dispense with the idea that the role of SME policy is to resolve market failures which hinder the operation of small enterprises. To this end, the production structure and technological progress must be studied as co-evolutionary processes, in which the dependency of the trajectory and the increasing returns (static and dynamic) are dominant. More complex structures promote learning, which, in turn, feeds back into structural change. Technological policies cannot be considered unless they are firmly anchored in the realm of production.

30 See Goldstein and Kulfas, 2011. 
While differences in productivity between European and Latin American firms may be attributed to differences in access to technology, financing, public support for the diffusion of innovations, among others, they are also strongly influenced by the sector in which the relevant firms operate. Latin American SMEs are for the most part engaged in low-tech activities in the production matrix, whereas European SMEs have a greater presence in more knowledgeintensive sectors. This affects not only the productivity observed but also the potential and learning path of both types of firm.

In addition, the difficulties with technology diffusion cannot be disregarded. Simply choosing and procuring the best technology on the market will not necessarily, by itself, bring the firm closer to the technological frontier. Learning must be approached from another perspective in which tacit knowledge (that is, knowledge that cannot be transmitted in a codified form) and the accumulation of experience over a long period are crucial. This makes temporary protection, subsidies and different types of public support necessary in order to break the inertia of the dominant learning pattern. It is also necessary to accept the fact that innovation is highly uncertain and that not all of the efforts undertaken should be expected to bear fruit.

One of the basic features of the business universe is its heterogeneity. By targeting instruments more accurately, greater coherence is achieved and it is easier to attain the established goals. Special attention must be paid to businesses with a growth potential and to more dynamic medium-sized firms, which help to generate more and better employment and, at the same time, have the capacity to grow into large companies. It is also fundamental to work with the more mature and traditional SME segment on the basis of strategies designed to update technology and overcome the usual problems of access to credit and information.

Second, SMEs must be viewed as part of a network. Clustering, association strategies and the development of production chains are central elements of a more global, high-impact approach to SME policies. This approach is very important for regional development policies but also as a means of enhancing the competitiveness and international integration of SMEs. However, in this field, continuity in action must be ensured, bearing in mind the importance of forging ties between private entities and between the latter and public stakeholders not only within countries but also at the regional level and with other regions in the world. Policies geared to production complexes must be considered as one chapter of industrial and productive development policy with a long-term perspective. Trust and institutions can only be built up over a long period of time but may be lost in the blink of an eye unless there are consistent policies over time.

Third, steps must be taken to move towards a more selective policy not only by targeting instruments to address the different types of SME but also by using sectoral policies to promote the development of strategic knowledge-intensive activities. SMEs can play a major role in sectors with a great potential for development in areas such as software, biotechnology, new 
materials, medications, chemicals, machinery and equipment, agricultural machinery, satellite and aerospace technology, and auto parts. This role can be fulfilled in certain niches opened up in the above sectors as well as through participation in production networks.

Lastly, the tendency to treat SME policy as a set of tools rather than objectives must be overcome. This error leads to a situation where support instruments - for financing, export, training and so forth - eventually become ends in themselves rather than a means for attaining development targets. In this regard, a comprehensive vision of SME policy should order and prioritize the implementation of tools subordinating them to the central purpose of productive development and the special role that small and medium-sized enterprises need to play within that framework. ${ }^{31}$

Some of the strategic areas for public action may be summed up as follows: (a) to reduce the financing gap between SMEs and large businesses; (b) to reduce the productivity gap, improving intra-sector efficiency and promoting the entry of SMEs into more high-technology-intensive sectors; (c) to facilitate access to quality infrastructure in order to improve the production capacity of businesses and their access to new markets; (d) to raise substantially the incorporation of technologies in particular general purpose ones such as ICTs, those that have a high potential for improving management techniques and entry into international markets; (e) to improve the education of workers and management staff; $(f)$ to promote greater coordination between the education system and the production system; and ( $\mathrm{g}$ ) to integrate SMEs into clusters and value chains in areas that represent opportunities for learning and upgrading of production.

Thus, the experience that the European Union has already accumulated in the area of SME support policies and requests by Latin America for investment in diversification of production and technological upgrading offer broad opportunities for political and economic cooperation between the two regions. It is hoped that these factors will remove or reduce the main barriers faced by SMEs, which are summed up in the concluding table presented below:

31 See Ferraro, 2011. 
Recovering lost time: Barriers to the productive development of SMES and public policy

\begin{tabular}{|c|c|}
\hline Barriers & Policies \\
\hline $\begin{array}{l}\text { Weak SME integration in } \\
\text { GVCs }\end{array}$ & $\begin{array}{l}\text { - Technological support policies for SMEs } \\
\text { - Policies for identifying opportunities in GVCs } \\
\text { - Development of suppliers, standards and systems of weights and } \\
\text { measures } \\
\text { - Support policies for identifying and promoting entry into external } \\
\text { markets } \\
\text { - Specific policies for ICT training and incorporation in production and } \\
\text { management }\end{array}$ \\
\hline $\begin{array}{l}\text { Scant coordination of } \\
\text { production and cluster } \\
\text { formation }\end{array}$ & $\begin{array}{l}\text { - Policies for coordinating public and private investments } \\
\text { - Industrial commons } \\
\text { - Coordination between firms, universities and R\&D agencies } \\
\text { - Foster cooperation tools between firms }\end{array}$ \\
\hline Weak training & $\begin{array}{l}\text { Policies for human resource training and upgrading in the sphere of } \\
\text { business and technical and worker training. }\end{array}$ \\
\hline Financing gap & $\begin{array}{l}\text { Reduce the financing gap between large companies and SMEs (by } \\
\text { means of collateral, subsidized loans, development banking). Many } \\
\text { of the barriers to productivity, technological barriers and barriers to } \\
\text { international market access are exacerbated by difficulties in accessing } \\
\text { financing. }\end{array}$ \\
\hline $\begin{array}{l}\text { Weak institutional frame- } \\
\text { work }\end{array}$ & $\begin{array}{l}\text { - Strengthen mechanisms for policy evaluation and adjustment. } \\
\text { - Invest in training public agencies responsible for policymaking and } \\
\text { implementation. } \\
\text { - Strengthen transparency and communication between agents in order } \\
\text { to avoid problems of asymmetry in information and data capture. }\end{array}$ \\
\hline $\begin{array}{l}\text { Low diversification of pro- } \\
\text { duction }\end{array}$ & $\begin{array}{l}\text { Changes in the pattern of specialization do not arise automatically. } \\
\text { SME policies must be tied to a broader policy for diversification to- } \\
\text { wards more knowledge-intensive sectors. In other words, this policy } \\
\text { must be viewed as a component of industrial policy. }\end{array}$ \\
\hline Scant regional cooperation & $\begin{array}{l}\text { - Sharing of experiences between Latin American and European SMEs. } \\
\text { - Analysis and discussion in Latin America and the Caribbean of the Eu- } \\
\text { ropean experience with SMEs, its strengths and weak points. } \\
\text { - Programmes for sharing technologies and supporting institution-buil- } \\
\text { ding in Latin America and the Caribbean. } \\
\text { - Cooperation on technology transfer, especially green and inclusive } \\
\text { technologies. }\end{array}$ \\
\hline
\end{tabular}




\section{BIBLIOGRAPHY}

ANII-INE (National Research and Innovation Agency/National Institute of Statistics) (2013), V Encuesta de Actividades de Innovación en la Industria, Montevideo.

Argentine Chamber of Exporters (2013), Las PYMEX 2003-2013. Una mirada actual, Buenos Aires, May.

Chamber of Industries and Production (2011), "Principales resultados del Censo Económico", Boletín Económico, October.

DANE (National Administrative Department of Statistics) (2008), Censo General 2005, Bogotá.

ECLAC (Economic Commission for Latin America and the Caribbean) (2015), Foreign Direct Investment in Latin America and the Caribbean 2014. Briefing Paper, Santiago, Chile, May.

(2012), Structural Change for Equality: An Integrated Approach to Development (LC/G.2524(SES.34/3)), Santiago, Chile, July.

ECLAC/CAF/OECD (Economic Commission for Latin America and the Caribbean/Development Bank of Latin America/Organization for Economic Cooperation and Development) (2014), Latin American Economic Outlook 2015: Education, Skills and Innovation for Development, Paris, OECD Publishing.

ECLAC/OECD (Economic Commission for Latin America and the Caribbean/Organization for Economic Cooperation and Development) (2012), Latin American Economic Outlook 2013: SME Policies for Structural Change (LC/G.2545), Paris, OECD Publishing.

European Commission (2010), Internationalisation of European SMEs, Brussels.

EUROSTAT (2012), Community Innovation Survey.

Ferraro, C. (comp.) (2011), Apoyando a las pymes: Políticas de fomento en América Latina y el Caribe (LC/R.2180), Santiago, Chile, Economic Commission for Latin America and the Caribbean (ECLAC).

Gereffi, G. (1994), "The organization of buyer-driven global commodity chains: How U.S. retailers shape overseas production networks", Commodity Chains and Global Capitalism, G. Gereffi and M. Korzeniewicz (eds.), Westport, Praeger.

Goldstein, E. and M. Kulfas (2011), "Alcances y limitaciones de las políticas de apoyo a las pymes en América Latina. Debates para un nuevo marco conceptual y de implementación", Apoyando a las pymes: Políticas de fomento en América Latina y el Caribe (LC/R.2180), C. Ferraro (comp.), Santiago, Chile, Economic Commission for Latin America and the Caribbean (ECLAC). Gothner, C. and S. Rovira (2011) (comps.), Impacto de la infraestructura de la calidad en América Latina (LCM.387), Santiago, Chile, Economic Commission for Latin America and the Caribbean (ECLAC).

IBGE (Brazilian Geographical and Statistical Institute) (2012), Estatísticas do Cadastro Central de Empresas 2010 [online] http://www.sidra.ibge.gov.br/bda/pesquisas/cempre/default.asp. 
(2011), Pesquisa de Inovação, PINTEC, Rio de Janeiro.

ILO (International Labour Organization) (2009), Crisis internacional y políticas para las Pymes. Desafíos y oportunidades para América Latina y Europa, Geneva.

ILO/SERCOTEC (International Labour Organization/Technical Cooperation Service) (2010), La situación de la micro y pequeña empresa en Chile, Santiago, Chile [online] http:// www.oitchile.cl/pdf/peq001.pdf.

INE (National Institute of Statistics) (2012), Uruguay en cifras. Empresas y sectores de actividad [online] http://www.ine.gub.uy/biblioteca/uruguayencifras2012/cap\%C3\%ADtulos/Empresas\%20y\%20Sectores\%20de\%20Actividad.pdf.

INEGI (National Institute of Statistics and Geography) (2011), Censos Económicos 2009: Micro, pequeña, mediana y gran empresa, Mexico City.

INEI (National Institute of Statistics and Informatics) (2011), Perú: Características económicas de las micro y pequeñas empresas en el año 2007, Lima.

Infante, R. (ed.) (2011), "El desarrollo inclusivo en América Latina y el Caribe: Ensayos sobre políticas de convergencia productiva para la igualdad”, Libros de la CEPAL series, No. 112 (LC/ G.2500-P), Santiago, Chile. United Nations publication, Sales No. S.11.II.G.56.

Katz, J. and G. Stumpo (2001), "Sectoral regimes, productivity and international competitiveness", CEPAL Review, No. 75 (LC/G.2150-P), Santiago, Chile, Economic Commission for Latin America and the Caribbean (ECLAC), December.

Lall, S. (2000), "The technological structure and performance of developing country manufactured exports, 1985-98”, Oxford Development Studies, vol. 28, No. 3, Taylor \& Francis.

Mazzucato, M. (2013), The Entrepreneurial State: Debunking Public vs. Private Sector Myths, London, Anthem Press.

MIF (Multilateral Investment Fund) (2014), Banks and the Missing Middle, Washington, D.C. Milberg, W. and D. Winkler (2013), Outsourcing Economics: Global Value Chains in Capitalist Development, New York, Cambridge University Press.

MINEC/DIGESTYC (Ministry of Economic Affairs/Department of Statistics and Censuses) (2006), Censos Económicos 2005.

Ministry of Economy, Development and Tourism (2013), "Octava Encuesta de Innovación en Empresas, 2011-2012" [online] http://www.economia.gob.cl/estudios-y-encuestas/encuestas/ encuestas-de-innovacion-e-id/octava-encuesta-de-innovacion-en-empresas-2011-2012/.

OECD (Organization for Economic Cooperation and Development) (2014), Financing SMEs and Entrepreneurs 2014. An OECD Scoreboard, Paris, OECD Publishing.

(2012), Resultados de PISA 2012 en foco: Lo que los alumnos saben a los 15 años de edad y lo que pueden hacer con lo que saben, Programme for International Student Assessment (PISA).

OEDE (Employment and Business Dynamics Observatory) (2013), Estadísticas e indicadores para el total del país [online] http://www.trabajo.gob.ar/left/estadisticas/oede/estadisticas_nacionales.asp

Santoleri, P. and G. Stumpo (2014), "Microempresas y pymes en América Latina: Características de las firmas y políticas de apoyo", Santiago, Chile.

SEBRAE (Brazilian Micro and Small Business Support Service) (2011), As micro e pequenas empresas na exportacao brasileira 1998-2011, Brasilia. 
Timmer, M.P. and others (2014), "Slicing up global value chains", Journal of Economic Perspectives, vol. 28, No. 2, Nashville, Tennessee, American Economic Association.

TiVA (OECD-WTO Trade in Value Added) (2014) [online] http://www.oecd.org/sti/ind/whatistradeinvalueadded.htm.

UNDP (United Nations Development Programme) (2014), Perfil de los estratos sociales en América Latina: Pobres, vulnerables y clases medias, New York.

WIOD (World Input-Output Database) (2014) [online] http://www.wiod.org/new_site/home.htm. 
FUNDACIÓN EU-LAC 2015 